\title{
Interventions for nail psoriasis (Review)
}

de Vries ACQ, Bogaards NA, Hooft L, Velema M, Pasch M, Lebwohl M, Spuls PI

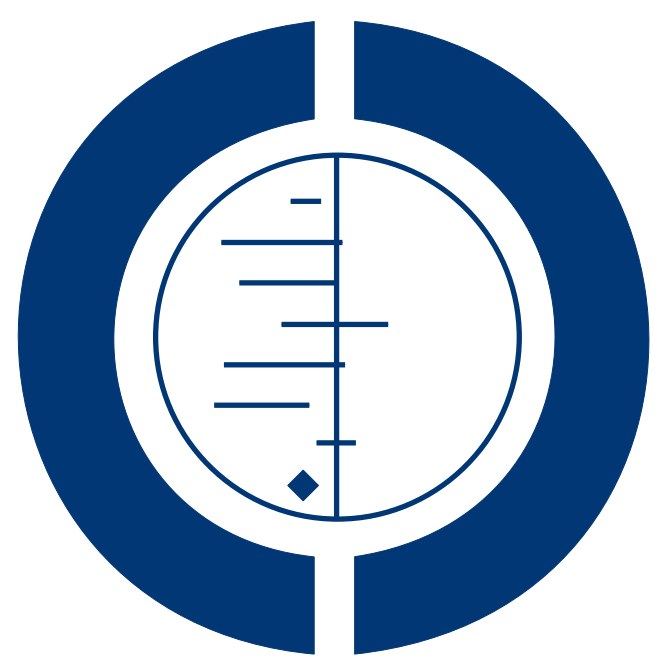

\section{THE COCHRANE COLLABORATION $^{\circledR}$}

This is a reprint of a Cochrane review, prepared and maintained by The Cochrane Collaboration and published in The Cochrane Library 2013, Issue 1

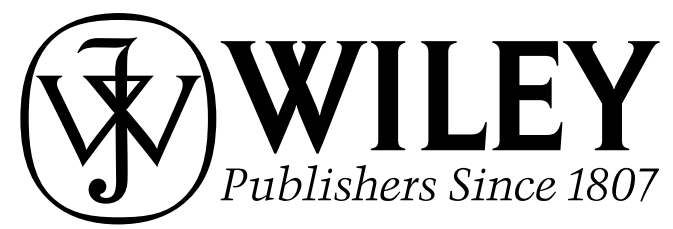


TABLE OF CONTENTS

HEADER

ABSTRACT

PLAIN LANGUAGE SUMMARY

BACKGROUND

OBJECTIVES

METHODS

RESULTS

Figure 1.

Figure 2 .

Figure 3.

Figure 4.

Figure 5.

DISCUSSION

AUTHORS' CONCLUSIONS

ACKNOWLEDGEMENTS

DATA AND ANALYSES . . . . . . . . . . . . . . . . . . . . . . . . . . . . . . . . . . . . . . . . . . .

Analysis 1.1. Comparison 1 (Systemic) ciclosporin $2.5 \mathrm{mg} / \mathrm{kg}$ vs topical dithranol + salicylic acid + UVB, Outcome 1

Participants with at least $50 \%$ nail score improvement after short-term treatment duration.

Analysis 2.1. Comparison 2 (Topical) ciclosporin $70 \%$ in maize oil vs maize oil, Outcome 1 Participants with at least $50 \%$ nail score improvement after short-term treatment duration.

Analysis 3.1. Comparison 3 (Topical) calcipotriol $0.005 \%$ vs calcipotriol $0.005 \%+0.05 \%$ betamethasone dipropionate, Outcome 1 Participants with at least $50 \%$ nail score improvement after short-term treatment duration.

Analysis 4.1. Comparison 4 Topical - Systemic - Radiotherapy, Outcome 1 Participants with adverse effects (AE).

Analysis 5.1. Comparison 5 (Topical) calcipotriol $50 \mathrm{ug} / \mathrm{g}$ vs betamethasone dipropionate $64 \mathrm{mg} / \mathrm{g}+$ salicylic acid $0.03 \mathrm{~g} / \mathrm{g}$, Outcome 1 Participants with at least 50\% nail score improvement after short-term treatment duration.

Analysis 5.2. Comparison 5 (Topical) calcipotriol $50 \mathrm{ug} / \mathrm{g}$ vs betamethasone dipropionate $64 \mathrm{mg} / \mathrm{g}+$ salicylic acid $0.03 \mathrm{~g} / \mathrm{g}$,

Outcome 2 Nail score improvement after short-term treatment duration.

Analysis 6.1. Comparison 6 (Systemic) ustekinumab $45 \mathrm{mg}$ versus placebo, Outcome 1 Nail score improvement after shortterm treatment duration.

Analysis 7.1. Comparison 7 (Systemic) ustekinumab $90 \mathrm{mg}$ versus placebo, Outcome 1 Nail score improvement after shortterm treatment duration.

Analysis 8.1. Comparison 8 (Systemic) ustekinumab $45 \mathrm{mg}$ versus $90 \mathrm{mg}$, Outcome 1 Nail score improvement after shortterm treatment duration.

Analysis 9.1. Comparison 9 (Systemic) methotrexate versus ciclosporin, Outcome 1 Nail score improvement after medium-

APPENDICES

CONTRIBUTIONS OF AUTHORS

DECLARATIONS OF INTEREST

SOURCES OF SUPPORT

DIFFERENCES BETWEEN PROTOCOL AND REVIEW

INDEX TERMS

Interventions for nail psoriasis (Review)

Copyright (๑) 2013 The Cochrane Collaboration. Published by John Wiley \& Sons, Ltd. 


\section{[Intervention Review]}

\section{Interventions for nail psoriasis}

Anna Christa Q de Vries ${ }^{1}$, Nathalie A Bogaards ${ }^{1}$, Lotty Hooft ${ }^{2}$, Marieke Velema ${ }^{1}$, Marcel Pasch ${ }^{3}$, Mark Lebwohl ${ }^{4}$, Phyllis I Spuls ${ }^{1}$

${ }^{1}$ Department of Dermatology, Academic Medical Center, Amsterdam, Netherlands. ${ }^{2}$ Dutch Cochrane Centre, Academic Medical Center, Amsterdam, Netherlands. ${ }^{3}$ Department of Dermatology, Radboud University Nijmegen Medical Centre, Nijmegen, Netherlands.

${ }^{4}$ Department of Dermatology, Mount Sinai School of Medicine, New York, USA

Contact address: Phyllis I Spuls, Department of Dermatology, Academic Medical Center, Meibergdreef 9, Amsterdam, 1105 AZ, Netherlands.ph.i.spuls@amc.uva.nl.

Editorial group: Cochrane Skin Group.

Publication status and date: New, published in Issue 1, 2013.

Review content assessed as up-to-date: 22 March 2012.

Citation: de Vries ACQ, Bogaards NA, Hooft L, Velema M, Pasch M, Lebwohl M, Spuls PI. Interventions for nail psoriasis. Cochrane Database of Systematic Reviews 2013, Issue 1. Art. No.: CD007633. DOI: 10.1002/14651858.CD007633.pub2.

Copyright (C) 2013 The Cochrane Collaboration. Published by John Wiley \& Sons, Ltd.

\section{A B S T R A C T}

\section{Background}

Psoriasis is a common skin disease that can also involve the nails. All parts of the nail and surrounding structures can become affected. The incidence of nail involvement increases with duration of psoriasis. Although it is difficult to treat psoriatic nails, the condition may respond to therapy.

\section{Objectives}

To assess evidence for the efficacy and safety of the treatments for nail psoriasis.

\section{Search methods}

We searched the following databases up to March 2012: the Cochrane Skin Group Specialised Register, CENTRAL in The Cochrane Library, MEDLINE (from 1946), EMBASE (from 1974), and LILACS (from 1982). We also searched trials databases and checked the reference lists of retrieved studies for further references to relevant randomised controlled trials (RCTs).

\section{Selection criteria}

All RCTs of any design concerning interventions for nail psoriasis.

\section{Data collection and analysis}

Two authors independently assessed trial risk of bias and extracted the data. We collected adverse effects from the included studies.

\section{Main results}

We included 18 studies involving 1266 participants. We were not able to pool due to the heterogeneity of many of the studies.

Our primary outcomes were 'Global improvement of nail psoriasis as rated by a clinician', 'Improvement of nail psoriasis scores (NAS, NAPSI)', 'Improvement of nail psoriasis in the participant's opinion'. Our secondary outcomes were'Adverse effects (and serious adverse effects)'; 'Effects on quality of life'; and 'Improvement in nail features, pain score, nail thickness, thickness of subungual hyperkeratosis, number of affected nails, and nail growth'. We assessed short-term (3 to 6 months), medium-term (6 to 12 months), and long-term (> 12 months) treatments separately if possible. 
Two systemic biologic studies and three radiotherapy studies reported significant results for our first two primary outcomes. Infliximab $5 \mathrm{mg} / \mathrm{kg}$ showed $57.2 \%$ nail score improvement versus $-4.1 \%$ for placebo $(\mathrm{P}<0.001)$; golimumab $50 \mathrm{mg}$ and $100 \mathrm{mg}$ showed $33 \%$ and $54 \%$ improvement, respectively, versus $0 \%$ for placebo $(\mathrm{P}<0.001)$, both after medium-term treatment. Infliximab and golimumab also showed significant results after short-term treatment. From the 3 radiotherapy studies, only the superficial radiotherapy (SRT) study showed $20 \%$ versus $0 \%$ nail score improvement $(\mathrm{P}=0.03)$ after short-term treatment.

Studies with ciclosporin, methotrexate, and ustekinumab were not significantly better than their respective comparators: etretinate, ciclosporin, and placebo. Nor were studies with topical interventions (5-fluorouracil $1 \%$ in Belanyx® lotion, tazarotene $0.1 \%$ cream, calcipotriol $50 \mathrm{ug} / \mathrm{g}$, calcipotriol 0.005\%) better than their respective comparators: Belanyx ${ }^{\circledR}$ lotion, clobetasol propionate, betamethasone dipropionate with salicylic acid, or betamethasone dipropionate.

Of our secondary outcomes, not all included studies reported adverse events; those that did only reported mild adverse effects, and there were more in studies with systemic interventions. Only one study reported the effect on quality of life, and two studies reported nail improvement only per feature.

\section{Authors' conclusions}

Infliximab, golimumab, SRT, grenz rays, and electron beam caused significant nail improvement compared to the comparative treatment. Although the quality of trials was generally poor, this review may have some implications for clinical practice.

Although powerful systemic treatments have been shown to be beneficial, they may have serious adverse effects. So they are not a realistic option for people troubled with nail psoriasis, unless the patient is prescribed these systemic treatments because of cutaneous psoriasis or psoriatic arthritis or the nail psoriasis is severe, refractory to other treatments, or has a major impact on the person's quality of life. Because of their design and timescale, RCTs generally do not pick up serious side-effects. This review reported only mild adverse effects, recorded mainly for systemic treatments. Radiotherapy for psoriasis is not used in common practice. The evidence for the use of topical treatments is inconclusive and of poor quality; however, this does not imply that they do not work.

Future trials need to be rigorous in design, with adequate reporting. Trials should correctly describe the participants' characteristics and diagnostic features, use standard validated nail scores and participant-reported outcomes, be long enough to report efficacy and safety, and include details of effects on nail features.

\section{PLAIN LANGUAGE SUMMARY}

\section{Treatments for nail psoriasis}

Psoriasis is a common chronic skin disease with a prevalence in $2 \%$ to $3 \%$ of the population, according to European studies. Involvement of the nails occurs in about $50 \%$. Nail psoriasis is difficult to treat, but may respond to some treatments. We aimed to review the efficacy and safety of the treatments used for nail psoriasis.

We included 18 randomised controlled clinical trials (RCTs), which involved 1266 participants and were mostly based on a single study per treatment. Ten studies assessed topical treatments, i.e. applied to the surface of the skin (clobetasol, ciclosporin in maize oil, hyaluronic acid with chondroitin sulphates, 5-fluorouracil, a combination of dithranol with salicylic and UVB, tazarotene, and calcipotriol); 5 studies assessed systemic treatments, i.e. taken orally (golimumab, infliximab, ustekinumab, ciclosporin, and methotrexate); and 3 studies assessed radiotherapy (electron beam, grenz ray, and superficial radiotherapy). With regard to other treatments that are used for nail psoriasis, no RCTs had been carried out.

It was not possible to pool and compare the results because the studies were all so different.

In 5 studies, we found significant improvement of nail psoriasis compared to placebo: with infliximab ( $5 \mathrm{mg} / \mathrm{kg})$, golimumab (50 mg and $100 \mathrm{mg}$ ), superficial radiotherapy, electron beam, and grenz rays.

Although powerful systemic treatments have been shown to be beneficial, they may have serious adverse effects. So they are not a realistic option for people troubled with nail psoriasis, unless the patient is a candidate for these systemic treatments because of skin psoriasis or psoriatic arthritis. Because of their design and timescale, RCTs generally do not pick up serious side-effects. This review reported only mild adverse effects, recorded mainly for systemic treatments.

Radiotherapy for psoriasis is not used in common practice. The evidence for the use of topical treatments is inconclusive and of poor quality; however, this does not imply that they do not work. Topical treatment options could be beneficial and need to be further investigated.

Interventions for nail psoriasis (Review)

Copyright () 2013 The Cochrane Collaboration. Published by John Wiley \& Sons, Ltd. 
Clinical trials on nail psoriasis need to be rigorous in design, with clear reporting to enable readers to better interpret the results. Trials should accurately describe the participants' characteristics and diagnostic features of nail psoriasis; use standard validated nail scores and patient-reported outcomes; be long enough to report efficacy and safety; and include more details of effects on nail features.

\section{B A C K G R O U N D}

\section{Description of the condition}

Psoriasis is a common chronic skin disease with a prevalence in $2 \%$ to $3 \%$ of the population, according to population-based European studies (Schafer 2006). The disease of the skin and joints is an autoimmune disorder mediated by T-cell interactions with keratinocytes and other skin cells; this condition can also include nail involvement, ranging from mild to severe. There is a subgroup of people who have only nail psoriasis or whose nail psoriasis is the main manifestation that drives them to seek treatment. Of those with psoriasis, $40 \%$ were found to have nail psoriasis when questioned (van de Kerkhof 1998). Salomon et al examined 106 individuals with psoriasis in which nail changes were present in about $78 \%$. Men and women were equally affected (Salomon 2003; Tham 1988). There is a higher prevalence of nail psoriasis in those with psoriatic arthritis (Sadek 2007), a type of inflammatory arthritis that affects around $10 \%$ to $30 \%$ of people suffering from psoriasis. The incidence of nail involvement increases with duration of psoriasis (de Jong 1996).

Some details about the cause(s) and pathogenesis of psoriasis and psoriatic nails are known. A major susceptibility gene is known, located in the major histocompatibility complex class I region on chromosome six near to the HLA-Cw6 gene. People with the HLA-Cw*0602 positive gene have a higher incidence of the guttate type and the eruptive type of psoriasis, a younger age of onset, more exacerbations with throat infections, higher appearance of the Koebner phenomenon, and more extensive disease. However, all variations of nail changes are more frequent in people who are $\mathrm{Cw}^{*} 0602$-negative (Gudjonsson 2006). Furthermore, minor trauma to the nails may play a role in the onset of nail psoriasis. Fingernails are more affected than toenails (Dawber 1992; Farber 1992; Scher 1990; Tham 1988). Psoriasis may affect both the nail matrix and the nail bed. Clinical observations that aid the diagnosis of nail psoriasis include irregular pitting, salmon patches of the nail bed, and separation of the nail from the nail bed with reddening of the border (paronychia). Furthermore, splinter haemorrhages, subungual hyperkeratosis, nail plate thickening, and crumbling may be seen (Bolognia 2003; Kaur 2001). The most common nail abnormalities are pitting and subungual hyperkeratosis. Pitting of the nail is caused by small parakeratotic foci in the distal portion of the nail matrix. The salmon patches or 'oil spots' reflect exocytosis of leukocytes beneath the nail plate. Increased capillary fragility leads to splinter haemorrhages. Subungual hyperkeratosis and distal onycholysis are the result of parakeratosis of the distal nail bed (Bolognia 2003).

Differential diagnoses include onychomycosis, lichen planus, parakeratosis pustulosa, acropustulosis keratotica, acrodermatitis continua of Hallopeau, and eczema. Because onychomycosis is more prevalent in people with nail psoriasis, it is important to rule out fungal infection of the nails in those with nail psoriasis.

It is known that more severe psoriasis is associated with poorer quality of life (de Korte 2004). De Jong et al (de Jong 1996) investigated the influence of nail involvement on quality of life. Half of those with psoriasis of the nails are limited in their profession, housekeeping, and daily activities, or both. More than $90 \%$ have cosmetic problems that cause social embarrassment. Over $50 \%$ of those with nail psoriasis suffer from pain due to nail changes.

A glossary of the terms and abbreviations we have used throughout this review are shown in Table 1 and Table 2, respectively.

\section{Description of the intervention}

Although it is difficult to treat psoriatic nails, the condition may respond to therapy. Where there is a response to treatment, there is often no permanent nail plate damage, and marked improvement can be achieved. However, treatment response may be slow, the result is sometimes disappointing, and relapse is common. Therapeutic options include, for example, topical and intralesional corticosteroids and topical calcipotriol, ciclosporin (Cannavo 2003), 5fluorouracil, and tazarotene. In a review published by Forleo et al, it is mentioned that topical calcipotriol is a promising treatment, especially for subungual hyperkeratosis and onycholysis (Forleo 1999). Systemic, mostly oral, treatments, such as methotrexate and ciclosporin, may be very efficacious, but until now they have only been recommended in people with additionally diffuse skin or joint involvement because of the side-effects of these drugs. Other therapeutic approaches used are oral retinoids, different kinds of photo- and radiotherapy (Kwang 1995; Yu 1992), grenz ray (Lindelof 1989), ultraviolet B phototherapy, and photochemotherapy (de Berker 2000).

Biologics are relatively new therapeutic agents for the treatment of psoriasis, which are now being used as routine therapy for those with chronic moderate to severe plaque type psoriasis and psoriatic 
arthritis unresponsive to conventional systemic treatments or with contraindications for these. As a result of their proven efficacy and relative safety, the biologics are considered a valuable supplement for treating moderate to severe psoriasis, and the effects of some have been investigated for nail psoriasis (Reich 2005). Currently, the following are registered for psoriasis treatment: the tumour necrosis factor- $\alpha$ (TNF- $\alpha$ ) inhibitors etanercept, infliximab, and adalimumab; and the T-cell blocker, alefacept. Etanercept is a fully human receptor p75 fusion protein. Infliximab and adalimumab are monoclonal antibodies, of which adalimumab is fully human, and infliximab is chimeric, which means $75 \%$ human and $25 \%$ mouse. Alefacept is a totally human fusion protein of the receptor LFA3 and human IgG1. Ustekinumab, a human monoclonal anti-p40 antibody that blocks the IL 12/23 receptor, has also been approved recently for psoriasis, and it is the subject of a Cochrane review that is in progress (Roberts 2010). Another fully human monoclonal antibody, golimumab, has been approved for treatment of psoriatic arthritis, but also improves skin lesions of psoriasis. Anti-CD11a efalizumab has been removed from the market because several cases of progressive multifocal leukoencephalopathy have been reported.

\section{Assessment of nail psoriasis severity}

Different outcome measures have been developed for nail psoriasis compared to the disease of the skin and joints. Besides a clinical description of improvement or worsening of nail psoriasis features, there are severity scoring systems. There is no consensus on core outcomes to be used.

In 1994, Jones et al used a scoring system later referred to as the Psoriasis Nail Severity Score (PNSS). In this system, fingernails are assessed for pitting, onycholysis, hyperkeratosis, and severe nail deformity with involvement of both sides of the nail. Each of these nail features scores 1 point with a possible maximum nail score of 40 for all finger nails (Jones 1994). Subsequently, Williamson extended this score by also including toenails to a possible maximum score of 80 (Williamson 2004).

Another score is the total Nail Area Severity (NAS) score including parameters for the number of nail pitting areas, number of nail pits, amount of subungual keratoses, onycholysis, and oil spots (de Jong 1999).

Rich et al developed a more complex scoring system, the Nail Psoriasis Severity Index (NAPSI). This index is formed by the sum of a score for each nail per quadrant, distinguishing nail bed, and nail matrix. Nail matrix psoriasis includes one of the following nail features: pitting, leuconychia, red spots in the lunula, and crumbling. For nail bed psoriasis, the existence of onycholysis, oil drop, splinter haemorrhages, and nail bed hyperkeratosis will be scored (Rich 2003).

Because of its complexity, Parrish et al concluded that the existing NAPSI system is probably not sensitive enough to reflect significant clinical improvement. Therefore, they proposed a modi- fied score with a classification for each parameter of zero to three (Parrish 2005).

Baran et al suggested that the signs of nail psoriasis should be scored from zero to three, with a standardised legend for each feature separately. However, splinter haemorrhages, which are often of traumatic origin, should not be taken into account in their opinion, nor should onychomadesis or nail loss (Baran 2004).

\section{Why it is important to do this review}

Although nail psoriasis is a common disorder that causes pain and restrictions in daily activities in half of those affected, and cosmetic problems in almost all, a summary of the evidence of possible treatments is missing. There is no uniform therapeutic regimen and no nail psoriasis treatment algorithm available in textbooks or reviews. However, although many available treatments are not well documented and comparative studies are scarce, marked improvement can be achieved with some treatments.

Cassell and Kavanaugh published a review of 20 studies (including clinical trials, case series', and observational studies) on the treatment of nail psoriasis, and they also presented a list of treatment recommendations (Cassell 2006). Some elements of this systematic review may be improved: searching more databases, not applying a language restriction, reviewing all treatments, assessing the validity of the studies, extracting the data independently, and drawing conclusions concerning all of the objectives of the review (also 'symptoms', 'quality of life', and 'toxicity of therapies' as outcome measures) based on the level of evidence.

The goal of this Cochrane systematic review was to summarise the best available evidence, in order to inform both physicians and those with nail psoriasis and to identify future research areas about treatment possibilities.

\section{O B J E C T I VES}

To assess evidence for the efficacy and safety of the treatments for nail psoriasis.

\section{METHODS}

\section{Criteria for considering studies for this review}

\section{Types of studies}

All randomised controlled trials.

We included studies if nail psoriasis was the main clinical feature as well as studies where nail psoriasis was just one of several components of the disease besides arthritis or plaque type psoriasis. 


\section{Types of participants}

All participants diagnosed with nail psoriasis and no other nail disorder.

We excluded studies concerning mainly participants with pustular psoriasis of the nails, acropustulosis keratotica, and acrodermatitis continua of Hallopeau.

\section{Types of interventions}

Any type of intervention used, either alone or in combination, to treat nail psoriasis.

We included comparison studies with placebo or active treatment.

\section{Types of outcome measures}

Because there is no consensus on core outcome measures for nail psoriasis, we included all possible outcome measures.

We dichotomised results in participants with less, equal, or more than $50 \%$ improvement, regardless of which score measurement was used.

To calculate the number of participants with at least $50 \%$ nail score improvement, we proportionally converted point scores to percentage improvement. For example, a 5-point scale of 'no improvement', 'slight improvement', 'moderate improvement', 'almost complete resolution', and 'complete resolution' was converted to $0 \%, 25 \%, 50 \%, 75 \%$, and $100 \%$, respectively. For example, a 4-point scale of 'worsened', 'failure', 'improved', and 'cured' was converted to $0 \%, 25 \%, 50 \%$, and $100 \%$, respectively. The reverse situation, as in 'absence of lesions', 'mild lesions', 'moderate lesions', and 'severe lesions', was converted to $100 \%, 75 \%, 50 \%$, and $25 \%$ improvement, respectively.

The participants with the converted $50 \%$ or more nail score improvement, according to the point scales, were calculated for the following primary and secondary outcome parameters.

\section{Primary outcomes}

(a) Global improvement of nail psoriasis as rated by a clinician (ordinal scale).

(b) Improvement of nail psoriasis scores (NAS, NAPSI) (ordinal scales).

(c) Improvement of nail psoriasis in the participant's opinion (ordinal scale).

\section{Secondary outcomes}

(a) Adverse effects (and serious adverse effects, i.e. serious enough to require withdrawal of the treatment).

(b) Effects on quality of life.

(c) Improvement in nail features, pain score, nail thickness, thickness of subungual hyperkeratosis, number of affected nails, and nail growth.

\section{Additional: nail features}

The effects of interventions on specific nail features were evaluated separately for nail matrix and nail bed features. In this way, the outcomes of research are applicable for daily practice.

\section{Timing of outcome assessment}

If possible, we assessed separately the outcomes in the short-term ( 3 to 6 months, closest to 3 months), medium-term (6 to 12 months, closest to 6 months), and long-term (> 12 months, closest to 1 year).

\section{Search methods for identification of studies}

We aimed to identify all relevant randomised controlled trials (RCTs) regardless of language or publication status (published, unpublished, in press, or in progress).

\section{Electronic searches}

We searched the following databases up to 22 March 2012:

- the Cochrane Skin Group Specialised Register using the following terms: psoria* and (nail* or toenail* or onycholysis or ungu* or paronychia or (subungu* AND hyperkerato*) or pitting or pitted or leukonychia);

- the Cochrane Central Register of Controlled Trials (CENTRAL) in The Cochrane Library using the strategy in Appendix 1;

- MEDLINE via OVID (from 1946) using the strategy in Appendix 2;

- EMBASE via OVID (from 1974) using the strategy in Appendix 3; and

- LILACS (Latin American and Caribbean Health Science Information database, from 1982) using the strategy in Appendix 4.

\section{Trials registers}

We searched the following trials registers on 22 March 2012 using the terms 'nail' and 'psoriasis':

- The metaRegister of Controlled Trials (www.controlledtrials.com).

- The US National Institutes of Health ongoing trials register (www.clinicaltrials.gov).

- The Australian New Zealand Clinical Trials Registry ( www.anzctr.org.au).

- The World Health Organisation International Clinical Trials Registry platform (www.who.int/trialsearch).

- The EU Clinical Trials Register (https:// www.clinicaltrialsregister.eu/).

Interventions for nail psoriasis (Review) 


\section{Searching other resources}

\section{Reference lists}

We checked the bibliographies of the included studies and of general articles about nail psoriasis for further references to relevant RCTs.

\section{Adverse effects}

We summarised adverse effects described in the included RCTs and gave the percentage of participants with adverse effects and the type of adverse effects.

\section{Data collection and analysis}

\section{Selection of studies}

Two review authors (AV and NB) independently checked the titles and abstracts identified from the searches, taking into account the inclusion and exclusion criteria. We also independently assessed those initially selected studies to determine whether they met the predefined eligibility criteria. We discussed differences in selection with a third review author (PS). We also described excluded studies and the reasons for exclusion. If necessary, we asked the Dutch Cochrane Centre or the Cochrane Skin Group for assistance in the translation of articles that were not published in English, Dutch, or German.

\section{Data extraction and management}

Two review authors (AV and NB) independently extracted the data. A third review author (PS or LH) resolved any differences. We adapted a data extraction form template from the Cochrane Skin Group in order to summarise the trials. This form addressed the following issues: baseline characteristics of the participants for age, sex, duration, and severity of nail psoriasis; aims; description of the intervention (including drug doses and duration of treatment); the methods and methodological quality of the study; outcome measures; and results. We contacted trial authors requesting that they provide missing data where possible. Two reviewers (AV and NB) checked and entered the data into Review Manager. We reviewed data from studies with nails as the main diagnosis and studies where nail psoriasis was one of several components of disease in the results separately.

\section{Assessment of risk of bias in included studies}

Two review authors (AV and NB) independently assessed risk of bias in the included studies following the domain-based evaluation described in Chapter 8 in the Cochrane Handbook for Systematic Reviews of Interventions (Higgins 2011).

We compared the evaluations and discussed and resolved any inconsistencies between the review authors. We evaluated the following components for each included study (Juni 2001) as 'low risk of bias', 'high risk of bias', and 'unclear' if the risk of bias was uncertain or unknown:

(a) the method of generation of the randomisation sequence;

(b) the method of allocation concealment - it was considered 'adequate' if the assignment could not be foreseen;

(c) who was blinded/not blinded (participants, clinicians, outcome assessors);

(d) how many participants were lost to follow up in each arm, and whether participants were analysed in the groups to which they were originally randomised (intention-to-treat);

(e) if there was selective outcome reporting (assessed by comparing the outcomes in the methods section with the reported outcomes in the results section); and

(f) if the studies were free of other bias.

We recorded the information in a 'Risk of bias' table for each included study as part of the Characteristics of included studies section.

\section{Measures of treatment effect}

It was impossible to extract or calculate all relevant data, like the 95\% confidence interval (CI) and standard deviation (SD). The diversity of design and study outcomes made it impossible to do so. We did not contact the original authors when we encountered missing data. Therefore, we described data with qualitative descriptions, if available in the original studies.

\section{Unit of analysis issues}

\section{Internally-controlled studies}

Internally-controlled studies are statistically analogous to crossover studies, and results should be adjusted by the correlation coefficient (Cochrane Handbook for Systematic Reviews of Interventions, section 16.4.6 (Higgins 2011)). No study included in this review reported these statistical data to impute, and we did not have access to patient-level data.

We considered whether in each study individuals (also for internally-controlled studies) underwent more than one intervention (e.g. in a cross-over trial) and if there were multiple observations for the same outcome (e.g. repeated measurements).

\section{Cross-over trials}

When we considered no carry-over effect to be present, we analysed the trial as a parallel-group trial. If carry-over effect was present, we included only data from the first period. 


\section{Repeated measurements}

Outcomes were given for the following treatment durations: shortterm ( 3 to 6 months, closest to 3 months), medium-term (6 to 12 months, closest to 6 months), and long-term (> 12 months, closest to 1 year) treatment.

It was not possible to pool data because of clinical and methodological heterogeneity and limited reporting of statistical data. Considering the differences, we tried to make homogeneous groups based on three interventions types (topical, systemic, and radiotherapy). We decided to describe all the data presented in these groups in accordance with the primary and secondary outcomes, as we believe that this will be useful in clinical practice.

\section{Dealing with missing data}

In the case of participant dropout and continuous outcomes, we analysed only the available data. We contacted trial authors requesting that they provide missing data where possible.

\section{Assessment of heterogeneity}

We assessed statistical heterogeneity using $\mathrm{I}^{2}$ statistic. In the case of mild heterogeneity ( $\mathrm{I}^{2}$ statistic $=<30 \%$ ), we used the fixed-effect model (FEM). In the case of moderate heterogeneity $\left(\mathrm{I}^{2}\right.$ statistic $=$ $30 \%$ to $60 \%$ ), we used the random-effects model (REM) instead of the FEM. In the case of notable heterogeneity $\left(\mathrm{I}^{2}\right.$ statistic $=>$ $60 \%$ ), we identified subgroups to explain the heterogeneity.

In the case of severe methodological and clinical heterogeneity, we did not perform meta-analyses using either a FEM or REM. Instead, we described the data per intervention group (topical, systemic, and radiotherapy). In the analyses, we reported the participants with at least $50 \%$ nail score improvement.

\section{Assessment of reporting biases}

If possible, we would have used funnel plots to test publication bias. However, since performing a meta-analysis was not possible due to heterogeneity, we did not use funnel plots (this is only informative when there are at least 10 homogeneous studies included in the meta-analysis (Higgins 2011)).

\section{Data synthesis}

For studies with similar types of intervention, we performed a meta-analysis when possible; we only carried out a meta-analysis of all outcomes (primary and secondary) if we were able to identify an adequate number of studies that were investigating similar interventions and reporting data that exhibited not less than moderate heterogeneity. In that case, we used a fixed-effect or randomeffects model to pool the data into a meta-analysis.

We dichotomised outcomes for nail score improvement and calculated and analysed the available data, reporting participants with at least $50 \%$ nail score improvement, regardless of which score measurement was used, and differentiated between short-term and medium-term treatment.

If possible, we analysed the 'mean nail score improvement per intervention after short and medium term treatment duration' and used the outcome as a continuous variable.

When it was not possible to perform a meta-analysis, we presented the extracted data qualitatively.

\section{Subgroup analysis and investigation of heterogeneity}

Where there was substantial clinical heterogeneity, we performed subgroup analyses when sufficient information was given to explore the reasons for heterogeneity, such as disease severity, type of nail psoriasis (isolated nail psoriasis or with skin involvement), the extensiveness (different groups based on number of nails affected), and the dosage and duration of treatment.

\section{Sensitivity analysis}

We carried out sensitivity analyses to assess the robustness of the results of this review; thus, we repeated all fixed-effect meta-analyses using random-effects models. With these sensitivity analyses we wanted to show that the overall results were not affected by differences caused by the following methodological items:

1. concealment of allocation;

2. blinding of the participant;

3. blinding of care provider; and

4. interparticipant comparison (versus intraparticipant comparison).

\section{R E S U L T S}

\section{Description of studies}

See: Characteristics of included studies; Characteristics of excluded studies; Characteristics of studies awaiting classification; Characteristics of ongoing studies.

\section{Results of the search}

We retrieved 212 references from the electronic searches and 8 ongoing studies when we searched the websites of trials registers (Characteristics of ongoing studies).

Of these 220 references, we obtained the full text for 49 . Twentysix references related to our 18 included studies (see Characteristics of included studies). One single reference referred to two separate trials, which we counted as two included studies. Eleven other references referred to 3 of the included studies; in the latter, we have marked the primary publication. 
Of the remaining 23 references, we excluded 7 (see Characteristics of excluded studies); 8 are in Studies awaiting classification (see Characteristics of studies awaiting classification); and 8 are ongoing trials (see Characteristics of ongoing studies).

We summarised our process for screening and selecting studies in Figure 1. 
Figure I. Study flow diagram

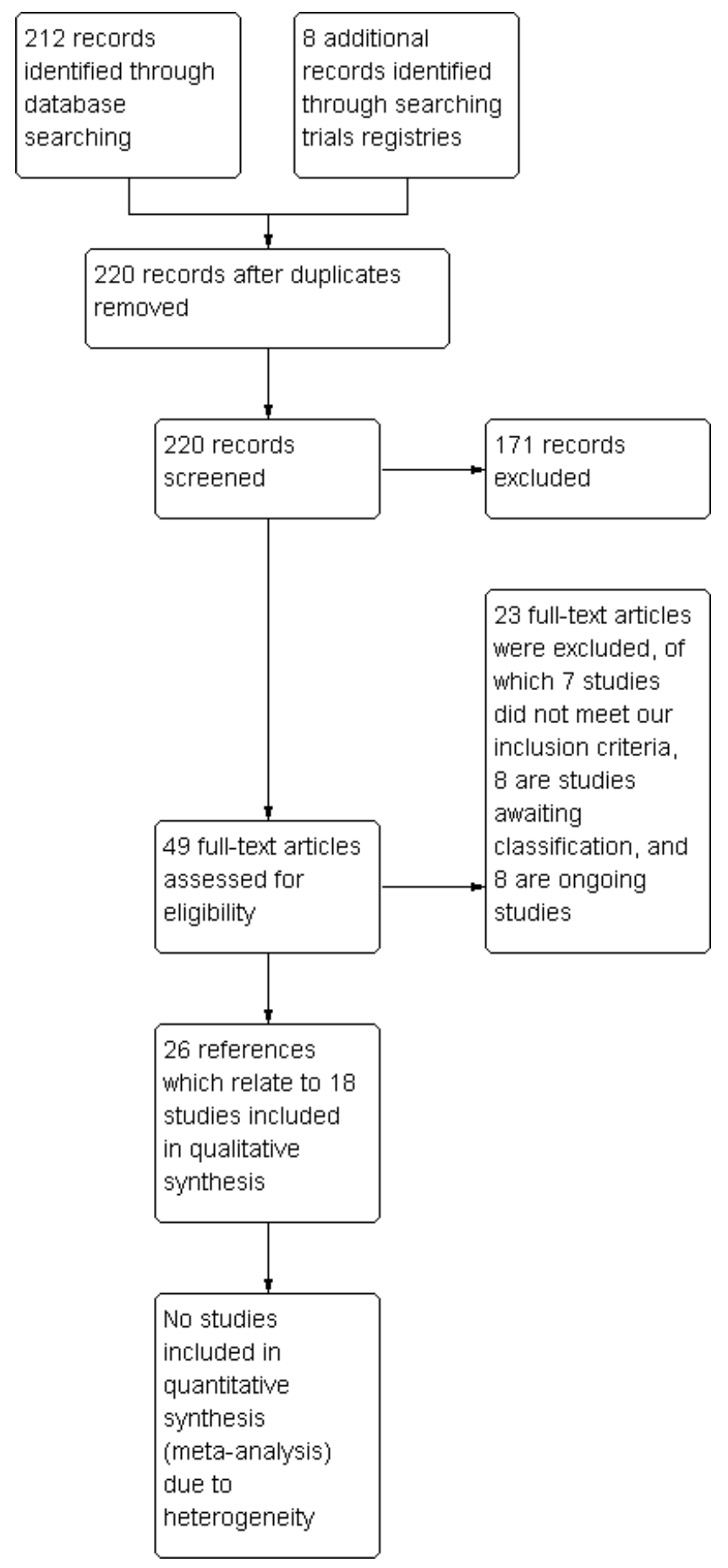


We checked the bibliographies of the included studies and other general papers about nail psoriasis for possible references to RCTs, but found no additional studies.

\section{Included studies}

We included 18 trials, with a total of 1266 participants. Twentysix references, including abstracts and full text, represented the included studies. The data were extracted from 17 primary references. The study by Baran 1999 reported two independent trials; this review reported these trials separately (Baran 1999; Baran 1999a), so counted them as two included studies. There were two references referring to the trial by Cannavo 2003, six references referring to the trial by Rich 2008, and three references referring to the trial by Scher 2001 .

These 18 trials include 6 with topical therapies versus placebo, 3 trials comparing 2 topicals, 1 topical therapy versus conventional systemic therapy, 2 studies comparing conventional systemic therapies, 3 with biologics versus placebo, and 3 with radiotherapy versus placebo.

The basic characteristics of the included studies are reported in Table 3. Further information, together with the 'Risk of bias' information, are reported in the 'Characteristics of included studies' tables. These tables show clinical and methodological heterogeneity for all outcomes, so we were not able to pool data and perform sensitivity analyses, except the $50 \%$ nail score improvement.

\section{Design}

Twelve trials adopted a parallel-group design and 6 (Baran 1999; Baran 1999a; de Jong 1999; Kwang 1995; Lindelof 1989; Yu 1992), an internally-controlled design.

There were four trials (Igarashi 2012; Lindelof 1989; Mahrle 1995; Rich 2008) with a cross-over design.

In Mahrle 1995 after 10 weeks, there was cross-over to another treatment (phase 2). Because no wash-out was required, there was a possibility of a carry-over effect in the second phase. Therefore, we only analysed the first 10 weeks (phase 1), representing a parallelgroup trial.

The studies by Igarashi 2012, Lindelof 1989, and Rich 2008 performed a cross-over design from placebo to active treatment. However, this cross-over had no carry-over effect; therefore, we included both phases.

The methods and study design of Rich 2008 originated from the EXPRESS study (Reich 2005); however, the Rich 2008 study reported the nail results. Reich 2010 reported the results of a retrospective analysis of the EXPRESS study.

Ten trials included participants with skin psoriasis and nail involvement (Cannavo 2003; Flori 1994; Igarashi 2012; Gü mü ș el 2011; Kavanaugh 2009; Levell 1995; Mahrle 1995; Rich 2008;
Rigopoulos 2007; Scher 2001). Another eight trials were unclear about the coexistence of the skin psoriasis (Baran 1999; Baran 1999a; de Jong 1999; Kwang 1995; Lindelof 1989; Tosti 1998; Tzung 2008; Yu 1992), so it is probable none of the trials included participants with 'only nail psoriasis'.

The treatment duration ranged from 2 weeks to 64 weeks (Igarashi 2012).

The studies originated from 12 different countries (The Netherlands, France, Singapore, Sweden, Germany, Greece, Turkey, Taiwan, Japan, United Kingdom (2), USA (3), Italy (3)). One study was written in Italian (Flori 1994).

The included studies were published between 1989 and 2012.

\section{Sample sizes}

The number of participants included in the individual studies varied widely, from 10 to 305 participants (1 had 102 participants (Igarashi 2012); 1 had 137 participants (Mahrle 1995); and 1 trial by Rich 2008 studied 305 participants), but with between 10 and 60 representing the most common sample size.

\section{Participants}

Participants were adults (> 18 years), of either sex, with nail psoriasis.

\section{Interventions}

We evaluated a wide range of interventions. Therefore, the study results are presented in the three intervention groups (topical, systemic, and radiotherapy).

Ten trials examined topical treatments: calcipotriol monotherapy versus calcipotriol in combination with betamethasone dipropionate (Tzung 2008), calcipotriol monotherapy versus calcipotriol with betamethasone and salicylic acid (Tosti 1998), hyaluronic acid with chondroitin sulphates (Flori 1994), tazarotene $0.1 \%$ gel (Scher 2001) and tazarotene cream (Rigopoulos 2007), dithranol with salicylic acid and additional UVB (Levell 1995), ciclosporin dissolved maize oil solution (Cannavo 2003), 5-fluorouracil (5FU) in a penetration-enhancing vehicle (de Jong 1999), and clobetasol propionate cream (Baran 1999; Baran 1999a).

Six trials examined systemic therapies: ciclosporin (Gü mú ș el 2011; Levell 1995; Mahrle 1995), methotrexate (Gú mú ș el 2011), etretinate (Mahrle 1995), golimumab (Kavanaugh 2009), ustekinumab (Igarashi 2012), and infliximab (Rich 2008). Levell 1995 was included in the topical intervention and the systemic intervention group.

Three trials examined radiotherapy treatments: superficial radiotherapy (Yu 1992), grenz rays (Lindelof 1989), and electron beam 
(Kwang 1995). In the trial with superficial radiotherapy, they used 150 centiGray (cGy (1/100 of a Gray)) $(90 \mathrm{kV}, 5 \mathrm{~mA}, 1.00 \mathrm{~mm}$ aluminium filter). The amount of grenz rays used was $5 \mathrm{Gray}$ (Gy) (10 kV, $10 \mathrm{~mA}$, half-value layer $0.02 \mathrm{~mm} \mathrm{Al}$, half-value depth in tissue $0.5 \mathrm{~mm}$, focus skin distance $10 \mathrm{~cm}$ ). Kwang 1995 used electron beam of 7 mega-electron volts.

\section{Outcomes}

The NAPSI, an ordinal scale of nail psoriasis severity, was scored in five studies (Gü mü ș el 2011; Igarashi 2012; Kavanaugh 2009; Rich 2008; Tzung 2008); Rigopoulos 2007 used the NAPSI partly; and de Jong 1999 applied the ordinal NAS score. de Jong 1999, Gủ mú ș el 2011, Kavanaugh 2009, and Tzung 2008 also used a point scale next to the NAPSI or NAS. Ten studies utilised only an ordinal 3-, 4-, or 5-point scale for assessing the nails during treatment. This scale was assessed by the investigator or physician, and in some studies, not adequately defined. One study (Tosti 1998) assessed the nail thickness, not using a NAPSI or point scale. The categories from the point scores (absent, slight, mild, moderate, severe, cured) are described as mentioned in the original text.

An ordinal scale for 'Improvement of nail psoriasis in the participant's opinion' was used in five studies (Cannavo 2003; de Jong 1999; Gủ mú ș el 2011; Tosti 1998; Tzung 2008).

All studies, except Baran 1999 and Baran 1999a, assessed adverse effects.

Only Cannavo 2003 reported 'Effects on quality of life'.

Eleven studies assessed 'Improvement in nail features, pain score, nail thickness, thickness of subungual hyperkeratosis, number of affected nails, and nail growth' (Baran 1999; Baran 1999a;
Cannavo 2003; de Jong 1999; Flori 1994; Kwang 1995; Rich 2008; Rigopoulos 2007; Scher 2001; Tzung 2008; Yu 1992).

\section{Excluded studies}

Of the 49 initially eligible references, we included 26 . Of the remaining 23 references, we excluded 7, details of which and the reasons for exclusion are described in the 'Characteristics of excluded studies' tables.

\section{Studies awaiting assessment}

There were eight studies that were only published in abstract form (poster or conference publication), so we were unable to assess them for this review, but details are given in the 'Characteristics of studies awaiting classification' tables. This includes the study abstract by Baerveldt 2010, which was retrieved from a national source.

\section{Ongoing studies}

We give details of the eight ongoing studies in the Ongoing studies tables.

\section{Risk of bias in included studies}

We assessed and presented the risk of bias of each study as part of the 'Characteristics of included studies' tables.

Figure 2 presents the review authors' judgements on the methodological quality of the included studies. Figure 3 presents the review authors' judgements on the methodological quality as percentages across all included studies. 
Figure 2. Methodological quality summary: review authors' judgements about each methodological quality item for each included study

\begin{tabular}{|c|c|c|c|c|c|c|c|c|}
\hline & 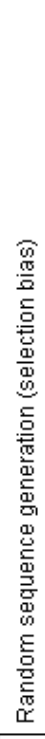 & 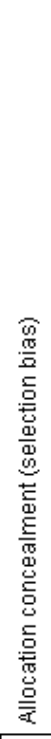 & 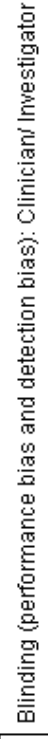 & 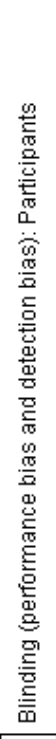 & 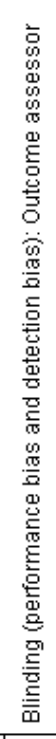 & 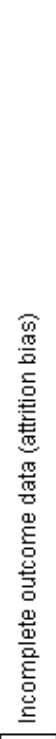 & 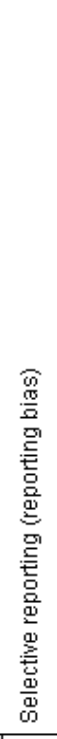 & 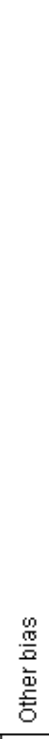 \\
\hline Baran 1999 & $?$ & $?$ & + & + & $\bullet$ & + & + & + \\
\hline Baran 1999a & $?$ & $?$ & + & + & 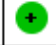 & $\odot$ & $\odot$ & + \\
\hline Cannavo 2003 & + & $?$ & $?$ & $?$ & $?$ & $?$ & $\odot$ & + \\
\hline de Jong 1999 & + & $?$ & + & 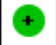 & + & + & + & + \\
\hline Flori 1994 & + & $?$ & $\odot$ & 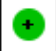 & $\odot$ & + & $\theta$ & $?$ \\
\hline Güműşel 2011 & + & $\oplus$ & $?$ & $\odot$ & $?$ & $\odot$ & + & + \\
\hline Igarashi 2012 & + & $?$ & + & $\odot$ & + & $?$ & + & $?$ \\
\hline Kavanaugh 2009 & + & + & + & + & + & $?$ & + & C \\
\hline Kwang 1995 & + & $?$ & $?$ & $?$ & $?$ & + & + & $?$ \\
\hline Levell 1995 & + & $\odot$ & - & - & 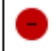 & $\odot$ & $\theta$ & - \\
\hline Lindelof 1989 & + & $?$ & + & + & + & + & $\theta$ & $?$ \\
\hline Mahrle 1995 & + & $?$ & $?$ & $?$ & $?$ & $?$ & $\odot$ & \\
\hline Rich 2008 & + & + & + & + & 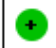 & $?$ & + & $?$ \\
\hline Rigopoulos 2007 & + & $\odot$ & $\oplus$ & 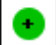 & 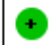 & $\odot$ & + & $?$ \\
\hline Scher 2001 & $?$ & $?$ & + & + & + & + & + & $?$ \\
\hline Tosti 1998 & $?$ & $?$ & + & + & + & $\odot$ & + & \\
\hline Tzung 2008 & $?$ & $?$ & + & - & + & + & + & + \\
\hline Yu 1992 & + & $?$ & $?$ & + & + & $\odot$ & + & $?$ \\
\hline
\end{tabular}


Figure 3. Methodological quality graph: review authors' judgements about each methodological quality item presented as percentages across all included studies.

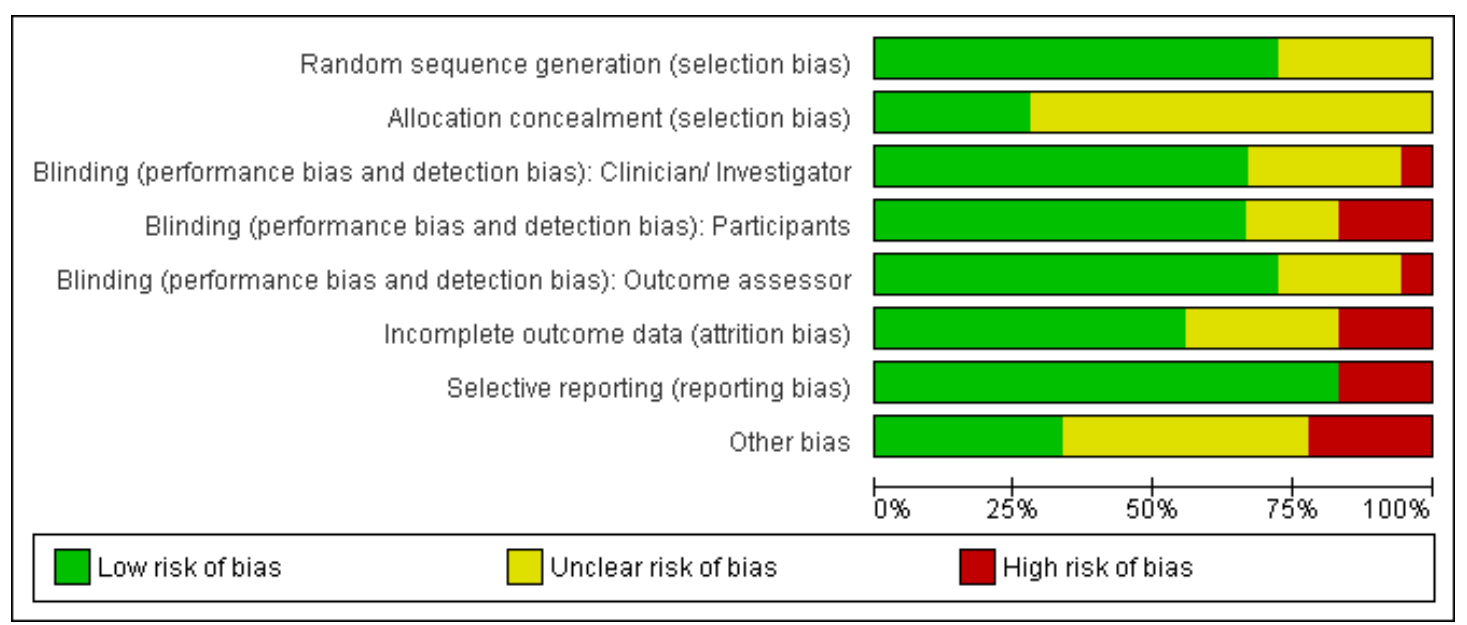

\begin{abstract}
Allocation
'Adequate sequence generation' and 'allocation of concealment' are the two most important indicators that can minimise bias in trials.

Five studies (Gü mú ș el 2011; Kavanaugh 2009; Levell 1995; Rich 2008; Rigopoulos 2007) had adequate sequence generation and allocation of concealment. Without knowledge of the underlying allocation criteria, these studies used either a dice, centralised interactive voice responses (IVR), or a code of randomisation available to an uninvolved pharmacist or a computer.

The randomisation methods and allocation of concealment were unclear in 5 of the 18 included trials. Eight studies reported an adequate sequence generation and an unclear allocation of concealment.
\end{abstract}

\section{Blinding}

Twelve trials had a double-blind design, of which 11 trials blinded the investigator and participant and 1 trial (Yu 1992) blinded the participant and outcome assessor. Yu 1992 was unclear about the investigator/physician blinding.

Two trials were single-blind (Gü mú ș el 2011; Tzung 2008), and their comparisons were active-controlled. Tzung 2008 had a blinded investigator. Gü mü ș el 2011 had unclear blinding for physician and observer; the initials of the blinded observer were the same as the initials of the probably unblinded physician.
Levell 1995 was an open study (active-controlled) so was judged at high risk of bias for these three domains.

The studies by Cannavo 2003, Kwang 1995, and Mahrle 1995 reported insufficient information to permit a clear judgment of the risk of bias for these three domains.

\section{Incomplete outcome data}

Five studies were 'unclear' for the risk of bias in reporting incomplete outcome data: Igarashi 2012, Kavanaugh 2009, and Mahrle 1995 described data about the dropouts and withdrawals of all randomised participants, but there were no separate data available about participants with nail psoriasis. Cannavo 2003 and Rich 2008 did not mention dropouts or withdrawals.

We judged the following studies at low risk of bias for this domain: Flori 1994, Kwang 1995, and Scher 2001. These studies reported that there were no dropouts or withdrawals in the trial; Baran 1999, Baran 1999a, Gü mú ș el 2011, Lindelof 1989, Tzung 2008, and Yu 1992 reported less than 20\% dropouts of the study population, mostly unrelated to treatment (for example, lost to follow up); and de Jong 1999, which reported intention-to-treat (ITT) analysis. We judged three studies that had more than $20 \%$ dropouts per group at high risk of bias: Levell 1995, Rigopoulos 2007, and Tosti 1998. Levell 1995 and Tosti 1998 reported dropouts mostly because of participants failing to attend the visits. Rigopoulos 2007 reported dropouts because of the need for another treatment and 
had two participants with incomplete outcome data.

Kavanaugh 2009 reported intention-to-treat (ITT) analysis.

Gü mú ș el 2011, Igarashi 2012, and Rich 2008 used no ITT anal-

ysis. The other trials mentioned no dropouts or reported unclear data about the ITT analysis.

Not all the included studies assessed nail improvement compared to the control group.

\section{Selective reporting}

The studies by Flori 1994, Levell 1995, and Lindelof 1989 were not free of selective reporting, so we judged them at high risk of bias. Flori 1994 did not report the results of the assessed toenails in the placebo group. Levell 1995 did not describe data from the group using dithranol in Lassar's paste, and there was also a discrepancy in the article between the improvement score shown in the figure and the text. Lindelof 1989 did not separately discuss nail signs in the results.

The other trials reported all the outcomes mentioned in their methods, so we judged these studies at low risk of bias.

\section{Other potential sources of bias}

Pharmaceutical industries supported 8 of the 18 included trials (Flori 1994; Igarashi 2012; Kavanaugh 2009; Levell 1995; Mahrle 1995; Rich 2008; Scher 2001; Tosti 1998). Because the influence of the pharmaceutical industries was unclear, we could not exclude a potential source of bias.

Kavanaugh 2009, Levell 1995, Mahrle 1995, and Tosti 1998 had, regardless of the unclear bias by the pharmaceutical industries, other potential sources of bias, which could cause high risk of bias. In Kavanaugh 2009, a stable dose of methotrexate, non-steroidal anti-inflammatory drugs (NSAIDs), and corticosteroids were allowed as co-medication. Mahrle 1995 allowed salicylic acid-containing emollients for all participants during the study. Levell 1995 applied ciclosporin until two weeks after the psoriasis of the skin had cleared. This was not allowed for the dithranol group. The extra two weeks of ciclosporin were applied in the follow-up weeks. In Tosti 1998 at 3 months, treatment was continued for another 2 months if participants treated with calcipotriol or betamethasone had more than $50 \%$ reduction of the subungual hyperkeratotic thickness in at least 1 nail (responders). The baseline hyperkeratoses of these two treatment groups were not homogeneous.

Four trials (Kwang 1995; Lindelof 1989; Rigopoulos 2007; Yu 1992) reported no baseline characteristics of the participants. It was unclear if the groups were comparable at baseline. We could not exclude bias.

\section{Effects of interventions}

Because of the diversity of study designs, the outcomes, and severe clinical and methodological heterogeneity, it was impossible to calculate confidence intervals and pool the data from the studies.
To make the results more concise, we have presented forest plots of participants with at least $50 \%$ nail score improvement only for individual parallel-group studies. For internally-controlled studies, we have presented the $\mathrm{P}$ values for the randomised comparison when these were available.

The outcomes of this review were as follows.

\section{Primary outcomes}

1. Global improvement of nail psoriasis as rated by a clinician.

2. Improvement of nail psoriasis scores (NAS, NAPSI).

3. Improvement of nail psoriasis in the participant's opinion.

Two biologic (Kavanaugh 2009; Rich 2008) and three radiotherapy studies (Kwang 1995; Lindelof 1989; Yu 1992) reported significant improvement of nail psoriasis from nail scores and rating from a clinician. Infliximab $5 \mathrm{mg} / \mathrm{kg}$ showed $26.8 \%$ and $57.2 \%$ nail score improvement versus $-7.7 \%$ and $-4.1 \%$ for placebo, respectively, after short- and medium-term treatment (Rich 2008). Golimumab $50 \mathrm{mg}$ showed $25 \%$ and $33 \%$ nail score improvement, and $100 \mathrm{mg}$ showed $43 \%$ and $54 \%$ nail score improvement, respectively, after short- and medium-term treatment versus $0 \%$ in the placebo group for both durations (Kavanaugh 2009). From the 3 radiotherapy studies, only the superficial radiotherapy study showed underlying data: $20 \%$ versus $0 \%$ score improvement after short-term treatment (Yu 1992).

Seven studies showed no significant results in the primary outcomes compared to each other (de Jong 1999; Gü mú ș el 2011; Igarashi 2012; Mahrle 1995; Rigopoulos 2007; Tosti 1998; Tzung 2008). Four studies did not present comparative data (Baran 1999; Baran 1999a; Cannavo 2003; Levell 1995).

Two studies reported nail improvement only per feature (secondary outcome), and they did not show primary outcome on nail improvement (Flori 1994; Scher 2001).

In Table 4, we present the mean percentage score improvement of fingernail severity over time. Toenails were not assessed in all trials; therefore, they were not all included. We presented the outcomes as "moderate" (in accordance with NAPSI: $25 \%$ to $75 \%$ improvement, mild/moderate, medium) and "good" (in accordance with NAPSI: $\geq 75 \%$ improvement, no lesions, almost complete recovery), independent of the outcome measure used. Where possible, we shared data on nail improvement and significance compared to the other treatment. If this was not reported in the studies, we shared the improvement and significance compared to baseline. The outcome "no/worse" (in accordance with NAPSI: < 25\% improvement, no improvement, or worsening) is not shown in this table. The column 'Time to assessment' shows the exact treatment weeks associated with the score improvement. We could not give an overview of the onset of response because of missing data. The improvement is shown for 2 treatment periods: short-term (studies with $<12$ weeks of treatment) and medium-term (studies with 12 to 24 weeks of treatment). Rich 2008 and Igarashi 2012 were the only studies with $>24$ weeks, for which results are mentioned 
in the text only. These groups were necessary because no trials used a standard outcome measurement. We explained the exact definitions of the groups in the footnotes below the table.

In Figure 4, we gave data on short-term treatment with $>50 \%$ improvement $(\mathrm{n}=5)$ and data on medium-term treatment with > $25 \%$ improvement $(n=6)$. 
Figure 4.
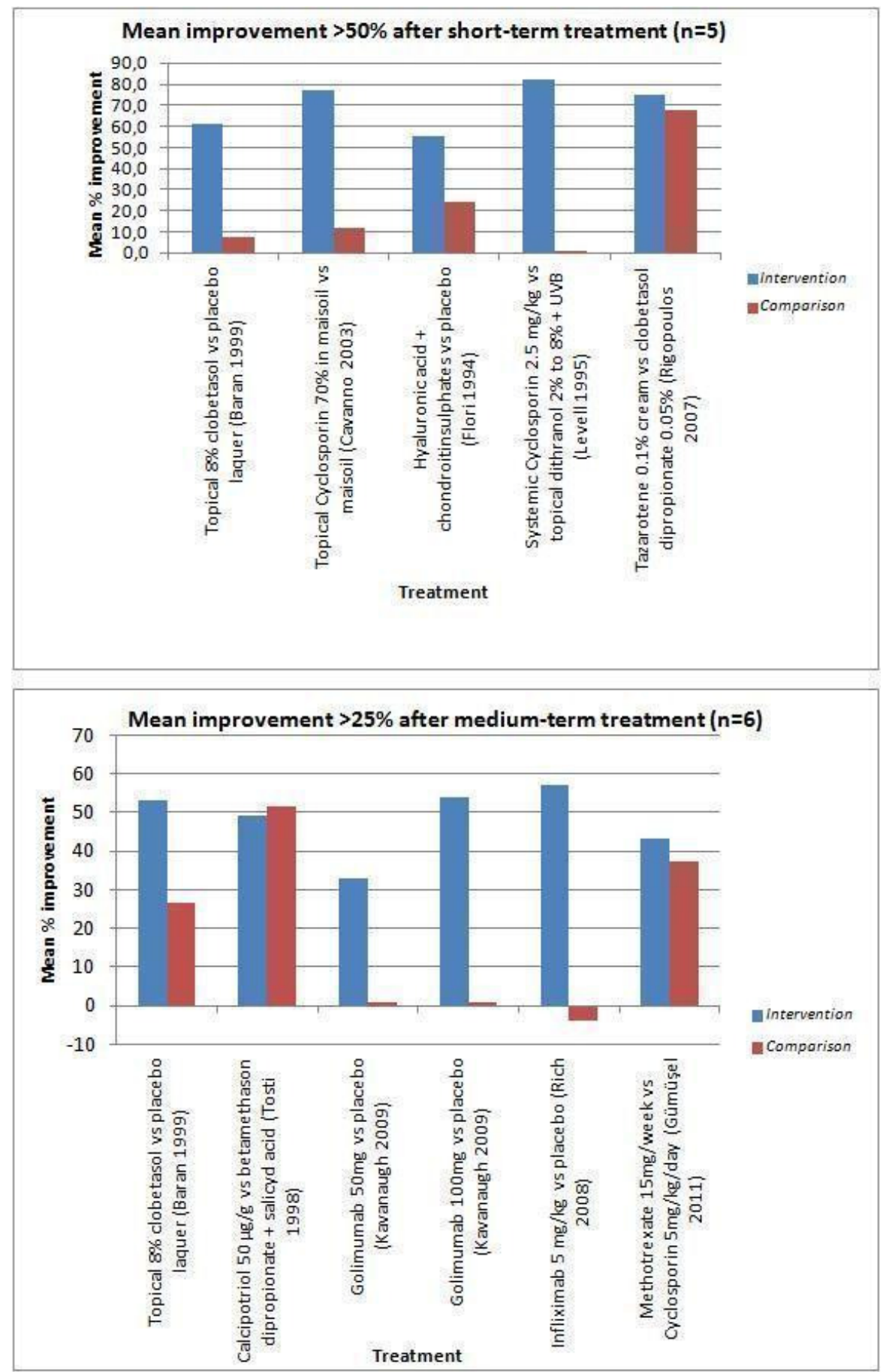

Interventions for nail psoriasis (Review)

Copyright @ 2013 The Cochrane Collaboration. Published by John Wiley \& Sons, Ltd. 


\section{Secondary outcomes}

1. Adverse effects (and serious adverse effects, i.e. serious enough to require withdrawal of the treatment).

2. Effects on quality of life.

3. Improvement in nail features, pain score, nail thickness, thickness of subungual hyperkeratosis, number of affected nails, and nail growth.

In Table 5, we present the adverse effects (the percentage of participants and the type of adverse effects).

Only one trial (Cannavo 2003) assessed effects on quality of life. Table 6 shows nail features with at least $50 \%$ improvement. The duration of treatment is divided into two groups: short- and medium-term. If specified, the improvement is shown per intervention regardless of the outcome parameter used. Not all trials assessed the same features; therefore, it was impossible to compare the results. One study reported the percentage of participants with nail feature improvement. In this study, all eight features of the 'NAPSI' score were presented.

Eleven studies showed separate data on nail features, of which three (Flori 1994; Scher 2001; Tzung 2008) showed significance compared to placebo in some features. One study (Rich 2008) showed a significant decrease in the occurrence of individual features over time, and three (de Jong 1999; Rigopoulos 2007; Tosti 1998) showed no significance between the treatments. Four studies reported no compared data.

\section{Additional: nail features}

We evaluated and separately reported the effects of interventions on specific nail features per nail feature instead of per intervention. In this way, the outcomes of research are applicable for daily practice.

We assess our outcomes under the three following headings: Topical therapy, Systemic therapy, and Radiotherapy. Finally, under an additional heading, we discuss nail features.

\section{Topical therapy ( 10 studies)}

Ten trials studied the effect of topical treatment on nail psoriasis (Baran 1999; Baran 1999a; Cannavo 2003; de Jong 1999; Flori 1994; Levell 1995; Rigopoulos 2007; Scher 2001; Tosti 1998; Tzung 2008).

Flori 1994 compared hyaluronic acid and chondroitin sulphate versus placebo for 90 days. Levell 1995 compared the topical combination of dithranol with salicylic acid and UVB, with systemic ciclosporin, while Cannavo 2003 compared 70\% ciclosporin in maize oil as a topical therapy versus maize oil only. Tosti 1998 and Tzung 2008 both used calcipotriol: Tosti 1998 compared calcipotriol with betamethasone dipropionate plus salicylic acid, and Tzung 2008 compared calcipotriol alone with calcipotriol in combination with betamethasone dipropionate. Baran 1999 and Baran 1999a both studied topical $8 \%$ clobetasol versus a placebo lacquer. de Jong 1999 reported 1\% 5-fluorouracil in Belanyx® lotion versus Belanyx ${ }^{\circledR}$ lotion alone. Scher 2001 and Rigopoulos 2007 both used tazarotene $0.1 \%$, versus, respectively, a vehicle gel and clobetasol propionate $0.05 \%$.

\section{Primary outcomes addressed by the topical studies}

\section{(a) Global improvement of nail psoriasis as rated by a clinician}

Six trials with 189 participants assessed nail psoriasis by clinicians. Levell 1995 compared topical dithranol with salicylic acid and UVB with oral ciclosporin for 16 weeks until clearance of psoriasis. Of the 15 participants treated with dithranol, salicylic acid, and UVB, 8 participants had improved nail psoriasis; 2 were unchanged; and 5 worsened (the median nail severity score at baseline was 5 ; after treatment, the median score change was $0(95.2 \%$ CI -3 to 2.5$)$ ).

\section{Follow-up}

In Levell 1995, all participants in the study with cleared skin psoriasis were followed until relapse or until eight months had elapsed. Ten participants whose psoriasis cleared with dithranol, salicylic acid, and UVB also had nail involvement. These 10 participants were assessed on their nails after treatment discontinuation, of which 1 had unchanged nail psoriasis, 7 improved, and 2 worsened; the median score improvement at the end of follow up was 4 (95.8\% CI 0 to 8)). For further details and data on ciclosporin treatment, please see the section 'Systemic therapy'.

Analysis 1.1 shows participants with at least $50 \%$ nail score improvement after a short-term treatment duration. There was no significant improvement when systemic ciclosporin was compared to topical dithranol with salicylic acid and UVB (RR 1.50, 95\% CI 0.85 to 2.64; Levell 1995).

Cannavo 2003 studied a topical oil solution of $70 \%$ oral ciclosporin versus maize oil alone. In the active group, 3 out of 8 participants came to a complete resolution of nail lesions compared to baseline, and 5 out of 8 showed a substantial improvement (between $55 \%$ and $70 \%$ ) of the overall severity score. In the placebo group, there was an improvement of $44 \%$ in 1 of the 8 participants, a minimal improvement (between 10 and 25\%) in 3 of the 8 participants, and no changes in 4 of the 8 participants, 
all compared to baseline. There were no data available about the comparison between the active and control group in this study. The mean improvement was $77 \%$ in the active group (initial median score $=8$, final score $=3$, significant $\mathrm{P}<0.0005$ ) and $12 \%$ in the placebo group (initial median score $=8$, final score $=6.5$; this was not significant).

\section{Follow-up}

After an eight-week follow-up, the study observed a relapse (not defined) in one case of the active group.

Analysis 2.1 showed participants with at least $50 \%$ nail score improvement after the short-term period. The study by Cannavo 2003 showed a significant improvement for topical ciclosporin $70 \%$ in maize oil versus maize oil (RR $17.00,95 \%$ CI 1.14 to 252.54).

After a short-term treatment period with calcipotriol in combination with betamethasone dipropionate versus calcipotriol alone (Tzung 2008), 53\% of the participants of both treatments showed at least a moderate improvement. There was no significant difference between the treatments using the Investigator's Global Assessment (IGA) $(\mathrm{P}=0.071)$. Once-daily combination therapy was as efficacious as, but not better than, twice-daily calcipotriol monotherapy. Once-daily did have an advantage in terms of compliance.

Analysis 3.1 showed participants with at least $50 \%$ nail score improvement after a short-term period. Tzung 2008 showed no significant outcome for calcipotriol versus calcipotriol + betamethasone dipropionate (RR 0.99, 95\% CI 0.52 to 1.91 ).

Baran 1999 and Baran 1999a studied clobetasol-17-propionate $8 \%$ in a colourless nail lacquer vehicle versus a placebo lacquer.

No participants in the group receiving $8 \%$ clobetasol experienced a complete disappearance (cured) of their nail lesions (Baran 1999). Eighteen participants $(69 \%)$ reported a clear reduction after therapy: $16(61.5 \%)$ in the active group and $2(7.7 \%)$ in the comparison group. In 7 participants (27\%), no efficacy of the therapy was observed. Only 1 participant $(3.8 \%)$ reported impairment of the nails.

Twelve participants $(80 \%)$ in the group receiving $8 \%$ clobetasol experienced a complete recovery or improvement (Baran 1999a). Four participants $(26.7 \%)$ had a complete disappearance of the nail lesions: 3 in the active group and 1 in the placebo group. Eight participants (53.3\%) showed an improvement: 5 (33.3\%) in the active group and $3(20.0 \%)$ in the placebo group. In 2 participants $(13.3 \%)$, no difference was reported after treatment. Only 1 participant (6.7\%) showed impairment of the nails.

A therapeutic response was directly related to the duration of the treatment. Healing could be reached when participants were treated long enough. No P values were available in these internallycontrolled studies (Baran 1999; Baran 1999a).

When Belanyx ${ }^{\circledR}$ lotion with 1\% 5-fluorouracil (5-FU) was compared to Belanyx ${ }^{\circledR}$ lotion alone (de Jong 1999), the clinician rated the overall improvement from baseline by $1 \% 5$-FU in Belanyx ${ }^{\circledR}$ lotion as significant $(\mathrm{P}=0.001)$ at week 12 of treatment.

\section{(b) Improvement of nail psoriasis scores (NAS, NAPSI)}

Three trials with 143 participants assessed nail psoriasis by NAS or NAPSI.

Tzung 2008 used the topical therapy calcipotriol as monotherapy compared to a combination with betamethasone dipropionate. Both treatments noted a significant reduction of total NAPSI score $(\mathrm{P}<0.045)$. However, there was no significant difference between treatments $(\mathrm{P}=0.649)$.

de Jong 1999 reported a change from baseline severity of $32 \%$ (score $=7.1$ to 4.8 ) and $39 \%$ (score $=7.1$ to 4.3 ) for the total NAS score ( 5 parameters) after 12 weeks, and $40 \%$ (score $=7.1$ to 4.2 ) and $46 \%$ (score $=7.1$ to 3.8 ) after 16 weeks ( 4 weeks' follow up), for, respectively, $1 \%$ 5-fluorouracil (5-FU) in Belanyx ${ }^{\circledR}$ lotion and Belanyx ${ }^{\circledR}$ lotion alone. These findings were in agreement with improvements recorded for the mean baseline severity of the total of the five individual assessed parameters. The nail parameters were shown to be similarly suppressed by 5-FU in Belanyx ${ }^{\circledR}$ lotion and Belanyx ${ }^{\circledR}$ lotion alone at the end of treatment $(P=0.063)$ or follow up $(\mathrm{P}=0.130)$.

\section{Follow-up}

After 4 weeks of follow up, 5-FU in Belanyx ${ }^{\circledR}$ lotion and Belanyx ${ }^{\circledR}$ lotion alone showed a further significant improvement for all assessed parameters $(\mathrm{P}<0.05)$, with total mean score changes of $10 \%($ score $=7.1(28 \%)$ to $6.1(38 \%))$ and $8 \%($ score $=6.1$ $(38 \%)$ to $5.3(46 \%))$, respectively.

In conclusion, administering 1\% 5-FU to Belanyx ${ }^{\circledR}$ does not enhance the efficacy in psoriatic nail dystrophy.

Rigopoulos 2007 compared tazarotene $0.1 \%$ cream with clobetasol propionate $0.05 \%$ cream. The results showed a significant time-effect improvement with both agents after 12 weeks of treatment $(\mathrm{P}<0.001)$. Comparison of the improvement between the two agents did not reach statistical significance.

\section{Follow-up}

Discontinuation of therapy resulted in significant regression of the nail signs for both groups, with the exception of hyperkeratosis treated with tazarotene, which seemed to retain significant improvement 12 weeks after the end of treatment. The baseline score of 1.80 changed to 0.36 after treatment and to 0.97 at the end of follow up $(\mathrm{P}<0.001)$. 
(c) Improvement of nail psoriasis in the participant's opinion Four trials with 171 participants assessed nail psoriasis through the participant's opinion.

Cannavo 2003 studied ciclosporin $70 \%$ in maize oil as a topical therapy versus maize oil alone. All the participants of the active group treated with $70 \%$ ciclosporin were positive about the results of the therapy (significant), while in the placebo group only 1 participant reported a moderate improvement.

In the study by Tosti 1998, where the participants' opinion of the acceptability of the treatment in the calcipotriol group was assessed at 3 months, $44 \%$ of the participants judged it as 'good', and 16\%, as 'excellent'. In the betamethasone group at 3 months, $58 \%$ of the participants judged it as 'good', and 19\%, as 'excellent'. After 5 months, $50 \%$ of the responders assessed the acceptability of calcipotriol as 'good', and $22 \%$, as 'excellent' (these participants had more then $50 \%$ improvement in hyperkeratosis in at least 1 nail at 3 months). The corresponding figures for the betamethasone responders were $57 \%$ 'good' and $24 \%$ 'excellent' at 5 months.

The result of participants' self-evaluation after treatment with calcipotriol monotherapy or combined with betamethasone showed a similar trend to the Investigators' Global Assessment, which showed that for $53 \%$ of the participants there was at least a moderate improvement after 12 weeks (Tzung 2008).

The overall nail improvement according to the participants treated with 5-FU in Belanyx ${ }^{\circledR}$ lotion or Belanyx ${ }^{\circledR}$ lotion alone was shown to be significant $(\mathrm{P}=0.001)$ at week 12 (de Jong 1999).

\section{Secondary outcomes addressed by the topical studies}

\section{(a) Adverse effects (and serious adverse effects, i.e. serious enough to require withdrawal of the treatment)}

Eight trials with 307 participants assessed adverse effects. Two trials with 45 participants did not assess adverse effects (Baran 1999; Baran 1999a).

In the studies by Flori 1994, Cannavo 2003, and Tzung 2008, participants reported no adverse effects during the study. Levell 1995 reported an increase of serum urate and burning sensation with dithranol, salicylic acid, and UVB treatment (see below under 'Systemic therapy' for further discussion). Tosti 1998 reported four adverse effects in three participants with calcipotriol treatment: one with erythema, one with irritation around the nail, one with a burning sensation at the place of application, and one participant with urticaria. Three participants with betamethasone (control) treatment reported erythema.

Six participants in de Jong 1999 reported possible treatment-related adverse effects, showing inflammation and infection or discolourations; three participants on 5-fluorouracil lotion showed onycholysis. For those given the vehicle lotion, none of the adverse effects were reported.

Five of 21 tazarotene-treated participants (Scher 2001) reported treatment-related adverse effects (all mild or moderate) - peeling of proximal nail fold skin, irritation of skin on the finger, periungual irritation, paronychia, and erythema of the proximal nail fold - but the control group reported no adverse effects. However, tazarotene generally was well tolerated in the treatment of nail psoriasis.

Rigopoulos 2007 reported that 3 of 16 participants receiving tazarotene experienced desquamation and erythema of nail fold skin, periungual irritation, paronychia, and irritation of the skin of the toe or finger. One of the 14 participants in the control group who was treated with clobetasol had a sensation of burning on the nail fold skin. All adverse events were mild, with the symptoms ameliorating after a few days.

Table 5 shows the weighted average of adverse effects for all topical therapies: $10.7 \%$ for the intervention group and $2.9 \%$ for the comparison group.

Analysis 4.1 (see Analysis 4.1.1) shows the numbers of participants who experienced adverse effects with topical therapy compared to the control group. In the studies by de Jong 1999, Rigopoulos 2007, Scher 2001, and Tosti 1998, there was no significant difference in the adverse effects experienced by the participants in the intervention and control groups. We were unable to estimate results for the other three studies.

\section{(b) Effects on quality of life}

One trial with 16 participants assessed the quality of life during treatment (Cannavo 2003). Eight participants treated with topical ciclosporin $70 \%$ in maize oil reported significant improvement, ranging from moderate to excellent (3 = 'excellent', 4 = 'good', and $1=$ 'moderate') compared to only 1 participant who had received maize oil alone who reported 'moderate' improvement.

(c) Improvement in nail features, pain score, nail thickness, thickness of subungual hyperkeratosis, number of affected nails, and nail growth

Eight trials with 265 participants separately assessed nail features (Baran 1999; Baran 1999a; Cannavo 2003; de Jong 1999; Flori 1994; Rigopoulos 2007; Scher 2001; Tzung 2008).

Two trials with 89 participants assessed nail growth and nail thickness (Tosti 1998; Scher 2001).

Nail signs for those treated with $8 \%$ clobetasol responded in the same sequence as the incidence rate observed in the studies: "onycholysis, pitting, subungual hyperkeratosis, salmon patches, splinter haemorrhages, ridging, transverse grooves, onychomadesis and periungual lesions, but with an exceptional response for onycholysis" (Baran 1999; Baran 1999a). There were no data available for the comparison between the active and control group in these studies.

Cannavo 2003 studied topical oil solution of $70 \%$ oral ciclosporin in maize oil versus maize oil alone. The best results for clinical nail response in the active group were obtained on onycholysis (score reduction from 3 to 0 ) and hyperkeratosis (score reduction from 
3 to 0.50$)$, which were both significant compared to baseline $(\mathrm{P}<$ 0.001 and $\mathrm{P}<0.005$, respectively). Pitting $(\mathrm{P}=0.086)$, crumbling $(\mathrm{P}<0.05)$, and oil drop $(\mathrm{P}=0.07)$ had minor significant results on therapy.

In de Jong 1999 after 12 weeks of 1\% 5-FU treatment in Belanyx ${ }^{\circledR}$ lotion, participants showed a significant improvement compared to baseline in 'nail pitting area' $(\mathrm{P}=0.004)$, subungual hyperkeratosis $(P=0.001)$, and oil spots $(P=0.001)$. There was no significant change in the number of pits or onycholysis $(\mathrm{P}>0.05)$. The Belanyx® lotion alone showed significant improvement of all assessed nail parameters at the end of treatment $(\mathrm{P}<0.05)$. There was no statistically-significant difference between the treatment groups.

Hyaluronic acid with chondroitin sulphate (Flori 1994) showed a significant improvement of $30 \%$ to $70 \%$ compared to baseline in all reported parameters $(\mathrm{P}<0.001$ to $\mathrm{P}=0.018)$. Pitting improved by $24.1 \%$ (score of 1.9 to 1.5 ) compared to baseline ( $\mathrm{P}$ $=0.018$ ) after 60 days of treatment. After 90 days of treatment, pitting, Beau's lines, and onycholysis improved compared to baseline: $41.4 \%$ (score $=1.9$ to $1.1, \mathrm{P}=0.003$ ), $31.8 \%$ (score $=1.5$ to $1.0, \mathrm{P}=0.018$ ), and $68.8 \%$ (score $=2.1$ to $0.7, \mathrm{P}<0.001$ ), respectively. For onychorrhexis, there was a significant improvement of $25 \%$ (score $=1.3$ to $1.0, \mathrm{P}=0.043$ ) compared to baseline after 30 days of treatment and an improvement of $65 \%$ (score $=1.3$ to $0.5, \mathrm{P}=0.018$ ) after 90 days. Hyperkeratosis showed a significant improvement of $70 \%$ (score $=1.3$ to $0.4, \mathrm{P}=0.005$ ) compared to baseline, after 60 days of treatment.

There was a significant difference between the hyaluronic acid + chondroitin sulphate group and the placebo group after 90 days for onychorrhexis (improvement of $65 \%$ (score $=1.3$ to 0.5 ) versus $15 \%$ (score $=1.3$ to 1.1 ), respectively; $\mathrm{P}=0.039$ ), onycholysis $(68.8 \%($ score $=2.1$ to 0.7$)$ versus $35.5 \%($ score $=2.1$ to 1.3$)$, respectively; $\mathrm{P}=0.041)$, and hyperkeratosis $(70 \%$ (score $=1.3$ to 0.4 ) versus $23.8 \%$ (score $=1.4$ to 1.1 ), respectively; $\mathrm{P}=0.041$ ).

The placebo group showed a significant improvement of $24 \%$ compared to baseline for pitting (after 90 days, score $=1.7$ to 1.3; $\mathrm{P}=0.028), 19.4 \%$ and $35.5 \%$ for onycholysis after 60 days (score $=2.1$ to $1.7, \mathrm{P}=0.028$ ) and after 90 days (score $=2.1$ to $1.3, \mathrm{P}=0.005$ ), respectively, and of $23.8 \%$ for hyperkeratosis after 90 days (score $=1.4$ to $1.1, \mathrm{P}=0.043$ ). A total improvement of all parameters was between $15 \%$ to $35.5 \%$ after 90 days. The median total improvement was $55 \%$ for the participants treated with hyaluronic acid and chondroitin sulphates versus $24 \%$ for the participants in the placebo group.

The treatment group was clinically more improved (30\% to $70 \%)$ compared to the placebo group ( $15 \%$ to $35.5 \%$ ) after 90 days. Rigopoulos 2007 compared tazarotene $0.1 \%$ cream with clobetasol propionate $0.05 \%$ cream. The results showed a significant time-effect improvement for pitting, onycholysis, hyperkeratosis, and salmon patches, with both agents after 12 weeks of treatment $(\mathrm{P}<0.001)$ (not significant between treatments).

\section{Follow-up}

Twelve weeks after discontinuation of treatment, the signs resulted in significant regression for both groups, with the exception of hyperkeratosis, which seemed to retain significant improvement $(\mathrm{P}<0.001)$.

Scher 2001 studied tazarotene $0.1 \%$ gel versus a vehicle gel. Tazarotene gel was significantly more efficacious than the vehicle in reducing onycholysis in occluded nails $(\mathrm{P} \leq 0.05$ at weeks 4 and 12) and non-occluded nails ( $\mathrm{P} \leq 0.05$ at week 24$)$. The tazarotene gel also resulted in a significantly greater reduction of pitting in occluded nails ( $\mathrm{P} \leq 0.05$ at week 24$)$. There were no other significant improvements between the two groups with regard to pitting (non-occluded), subungual hyperkeratosis, leuconychia, nail plate crumbling/loss, splinter haemorrhage, or nail growth rate.

Tzung 2008 studied calcipotriol in combination with betamethasone dipropionate versus calcipotriol alone. Both treatments were efficacious in improving oil drop discolourations $(\mathrm{P} \leq 0.039)$. Other nail bed features, as well as nail matrix features, failed to show significant improvement regardless of the treatment ( $P$ $>0.131)$. Nail crumbling even worsened during the treatment course.

Tosti 1998 studied the improvement of finger and toenail thickness. After 3 months, subungual hyperkeratosis of the fingernails reduced by $26.5 \%$ (score $=2.3$ to $1.5 \mathrm{~mm}$ ) and by $30.4 \%$ (score $=2.3$ to $1.6 \mathrm{~mm}$ ), respectively for calcipotriol and betamethasone (not significant compared to the other treatment). Eight out of 13 calcipotriol-treated participants and 10 out of 16 betamethasone-treated participants showed more than 50\% improvement of the hyperkeratosis in at least 1 fingernail (this was defined as responders), and these responders continued treatment for 2 more months. There was no homogeneity regarding the baseline thickness for these 2 subgroups (the thickness was $2.8 \mathrm{~mm}$ for the calcipotriol group and $2.1 \mathrm{~mm}$ for the betamethasone group). After 5 months of treatment, responders reported a score reduction of $49.2 \%$ in hyperkeratosis treated with calcipotriol (score $=2.8$ to $1.4 \mathrm{~mm}$ ) and a reduction of $51.7 \%$ (score $=2.1$ to $1.0 \mathrm{~mm}$ ) for the group treated with betamethasone (significant from baseline $(\mathrm{P}<0.001)$, but not significant between treatments).

\section{Follow-up}

Participants who were treated for five months were evaluated one month after discontinuation. The improvements persisted at the six-month visit.

After 3 months, the hyperkeratosis of the toenail treated with calcipotriol reduced by $20.1 \%$ (score $=2.6$ to $2.1 \mathrm{~mm}$ ) and by $22.9 \%$ (score $=3.0$ to $2.3 \mathrm{~mm}$ ) for the participants treated with betamethasone. This improvement was statistically significant compared to baseline hyperkeratosis $(\mathrm{P}<0.001)$, but it was not significant between the 2 treatments. Seven out of 20 of the calcipotrioltreated participants and 12 out of 24 of the betamethasone-treated 
participants were responders. These two subgroups were heterogeneous regarding hyperkeratosis at baseline. After 5 months, considering the responders from baseline to 5 months of treatment, there was a further reduction of $40.7 \%$ (score $=1.2 \pm 0.1 \mathrm{~mm})$ in the calcipotriol group and $51.9 \%($ score $=1.3 \pm 0.1 \mathrm{~mm})$ in the betamethasone group $(\mathrm{P}<0.0001$ from baseline). Unfortunately, the five-month data of the non-responders were not reported.

\section{Follow-up}

The improvement of the toenails persisted after follow up of one month.

There was no significant difference between the calcipotriol and betamethasone groups (RR 0.98, 95\% CI 0.55 to 1.75; Analysis 5.1) for the outcome 'Participants with at least $50 \%$ nail score improvement after short-term treatment duration', and there was also no significant difference in 'nail score improvement after shortterm treatment duration' between the calcipotriol and betamethasone groups (standardised mean differences (MD) $0.30,95 \% \mathrm{CI}$ -0.14 to 0.74 ; Analysis 5.2)

\section{Systemic therapy (six studies)}

Six trials studied the effect of systemic treatment on nail dystrophy (Gü mü ș el 2011; Igarashi 2012; Kavanaugh 2009; Levell 1995; Mahrle 1995; Rich 2008). The studies by Gủ mú ș el 2011, Mahrle 1995, and Levell 1995 compared treatment with systemic ciclosporin to methotrexate (for 24 weeks), to etretinate (for 22 weeks), and to topical dithranol with salicylic acid and UVB (up to 16 weeks), respectively.

Igarashi 2012, Kavanaugh 2009, and Rich 2008 studied biologicals. Igarashi 2012 studied ustekinumab 45 and 90 mg compared to placebo for 64 weeks. Kavanaugh 2009 compared golimumab to placebo for 20 weeks. Rich 2008 reported data on nail psoriasis involvement from the original skin psoriasis study by Reich 2005 (EXPRESS Study), which compared infliximab to placebo for 46 weeks.

\section{Primary outcomes addressed by the systemic studies}

\section{(a) Global improvement of nail psoriasis as rated by a clinician}

Four trials with 490 participants assessed nail psoriasis by a clinician.

In the study with methotrexate $15 \mathrm{mg} /$ week versus ciclosporin 5 $\mathrm{mg} / \mathrm{kg} /$ day by Gü mü s el 2011, the physician performed a general evaluation of the nail at each visit. Both treatment groups showed no significant difference in the mean physicians' global score $(\mathrm{P}=$ $0.28)$.

Mahrle 1995 reported non-significant nail score reductions of $17.5 \%$ and $9.2 \%$ in 90 participants treated with ciclosporin 2.5 $\mathrm{mg} / \mathrm{kg}$ and in 47 participants treated with etretinate $0.5 \mathrm{mg} / \mathrm{kg}$, respectively, during the first 10 weeks (phase 1) of the trial. This internally-controlled study had no available $P$ values.

In Levell 1995 after a median of 6 weeks' treatment, the global improvement of nail psoriasis, as rated by a clinician, to ciclosporin $2.5 \mathrm{mg} / \mathrm{kg}$ (with a median baseline score of 5.5) was improved for 8 participants; 1 had no change; and it was worse for 1 participant (median decrease in severity score of $4.5 ; 95.1 \%$ CI 0 to 8 ). The median nail score improvement was $82 \%$ at the end of treatment. After a median of 8 weeks' treatment, the global response of nail psoriasis, as rated by a clinician, to dithranol with salicylic acid and UVB treatment (with a median baseline score of 5) was improved for 8 participants, unchanged for 2 , and worsened for 5 (the median decrease in severity score was $0,95.2 \%$ CI -3 to 2.5 ). The median nail score improvement was $0 \%$ at the end of treatment.

\section{Follow-up}

All participants whose psoriasis cleared were followed up until relapse (return of psoriasis to $50 \%$ ) or until 8 months had elapsed. For 8 participants on ciclosporin treatment and 10 participants on dithranol with salicylic acid and UVB, their psoriatic nail involvement cleared. Of these eight ciclosporin participants, one showed no change, and seven worsened after stopping treatment. The median increase of the nail severity score by the end of the follow up was 5 (96.1\% CI 2 to 9.5). Of the 10 dithranol with salicylic acid and UVB participants, 1 showed no changes, 7 improved, and 2 worsened. The median improvement in score at the end of the follow-up period was 4 (95.8\% CI 0 to 8 ). Overall, psoriatic nail disease improved during ciclosporin treatment but deteriorated to more severe disease after treatment was stopped. No comparison was reported between the two treatment groups. No followup data were reported for the participants with nail involvement whose psoriasis had not cleared. This study showed participants with at least $50 \%$ nail score improvement after a short-term period of systemic therapy with ciclosporin, which was not significantly better than topical dithranol (RR $1.50,95 \%$ CI 0.85 to 2.64; Analysis 1.1).

In the study by Kavanaugh 2009, the baseline physician global assessment in the golimumab (50 mg and $100 \mathrm{mg}$ ) and placebo group was reported for $40 \%$ to $50 \%$ of the participants' nails as 'mild' (41/146 participants with golimumab $50 \mathrm{mg}$, 50/146 participants with golimumab $100 \mathrm{mg}$, and 52/113 participants with placebo) and for $30 \%$ to $40 \%$ as 'moderate' (39/146 participants with golimumab $50 \mathrm{mg}, 32 / 146$ participants with golimumab 100 $\mathrm{mg}$, and 35/113 participants with placebo).

Participants received injections of placebo, golimumab $50 \mathrm{mg}$, or golimumab $100 \mathrm{mg}$ every 4 weeks until week 20; however, the efficacy assessment was performed at weeks 14 and 24 . At week 14 , the number of participants with an improved nail assessment was significant compared to baseline, and it was almost equal for both golimumab doses, $47 \%$ (43/91 with $50 \mathrm{mg}$ ) and $48 \%$ (52/ 
108 with $100 \mathrm{mg})(\mathrm{P}<0.001)$, increasing further to $60 \%(53 / 89$ with $50 \mathrm{mg})$ and $63 \%(68 / 108$ with $100 \mathrm{mg})(\mathrm{P}<0.001)$ at week 24. At week 14, 14\% (11/81) of the placebo-treated participants had nail improvement, which increased to $18 \%$ of the participants $(14 / 79)$ at week 24 . No comparison was reported between the two treatment groups. It was not possible to analyse 'participants with at least $50 \%$ nail score improvement' using the data from this study.

\section{(b) Improvement of nail psoriasis scores (NAS, NAPSI)}

Four trials with 731 participants assessed nail psoriasis by NAPSI. Gú mú ș el 2011 showed the comparison with methotrexate and ciclosporin. At week 24, the mean NAPSI $( \pm$ SD) was $18.0( \pm 11.5)$ in the methotrexate group and $25.8( \pm 19.2)$ in the ciclosporin group. This was not significant between the 2 agents $(\mathrm{P}=0.27)$ (MD -7.80, 95\% CI -18.44 to 2.84; Analysis 9.1). From baseline to week 24 , a relative reduction of $43.3 \%$ and $37.2 \%$ was reported for methotrexate and ciclosporin, respectively $(\mathrm{P}=0.49)$.

At week 24, methotrexate had a mean NAPSI improvement of $49.3 \%$ for fingernails and $43.1 \%$ for toenails. The total nail matrix score significantly decreased $(\mathrm{P}=0.001)$ at week 24 . The total nail bed showed no significant improvement $(\mathrm{P}=0.093)$ at week 24 . The hand nail matrix, hand nail bed, and toenail matrix reported a significant improvement: $\mathrm{P}=0.002, \mathrm{P}=0.036$, and $\mathrm{P}=0.031$, respectively. However, no improvement was reported for the nail bed of the toes $(\mathrm{P}=0.070)$.

At week 24, ciclosporin had a mean NAPSI improvement of $45.2 \%$ for fingernails and $32.7 \%$ for toenails. The total score of the nail bed, hand nail bed, and toenail bed reported a significant improvement: $\mathrm{P}=0.001, \mathrm{P}=0.006$, and $\mathrm{P}=0.02$, respectively. There was no significant changes reported for the matrix scores.

\section{Follow-up}

After a follow up of 3 months, the mean NAPSI did not increase compared to week 24. A mean NAPSI of 18.3 and 25.4 was reported with methotrexate and ciclosporin, respectively. No impairment of nail psoriasis was reported with ciclosporin after follow up if complete improvement was reached at week 24. Both treatment groups showed a lower mean NAPSI after follow up compared to the mean score at week 24 .

Igarashi 2012 compared ustekinumab $45 \mathrm{mg}$ and $90 \mathrm{mg}$ to placebo. At week 12, the NAPSI had a mean percentage reduction of $7.7 \pm 95.1(\mathrm{P}=0.6541)$ for ustekinumab $45 \mathrm{mg}$ and $10.0 \pm$ $66.1(\mathrm{P}=0.4395)$ for ustekinumab $90 \mathrm{mg}$, compared to the placebo group's of $-2.9 \pm 27.8$, which was not significant (MD 0.41, 95\% CI -30.94 to 31.76 ; MD $0.54,95 \%$ CI -23.84 to 24.92 , respectively; Analysis 6.1; Analysis 7.1).

There was no significant nail score improvement in the ustekinumab $90 \mathrm{mg}$ group versus $45 \mathrm{mg}$ after short-term treatment duration (MD - $0.13,95 \% \mathrm{CI}-35.17$ to 34.91; Analysis 8.1).
After 64 weeks of treatment, the NAPSI score had a mean improvement of $56.6 \pm 43.2 \%$ and $67.8 \pm 37.5 \%$ for the $45 \mathrm{mg}$ ustekinumab group and $90 \mathrm{mg}$ ustekinumab group (no P value). In Rich 2008 (nail subgroup from the original study, Reich 2005), the percentage reduction from NAPSI at baseline was significantly greater in infliximab-treated participants than in placebo-treated participants (26.8\% versus $-7.7 \%$, respectively) at week 10 and (57.2\% versus $-4.1 \%$, respectively) at week 24 (both $\mathrm{P}<0.001$ ). At week 50, the infliximab group maintained nail improvements achieved at week 24 . At week 24, the participants treated with placebo switched to infliximab and achieved further reductions. Infliximab was applied through until week 46; however, the NAPSI was assessed at week 50 .

A different subgroup of participants (original study Reich 2005) with nail psoriasis who initiated and continued infliximab treatment up to week 46 ( $n=186$ ) was conducted by Reich 2010 . The mean NAPSI improvement was $28.3 \%$ at week 10 , followed by $61.4 \%$ at week 24 , and $67.8 \%$ at week 50 . Among participants with PASI-75 (Psoriasis Area and Severity Index) and PASI-90 skin psoriasis improvement at week 50 , the mean percentage improvements in the NAPSI score were $29.6 \%$ and $31.2 \%$, respectively, at week $10 ; 63.4 \%$ and $65.3 \%$ at week 24 ; and $78.2 \%$ and $80.3 \%$ at week 50. Among the PASI-75 and PASI-90 responders, complete nail clearance was observed in $31.6 \%$ and $54 \%$ at week 24 , and in $55.8 \%$ and $62.0 \%$ at week 50 , respectively.

Kavanaugh 2009 studied golimumab in different doses $(50 \mathrm{mg}$ and $100 \mathrm{mg}$ ) versus placebo. There was a significant improvement in median NAPSI for golimumab $50 \mathrm{mg}$ and $100 \mathrm{mg}: 25 \%(\mathrm{P}=$ $0.015)$ and $43 \%(\mathrm{P}<0.001)$, respectively, versus $0 \%$ in the placebo group. Further significant improvement was seen through week 24 (1 month after treatment was stopped): $33 \%$ for golimumab $50 \mathrm{mg}(\mathrm{P}<0.001)$ and $54 \%$ for golimumab $100 \mathrm{mg}(\mathrm{P}<0.001)$. Placebo-treated participants still had no improvement at week 24. No comparison was reported between the two treatment doses.

\section{(c) Improvement of nail psoriasis in the participant's opinion}

One trial with 37 participants assessed nail psoriasis in the participants' opinion.

In the study with methotrexate $15 \mathrm{mg} /$ week versus ciclosporin $5 \mathrm{mg} / \mathrm{kg} /$ day by Gü mú ș el 2011, the participants performed a general evaluation of the nail. At week 24, the mean participants' global score showed no significant difference between the methotrexate and ciclosporin group $(P=0.06)$. A clinical evaluation using the NAPSI score (participants' response) was classified at week 24 . Seven $(41.1 \%)$ of the participants treated with methotrexate showed a moderate improvement, and 10 (58.8\%) participants, a mild improvement. One $(5.8 \%)$ participant treated with ciclosporin showed no improvement; 8 (47\%) participants showed mild improvement; 7 (41.1\%) participants showed moderate improvement, and $1(5.8 \%)$ participant showed a complete improvement. 
Secondary outcomes addressed by the systemic studies

\section{(a) Adverse effects (and serious adverse effects, i.e. serious enough to require withdrawal of the treatment)}

Six trials with 897 participants assessed the adverse effects (AE). Gü mü ș el 2011, Igarashi 2012, Mahrle 1995, Levell 1995, Rich 2008, and Kavanaugh 2009 reported adverse effects, which were in some trials not specified for the nail psoriasis group.

Adverse effects caused by methotrexate were detected in three participants (Gü mú ș el 2011): Two experienced nausea and telogen effluvium (thinning and shedding of hair) during the study period, and one who discontinued the treatment had an elevation of liver transaminase.

Five participants demonstrated adverse effects caused by ciclosporin in the control group: One developed hypercholesterolaemia; one, hirsutism; another had menstrual abnormalities; and two had an elevation of creatinine and lipids, therefore, discontinuing treatment.

None of the participants in the methotrexate or ciclosporin group experienced adverse effects on the nails, except for 1 participant treated with ciclosporin, who reported on the distal part of the nail a mild pain after 10 weeks.

During the first 12 weeks of administration of $45 \mathrm{mg}$ ustekinumab and $90 \mathrm{mg}$ ustekinumab (Igarashi 2012), the adverse effects reported were mostly mild. This did not result in discontinuation of the therapy. In the placebo group, $25 \%$ experienced an exacerbation of psoriasis as the most common adverse effect. In the ustekinumab groups, nasopharyngitis $(45 \mathrm{mg}=15.6 \%, 90 \mathrm{mg}=$ $16.1 \%$ ) was the most commonly-reported adverse effect. The proportion of participants reporting serious adverse effects was low (placebo $=6.3 \%$, ustekinumab $45 \mathrm{mg}=0 \%$, ustekinumab $90 \mathrm{mg}$ $=4.8 \%)$. Infections were mentioned in $18.8 \%$ of the participants in the placebo group, $20.3 \%$ of the $45 \mathrm{mg}$ ustekinumab group, and $24.2 \%$ of the $90 \mathrm{mg}$ ustekinumab group. Up to week 72 , the most common adverse effects reported were nasopharyngitis, increased blood triglycerides and increased creatine phosphokinase, and seasonal allergies, including allergic rhinitis.

The most common adverse effects in the ciclosporin group in the study by Mahrle 1995 were gastrointestinal, skin and mucous membrane symptoms, nervous system and psychiatric disorders, and general adverse reactions. The percentage of participants with adverse effects was higher in the etretinate (control) group compared to the (intervention) ciclosporin group. In the etretinate group, cheilitis (inflammation of the lip), dry mouth, and skin exfoliation were reported.

The study by Levell 1995 assessed minimal toxicity in the ciclosporin group. A $25 \%$ dose reduction of ciclosporin was needed because of high blood pressure $(150 / 100 \mathrm{mmHg})$ in 1 participant. The blood pressure subsequently returned to normal. In one participant, the serum creatinine increased when on ciclosporin by $>30 \%$ after 8 weeks' treatment, but this reversed after a $25 \%$ dose reduction. Besides this, both groups reported an increasing serum urate and fall in serum magnesium. The group administered dithranol with salicylic acid, and UVB also reported a burning sensation of the skin.

In the study by Rich $2008,82 \%$ of participants with infliximab 5 $\mathrm{mg} / \mathrm{kg}$ experienced at least 1 adverse effect at week 24 , compared to $71 \%$ in the placebo group. Kavanaugh 2009 reported adverse effects for participants with psoriatic arthritis who were given golimumab (50 and $100 \mathrm{mg}$ ) compared to the placebo group: $65 \%$ (222/343) of participants with golimumab had adverse effects (mostly nasopharyngitis and upper respiratory tract infections) at the week-24 measurement compared to 59\% (67/113) of those in the placebo group. Most infections were reported for those in the $100 \mathrm{mg}$ golimumab group (33\% in the $50 \mathrm{mg}$ group, $41 \%$ in the $100 \mathrm{mg}$ group, $24 \%$ in the placebo group).

Table 5 shows the weighted average of adverse effects for systemic therapy: $69.8 \%$ in the intervention group and $60.3 \%$ in the comparison group. Systemic therapy showed the highest weighted average of adverse effects, compared to topical and radiotherapy. The study by Mahrle 1995 (RR 1.78 , 95\% CI 1.30 to 2.44 ) showed that significantly more participants experienced adverse effects in the control than in the intervention group. In the studies by Igarashi 2012, Gü mü \$ el 2011, Kavanaugh 2009, and Rich 2008, there was no significant difference in adverse effects experienced by the participants in either group (Analysis 4.1, see Analysis 4.1.2).

\section{(b) Effects on quality of life}

None of the systemic studies addressed this outcome.

(c) Improvement in nail features, pain score, nail thickness, thickness of subungual hyperkeratosis, number of affected nails, and nail growth

One trial with 305 participants assessed separate nail features (Rich 2008).

In this study, participants on infliximab showed an improvement of nail features. At week 24, the nail matrix had a mean improvement from baseline of $52.9 \%$ compared to a worsening of $-1.9 \%$ for placebo $(\mathrm{P}<0.001)$, and the nail bed had a mean improvement of $69.2 \%$ compared to $18.4 \%$ for placebo $(\mathrm{P}<0.001)$.

Infliximab improved the nail score for most of the nail features measured at weeks 10, 24, and 50. In the placebo group, the score was unchanged or only modestly decreased. After cross-over from placebo to infliximab at week 24 , the nail score for all of the nail features further decreased.

At baseline, the most frequent nail matrix feature was pitting (70\%), and subsequently leuconychia, nail plate crumbling, and red spots in the lunula. Red spots in the lunula reported the fastest reduction. Only 33.3\% (9/77) of the infliximab participants had persistent red spots in the lunula at week 10 . By week 24 , the in- 
fliximab group showed significant $(\mathrm{P}<0.001)$ improvement compared to the placebo group for participants with persistent pitting (57\% versus $93 \%)$ and leuconychia (26.2\% versus $77.3 \%)$ features.

The most common nail bed feature was onycholysis (70\%), and subsequently oil drop discolourations, nail bed hyperkeratosis, and splinter haemorrhages. By week 24, the infliximab group showed significant improvement $(\mathrm{P}<0.001)$ compared to placebo: $\mathrm{Of}$ those participants receiving infliximab, $25.9 \%$ had persistent onycholysis compared to $79.1 \%$ receiving placebo, and $26.5 \%$ on infliximab had persistent oil drop discolourations compared to $69 \%$ receiving placebo.

\section{Radiotherapy (three studies)}

Three trials studied the effect of radiotherapy versus placebo on nail dystrophy (Kwang 1995; Lindelof 1989; Yu 1992). Lindelof 1989 studied 5 Gy of grenz rays (ultrasoft X-rays) on 10 occasions at intervals of 1 week. Yu 1992 studied superficial radiotherapy (SRT) given as 3 fractionated doses of $150 \mathrm{cGy}$, which were administered every 2 weeks to a total of $450 \mathrm{cGy}$ per fortnight (90 $\mathrm{kV}, 5 \mathrm{~mA}, 1.00 \mathrm{~mm}$ aluminium filter), and Kwang 1995 used electron beam, with a total of 6 Gy given in 8 fractions over 8 weeks.

\section{Primary outcomes addressed by the radiotherapy studies}

\section{(a) Global improvement of nail psoriasis as rated by a clinician}

In all 3 trials, with a total of 46 participants, a clinician assessed nail psoriasis.

After 10 weeks, Lindelof 1989 (internally-controlled study) showed a significantly better effect on psoriatic nails with grenz ray therapy compared to placebo $(\mathrm{P}<0.05)$. However, the response was moderate. Of the 24 included participants, 2 withdrew because of illness in their families. Of the 22 remaining, 1 participant showed almost complete recovery; however, 14 participants showed no improvement at all.

\section{Follow-up}

During the follow-up period of 6 months, there were no clear signs of further improvements (18 participants were unchanged; 2 improved moderately; 2 became slightly worse). All the nails that responded were of normal thickness; hyperkeratotic nails did not respond.

In Yu 1992, the superficial radiotherapy-treated group demonstrated a significant fall in the nail score compared to baseline. This was measured at 10 weeks (score $=5.5 \pm 0.4$ to $4.4 \pm 0.3$ $(20 \%))(\mathrm{P}<0.0001)$ and at 15 weeks (score $=5.5 \pm 0.4$ to $4.6 \pm$
$0.4(16 \%))(\mathrm{P}=0.046)$ after therapy. The control group showed no score improvement compared to baseline at week 10 (score = $5.4 \pm 0.4$ to $5.4 \pm 0.6(0 \%)$ and even worsening at week 15 (score $=5.4 \pm 0.4$ to $5.5 \pm 0.4(-1.85 \%)$ ) (no P value). At weeks 10 and 15 , a significant improvement was shown for the treated group compared to the untreated group $(\mathrm{P}=0.03$ and $\mathrm{P}=0.047$, respectively). At week 20, the nail score remained 4.6 (16\% improvement from baseline) in the treated group. In the untreated group, the nail score reduced to 4.8 (11\% improvement from baseline) (not significant) at week 20.

The efficacy of electron beam with eight fractions over eight weeks was studied in an internally-controlled trial by Kwang 1995 where treatment was administered to the affected nails of one hand; the other hand was used as control. Assessment was performed at 3, 6, and 12 months after treatment. Three months after treatment, electron beam showed a significant reduction $(\mathrm{P}<0.05)$ compared to the other hand; however, not at 6 months $(\mathrm{P}>0.5)$ or 1 year $(\mathrm{P}>$ $0.5)$. Compared to week 0 , the treated hands showed a significant improvement at 3 months $(\mathrm{P}<0.05)$ and 6 months $(\mathrm{P}<0.05)$ after treatment, but this was not shown at 1 year $(\mathrm{P}>0.5)$.

\section{(b) Improvement of nail psoriasis scores (NAS, NAPSI)}

None of the radiotherapy studies addressed this outcome.

(c) Improvement of nail psoriasis in the participant's opinion None of the radiotherapy studies addressed this outcome.

\section{Secondary outcomes}

(a) Adverse effects (and serious adverse effects, i.e. serious enough to require withdrawal of the treatment)

Three trials with 46 participants assessed adverse effects.

- Grenz rays (Lindelof 1989): 5 out of 22 participants showed slight pigmentation of the grenz ray-treated nail fold.

- Superficial radiotherapy (Yu 1992): This assessed adverse effects, but did not report any.

- Electron beam (Kwang 1995): The only local adverse effect was short-lasting brownish-black discolourations of all the nails treated with electron beam.

Table 5 shows the weighted average of adverse effects for radiotherapy: $40.5 \%$ in the intervention group and $0 \%$ in the comparison group.

Analysis 4.1 shows the number of participants with adverse effects of any treatment. The study from Kwang 1995 showed significantly more adverse effects in the intervention group compared to the control group (RR $0.04,95 \%$ CI 0.00 to 0.61 ). Lindelof 1989 showed no significant difference in adverse effects reported 
in the treatment group compared to the placebo group (RR 0.09, $95 \%$ CI 0.01 to 1.55$)$.

\section{(b) Effects on quality of life}

None of the radiotherapy studies addressed this outcome.

(c) Improvement in nail features, pain score, nail thickness, thickness of subungual hyperkeratosis, number of affected nails, and nail growth

One trial with 12 participants assessed separate nail features (Kwang 1995). One trial with 10 participants assessed nail growth and thickness (Yu 1992). These studies were both internally-controlled.

A decrease in subungual hyperkeratosis was the main improvement noted after eight fractions with electron beam, followed by pitting and onycholysis. No assessment was reported directly after 8 weeks' treatment, but at 3, 6, and 12 months after treatment (Kwang 1995). No P values or underlying data were available.

At 10, 15, and 20 weeks post-treatment, the rate of linear nail growth by Yu 1992 slightly diminished in the superficial radio- therapy (SRT)-treated nails compared with the control nails (not statistically significant). At week 15 , treated nails demonstrated a significant reduction in mean nail thickness $(1.10 \mathrm{~mm} \pm 0.08$ to $0.75 \mathrm{~mm} \pm 0.03)$ compared to the placebo group $(1.20 \pm 0.09$ to $0.88 \pm 0.04)(\mathrm{P}=0.005)$. This difference was not significant after 20 weeks of treatment.

\section{Additional: Nail features}

We evaluated the efficacy of interventions on nail features (nail matrix and nail bed features) and reported this separately per feature instead of per intervention. Eleven included trials assessed the following nail features: onycholysis, pitting, subungual hyperkeratosis, leuconychia, red spots in the lunula, salmon patches, splinter haemorrhages, ridging, furrows, transverse grooves, Beau lines, onychomadesis, periungual psoriasis, crumbling, oil drop, nail fold involvement, the extent of nail pitting, onychorrhexis, onicoressi, nail plate discolourations, nail thickness, and nail growth.

Table 7 presents the most common nail features in the nail matrix and nail bed. Figure 5 shows some pictures of nail features.

Figure 5. Some nail features: onycholysis, splinter haemorrhages, pitting, and oil drop or salmon patches
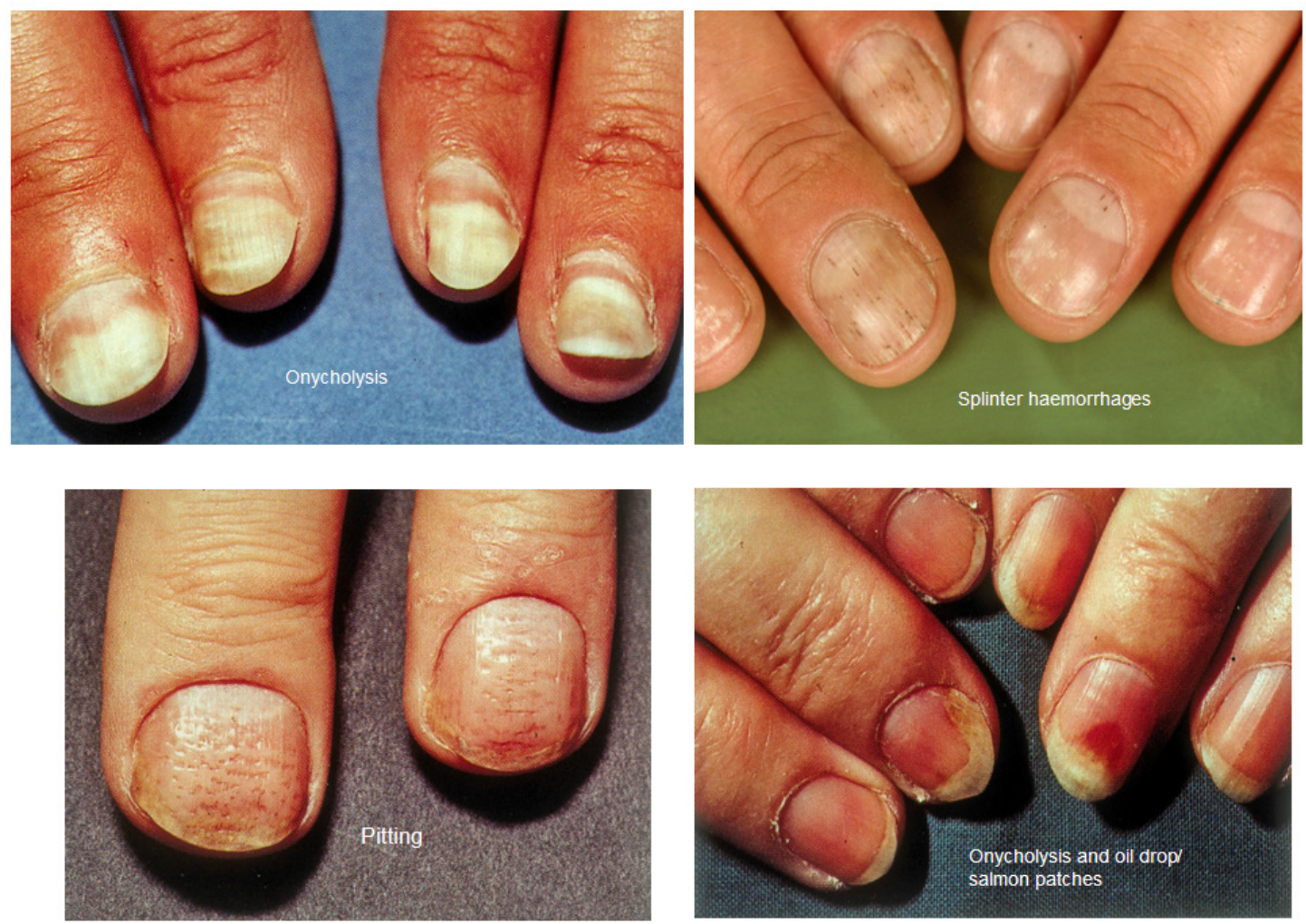

Interventions for nail psoriasis (Review)

Copyright @ 2013 The Cochrane Collaboration. Published by John Wiley \& Sons, Ltd. 


\section{Nail matrix}

\section{Pitting}

Pitting was studied separately in seven trials: Cannavo 2003, Flori 1994, de Jong 1999, Rich 2008, Rigopoulos 2007, Scher 2001, and Tzung 2008.

The best improvement in pitting was seen with topical ciclosporin $70 \%$ in maize oil twice daily for 12 weeks (Cannavo 2003). The median severity score changed from 0.5 before treatment to 0.0 after treatment, an improvement of $100 \%(\mathrm{P}=0.086)$.

Tazarotene $0.1 \%$ cream once daily for 12 weeks under occlusion showed a $75.2 \%$ nail score improvement after treatment (from score 1.13 to 0.28 ) (Rigopoulos 2007). The clobetasol group saw a nail score improvement of $67 \%$ in pitting (from 1.09 to 0.36 ). Although there was no significant difference between these 2 interventions, there was a significant improvement over time $(\mathrm{P}<$ 0.001 ) for both agents.

Infliximab $5 \mathrm{mg} / \mathrm{kg}$ gave a complete clearance to $56.4 \%(84 / 149)$ in the participants with pitting after 50 weeks (Rich 2008). At week 24, the placebo group crossed over to infliximab and showed for $67.5 \%(27 / 40)$ of the participants complete clearance at week 50 .

After 90 days of treatment with hyaluronic acid and chondroitin sulphates (Flori 1994), there was an improvement of $41.4 \%$ (severity score from $1.9 \pm 0.88$ to $1.1 \pm 0.74)$. This was significant compared to baseline $(\mathrm{P}=0.003)$, but not significant compared to placebo.

After 24 weeks of tazarotene $0.1 \%$ gel under occlusion, an improvement of $33.3 \%$ was shown (this was significant versus vehicle, $\mathrm{P} \leq 0.05)($ Scher 2001).

Treatment with 1\% 5-fluorouracil (de Jong 1999) gave a 28\% improvement in the nail pit area (score $=2.9$ to 2.1 ). The improvement of the number of nail pits was not significant $(\mathrm{P}>0.05)$.

Treatment with calcipotriol $0.005 \%$ failed to show significant improvement $(\mathrm{P} \geq 0.131)$ in pitting after 12 weeks (Tzung 2008).

\section{Red spots in the lunula}

Rich 2008 and Tzung 2008 described red spots in the lunula. Treatment with infliximab $5 \mathrm{mg} / \mathrm{kg}$ showed a complete clearance in 24 participants after 50 weeks (96\% (24/25)) (Rich 2008). At week 24 , the placebo group switched to infliximab and showed complete clearance in all $(3 / 3)$ participants at week 50 . Calcipotriol $0.005 \%$ failed to show significant improvement of the red spots in the lunula ( $P \geq 0.131$ ) after 12 weeks (Tzung 2008).

\section{Leukonychia}

Three trials (Rich 2008, Scher 2001, and Tzung 2008) studied leuconychia as a separate nail feature.

After 50 weeks, clearance was seen both in $82 \%$ of the participants treated with infliximab $(82 / 100)$ and also in the group who were initially given placebo (18/22) (Rich 2008).

Treatment with calcipotriol $(\mathrm{P} \geq 0.131)$ or tazarotene gel failed to show a significant improvement of leuconychia (Scher 2001; Tzung 2008).

\section{Crumbling}

Cannavo 2003, Rich 2008, Scher 2001, and Tzung 2008 studied nail crumbling as a separate nail feature.

Treatment with topical ciclosporin $70 \%$ in maize oil gave a median improvement of $100 \%$ for crumbling (score $=1.5$ to $0.0, \mathrm{P}<$ 0.05) after 12 weeks (Cannavo 2003). Also, 66.7\% (50/75) of the participants treated with infliximab showed a complete clearance after 50 weeks (Rich 2008).

Tazarotene $0.1 \%$ gel showed no significant difference for nail crumbling between the treated and placebo group (no underlying data) (Scher 2001). Calcipotriol $0.005 \%$ showed a worsening of nail crumbling after 12 weeks $(P \geq 0.131$; no further data were available) (Tzung 2008).

\section{Nail bed}

\section{Onycholysis}

Seven trials (Cannavo 2003; Flori 1994; de Jong 1999; Rich 2008; Rigopoulos 2007; Scher 2001; Tzung 2008) studied onycholysis. The best improvement was seen with topical ciclosporin $70 \%$ in maize oil (Cannavo 2003) and infliximab (Rich 2008). After 12 weeks, topical ciclosporin $70 \%$ in maize oil showed a $100 \%$ improvement of the onycholysis (median severity score before treatment was 3.0, whereas after treatment it was $0.0, \mathrm{P}<0.001$ ). Infliximab $5 \mathrm{mg} / \mathrm{kg}$ reported complete clearance in $73.2 \%(104 /$ 142) of the participants after 50 weeks (Rich 2008). At week 24 , the group who were initially given placebo switched to infliximab. After 50 weeks of treatment, $78 \%$ of these participants showed clearance (32/41).

After 90 days, hyaluronic acid and chondroitin sulphate showed a score improvement of $68.8 \%$ (score $=2.1$ to 0.7 ) compared to baseline for onycholysis (Flori 1994). Rigopoulos 2007 studied either tazarotene $0.1 \%$ cream or clobetasol propionate $0.05 \%$ once daily under occlusion for 12 weeks. Tazarotene $0.1 \%$ cream once daily under occlusion showed an improvement of $58.4 \%$ (severity score from 1.97 to 0.82 ) for onycholysis after 12 weeks, which was decreased to $21.8 \%$ (severity score $=1.54$ ) in the follow-up

Interventions for nail psoriasis (Review) 
period at 24 weeks. Clobetasol showed a total of $56.8 \%$ score improvement after 12 weeks (severity score from 1.90 to 0.82 ), which decreased to $8.9 \%$ (severity score $=1.73$ ) after 24 weeks. Although there was no significant difference between the 2 interventions in terms of onycholysis, there was a significant improvement over time $(\mathrm{P}<0.001)$ for both agents. In the non-occluded nails, tazarotene $0.1 \%$ gel showed an improvement of $33 \%$ compared to vehicle (which was statistically significant, $\mathrm{P} \leq 0.05$ ) after 24 weeks (Scher 2001). For the occluded nails, the study reported significant improvement compared to vehicle $(\mathrm{P} \leq 0.05)$ without underlying data. de Jong 1999 treated onycholysis with 1\% 5-fluorouracil for 12 weeks and reported a score improvement of $19 \%$ (score $=1.6$ to 1.3$)$, which was not significant $(\mathrm{P}>0.05)$.

Calcipotriol studied as monotherapy or in combination with betamethasone dipropionate failed to show significant improvement ( $P \geq 0.131$ ) in onycholysis (Tzung 2008).

\section{Splinter haemorrhages}

Rich 2008, Scher 2001, and Tzung 2008 separately described splinter haemorrhages. The only improvement was seen with infliximab $5 \mathrm{mg} / \mathrm{kg}$ (Rich 2008). After 50 weeks, 88\% (44/50) of the participants showed a complete clearance. Ninety per cent (9/10) of the placebo group that switched to infliximab after 24 weeks of treatment showed a complete clearance after 50 weeks. Treatment with tazarotene $0.1 \%$ gel and calcipotriol $0.005 \%$ (P $\geq 0.131$ ) failed to show a significant improvement (Scher 2001; Tzung 2008).

\section{Salmon patches and oil drop discolourations}

The terms 'salmon patches' and 'oil drop discolourations' are used interchangeably in the literature. The following described the features: Rigopoulos 2007 (salmon patches), Cannavo 2003 (oil drop), de Jong 1999 (oil spots), Rich 2008 (oil drop), and Tzung 2008 (oil drop).

Rich 2008 showed the best results with infliximab, and Rigopoulos 2007 showed the best results with tazarotene $0.1 \%$ cream or clobetasol $0.05 \%$. Infliximab showed a complete clearance in $81.2 \%$ (78/96) of the participants after 50 weeks. Tazarotene $0.1 \%$ cream once daily under occlusion showed a score improvement of $85.2 \%$ ( score $=1.15$ to 0.17$)$ after 12 weeks $(\mathrm{P}<0.001$ to baseline) . Clobetasol $0.05 \%$ once daily under occlusion showed a $82.2 \%$ (score $=1.07$ to 0.19$)$ score improvement $(\mathrm{P}<0.001$ to baseline $)$. There was no significant difference between these two interventions in terms of salmon patches.

$1 \%$-fluorouracil showed 63\% score improvement (score $=0.8$ to 0.3 ) after 12 weeks (de Jong 1999).

Participants who were treated twice daily with topical ciclosporin $70 \%$ in maize oil showed a $75 \%$ score improvement (median score at baseline was 2.0 to 0.5 after treatment, $\mathrm{P}=0.07$ ) after 12 weeks (Cannavo 2003).
Calcipotriol as monotherapy and as combination therapy with betamethasone dipropionate both showed efficacy in improving oil drop discolourations ( $\mathrm{P}<0.039$ ) (Tzung 2008). The study did not provide further underlying data.

\section{Subungual hyperkeratosis and nail thickness}

Eight studies (Cannavo 2003; de Jong 1999; Flori 1994; Rich 2008; Rigopoulos 2007; Scher 2001; Tzung 2008; Tosti 1998) described subungual hyperkeratosis as a separate nail feature. Yu 1992 assessed nail thickness.

A complete clearance was shown in $78.7 \%(70 / 89)$ of the participants treated with infliximab after 50 weeks (Rich 2008). Topical ciclosporin $70 \%$ in maize oil presented an improvement of $83 \%$ (median baseline score $=3.0$ to 0.50 after treatment, $\mathrm{P}<$ 0.005 ) after 12 weeks (Cannavo 2003). Tazarotene $0.1 \%$ cream showed an improvement of $80 \%$ (score $=1.8$ to 0.36 ), while clobetasol reported $66 \%$ improvement (score $=1.70$ to 0.58 ) after 12 weeks; both were significant to baseline $(\mathrm{P}<0.001)$, with no significance between agents (Rigopoulos 2007). Twelve weeks after the end of treatment hyperkeratosis seemed to retain significant improvement for participants applying tazarotene (score $=0.97$, $\mathrm{P}<0.001)$. Treatment with hyaluronic acid and chondroitin sulphates showed a mean score changed from 1.3 (at baseline) to 0.4 (after 90 days); this was an improvement of 70\% (Flori 1994).

Tazarotene $0.1 \%$ gel showed no significant difference between the treated group and the placebo group after 24 weeks (Scher 2001). After 12 weeks with 1\% 5-fluorouracil once daily, de Jong 1999 reported a $47 \%$ score improvement (score changed from 1.9 to 1.0).

Tzung 2008 failed to show significant improvement $(\mathrm{P} \geq 0.131)$ with calcipotriol $0.005 \%$ as well as treatment with calcipotriol in combination with betamethasone dipropionate .

Tosti 1998 studied calcipotriol $50 \mathrm{ug} / \mathrm{g}$, which showed an improvement of $26.5 \%$ (score $=2.3$ to $1.5 \mathrm{~mm}$ ) of the fingernail thickness and $20.1 \%$ (score 2.6 to $2.1 \mathrm{~mm}$ ) of the toenail thickness after 3 months. The comparison group given betamethasone and salicylic acid had an improvement of $30.4 \%$ (score $=2.3$ to $1.6 \mathrm{~mm}$ ) of their fingernails and $22.9 \%$ (score $=3.0$ to $2.3 \mathrm{~mm}$ ) improvement of their toenails. Responders (more than 50\% improvement in baseline hyperkeratosis in 1 or more nails at 3 months) were offered a continuation of the initially-applied treatment for 2 additional months. After 5 months' treatment with calcipotriol, subungual hyperkeratosis of the fingernails showed a $49.2 \%$ reduction (from 2.8 to $1.4 \mathrm{~mm}$ ) and the toenails showed a $40.7 \%$ (to $1.2 \mathrm{~mm}$ ) reduction. The betamethasone and salicylic acid group reported a $51.7 \%$ (score $=2.1$ to $1.0 \mathrm{~mm}$ ) and $51.9 \%$ (to $1.3 \mathrm{~mm}$ ) decrease of subungual hyperkeratosis in fingers and toenails, respectively. Superficial radiotherapy demonstrated a significant reduction in mean nail thickness of $31.8 \%(1.10 \pm 0.08$ to $0.75 \pm 0.03)$ compared to the sham-treated group $(\mathrm{P}=0.005)$ at week $15(\mathrm{Yu} 1992)$. 


\section{Other}

\section{Beau lines and onicoressi}

Flori 1994 assessed these two nail features separately after treatment with hyaluronic acid and chondroitin sulphates. After 90 days of treatment, there was an improvement of $31.8 \%$ of the Beau lines (score $=1.5 \pm 0.83$ to $1.0 \pm 0.65$ ), which was significant compared to baseline $(\mathrm{P}=0.018)$ but not significant compared to placebo, and a $65 \%$ improvement of onicoressi (score $=1.3 \pm 1.11$ to $0.5 \pm 0.64)$, which was significant compared to baseline ( $\mathrm{P}=$ $0.018)$ and placebo $(\mathrm{P}=0.039)$.

\section{Nail growth}

Scher 2001 and Yu 1992 described nail growth. In both studies, there was no significant difference in nail growth between the treated group (respectively, tazarotene gel $0.1 \%$ and superificial radiotherapy) and the placebo group.

\section{DISCUSSION}

In this review, we provided a summary of the best available evidence for several types of treatments for nail psoriasis: topical, systemic, and radiotherapy. This will be useful for producing guidelines and identifying future research.

\section{Summary of main results}

Of the 212 retrieved references, we could only include 18 trials, with a total of 1266 participants.

The quality of the studies was generally poor as assessed by the risk of bias of the studies (see Figure 3, 'Methodological quality graph: review authors' judgements about each methodological quality item presented as percentages across all included studies'), and the evidence of the efficacy and safety of treatment options for nail psoriasis was based on only one study per treatment for most therapies.

We assessed and compared between treatments the primary outcomes 'Global improvement of nail psoriasis as rated by a clinician' and 'Improvement of nail psoriasis scores'. Two biologic and three radiotherapy studies showed significant results for the improvement of nail psoriasis compared to placebo (Kavanaugh 2009; Kwang 1995; Lindelof 1989; Rich 2008; Yu 1992). Infliximab $5 \mathrm{mg} / \mathrm{kg}$ showed $57.2 \%$ nail score improvement versus $4.1 \%$ for placebo; golimumab $50 \mathrm{mg}$ and $100 \mathrm{mg}$ showed $33 \%$ and $54 \%$, respectively, versus $0 \%$ for placebo, both after mediumterm treatment (Kavanaugh 2009; Rich 2008). From the 3 radiotherapy studies, only the superficial radiotherapy study showed underlying data: $20 \%$ versus $0 \%$ score improvement after shortterm treatment (Yu 1992).
Seven studies using 5-fluorouracil 1\% in Belanyx ${ }^{\circledR}$ lotion (for both fingers and toenails), ciclosporin $2.5 \mathrm{mg} / \mathrm{kg}$, tazarotene $0.1 \%$ cream, calcipotriol $50 \mathrm{ug} / \mathrm{g}$, calcipotriol $0.005 \%$, methotrexate, and ustekinumab showed no statistically significant results compared to, respectively, belanyx lotion, etretinate, clobetasol propionate, betamethasone dipropionate with salicylic acid, betamethasone dipropionate alone, ciclosporin, and placebo when assessed by a clinician and by nail scores.

Not all of the included studies assessed nail improvement compared to the control group. This reflects the lower quality of these trials. Data on improvement compared to baseline was given in 7 studies, which reported significant nail improvement compared to baseline, of which topical ciclosporin $70 \%$ in maize oil (Cannavo 2003), tazarotene $0.1 \%$ cream, and clobetasol $0.05 \%$ (Rigopoulos 2007) showed $\geq 75 \%$ nail improvement after short-term treatment. The percentage score improvement of fingernail psoriasis, regardless of the outcome measures used, are presented in Table 4 with or without significant improvement to the comparison group and with or without significant improvement to baseline after short- and medium-term treatment.

Topical drugs are mostly formulated to treat skin disease, so they are not optimised for penetrating in and through the nail plate. To improve penetration, some of the topical therapies were applied with an enhancer or under occlusion with varying results (de Jong 1999; Rigopoulos 2007; Scher 2001). With regard to the penetration of radiotherapy through the nail bed, Kwang 1995 stated that an electron beam could penetrate to the nail bed, unlike grenz rays, which treat only the surface of the nail. Nails treated with grenz rays reported no improvement in hyperkeratotic nails. When nails are of normal thickness, the results of applied radiotherapy might be different.

Five studies (Cannavo 2003; de Jong 1999; Gú mú ș el 2011; Tosti 1998; Tzung 2008) assessed our primary outcome 'Improvement of nail psoriasis in the participant's opinion'. The participants preferred topical $70 \%$ ciclosporin treatment compared to the placebo (Cannavo 2003). The participants assessed a mainly 'good' acceptability for calcipotriol and betamethasone in Tosti 1998 . The studies by Tzung 2008 and de Jong 1999 showed similar trends for the participant's assessment compared to the Investigator's Global Assessment.

The secondary outcome 'Adverse effects' is shown per intervention in Table 5. The percentage of adverse events in the control groups consist of adverse effects due to placebo or active treatment. Furthermore, in studies about skin psoriasis (Igarashi 2012; Kavanaugh 2009; Levell 1995; Mahrle 1995; Rich 2008), data on adverse events were often not presented separately for participants with or without nail involvement.

In theory, for the internally-controlled trials, there could be a carry-over effect related to effects and adverse effects. In this review, we did not include internally-controlled trials with systemic treatment. The trials with topical treatment and radiotherapy are assumed to be a local treatment, with no or minimal carry-over 
effect.

We did not include studies with systemic therapy solely for nail psoriasis in this review. For nail psoriasis, when considering systemic therapy the risk and burden of adverse effects must be taken into account.

Only one study (Cannavo 2003) reported our secondary outcome 'Effects on quality of life'. The topical $70 \%$ ciclosporin group reported more improvement on the 'impact on every day life' and 'positively experienced social interactions' of their nail pathology compared to the control group.

Eleven studies showed separate data on nail features (secondary outcome parameter), of which 3 (hyaluronic acid + chondroitin sulphates (Flori 1994), tazarotene $0.1 \%$ gel (Scher 2001), and calcipotriol $0.005 \%$ (Tzung 2008)) showed significance in some features. One study (infliximab (Rich 2008)) showed a significant decrease in the occurrence of individual features over time. Three studies showed no significance between the treatments (de Jong 1999; Rigopoulos 2007; Tosti 1998), and four studies reported no compared data (Baran 1999; Baran 1999a; Cannavo 2003; Kwang 1995). Two trials (Scher 2001; Yu 1992) reported the outcome parameter nail growth effect.

Table 6, 'Nail features with $\geq 50 \%$ improvement', gives an impression of possible treatment options for each affected feature. Nevertheless, we should be cautious interpreting these data. Some studies assessed the improvement of all eight nail features; others assessed just one feature during the trial. Topical intervention trials mostly performed separate assessments of the nail features. Trials with systemic treatments concerning cutaneous psoriasis including nail psoriasis mainly assessed the global nail feature improvement. Therefore, it is difficult to compare the efficacy of the different interventions on the separate nail features. This table shows the high variability of reporting on nail features in the studies, which makes comparison impossible.

\section{Overall completeness and applicability of evidence}

The objective of our Cochrane review was to assess the best available evidence of the efficacy and safety of the treatments for nail psoriasis.

Psoriasis of the nail bed and nail matrix presents different nail features: four in the nail bed and four in the nail matrix, as described in detail above. These features are assessed separately in nail scores like NAPSI and NAS, but only a few studies used such specific scores. Most included studies reported the efficacy according to point scales of nail features assessed by the physician. Some studies assessed only a few nail features, according to a nail score or point scale. Therefore, studies were difficult to compare.

The question is whether the evidence from trials using treatments on participants with cutaneous psoriasis with nail psoriasis may be applied to those people with nail psoriasis only.
The systemic-intervention studies Igarashi 2012, Kavanaugh 2009, Levell 1995, Mahrle 1995, and Rich 2008 treated participants for their plaque psoriasis or psoriatic arthritis, with an effect on nail psoriasis as a secondary outcome. Therefore, information such as adverse effects and dropouts was often related to the total group of participants with psoriasis and not specifically to the participants with nail psoriasis.

Short-term adverse effects were mainly investigated. Two studies presented no data on adverse effects in their trial (Baran 1999; Baran 1999a).

The included studies mainly focused on fingernail, rather than toenail, psoriasis. The latter was assessed only by Flori 1994, Gú mú ș el 2011, and Tosti 1998, of which Gü mú ș el 2011 evaluated nail matrix and nail bed scores in toes only before and after treatment, and Flori 1994 presented no data at all. Therefore, in this review, we had insufficient data to report on treatments for toenail psoriasis.

The applicability of some of the treatments found in our included studies, such as electron beam therapy, may be disputable and of limited use in current practice. We identified some ongoing studies; these may eventually help to fill in the gaps in the evidence for the efficacy of, for example, adalimumab, etanercept, and topical methotrexate (see the 'Characteristics of ongoing studies' tables and the 'Characteristics of studies awaiting classification' tables).

\section{Quality of the evidence}

It was not possible to pool data because of methodological and clinical heterogeneity between the studies. There was considerable variation in how well the studies were reported, which created difficulties in making accurate assessments of the risk of bias.

We included 18 trials, of which 13 studies reported the method used to randomise participants. We assumed the study by Baran 1999a was randomised, although the method was unclear because the comparable trial in the same publication (Baran 1999) was indeed randomised.

Only 5 trials adequately concealed treatment allocation; in the other 13 studies, this was not clearly reported. Twelve trials had a double-blind design; 2 were single-blind; 1 was an open trial; and 3 were unclear about blinding. Three out of 18 studies were not free of selective reporting. Six studies were judged to be free of other bias; eight were unclear; and four were judged to be at high risk of other biases.

Point-scale measurements (ordinal) were the most commonly used outcomes for assessing nail psoriasis. Because of the clinical and methodological heterogeneity of the studies, missing statistical data, or limitations in study reports, we could not perform metaanalysis (pooling) and sensitivity analyses.

We could not express numbers needed to treat.

Four cross-over trials (Igarashi 2012; Kavanaugh 2009; Lindelof 1989; Rich 2008) had no carry-over effect because there was a cross-over from placebo to an intervention treatment. Participants 
treated with ciclosporin and etretinate in Mahrle 1995 crossed over to topical dithranol after 10 weeks (to phase 2). Because of no required wash-out, there might have been a carry-over effect in the second phase. Therefore, we only reported the first 10 weeks (phase 1) of the study.

There was too much clinical heterogeneity in the studies, for example, different populations, disease severity, doses, frequency and durations of treatment, time points of assessments, including follow up, different outcome measurements used, and type of nail psoriasis (isolated nail psoriasis or with skin involvement). The number of participants included in the individual studies varied widely, from 10 to 305 participants (1 study had 102 participants (Igarashi 2012); 1, 137 participants (Mahrle 1995); and 1 trial by Rich 2008 studied 305 participants), but with between 10 and 60 representing the most common sample size. Most comparison studies compared active treatment with placebo. The treatment duration ranged between 2 weeks and 64 weeks. The follow-up duration was variable, with a range of between 4 weeks and 12 months; 5 out of the 18 included studies had no follow-up period. Seven studies used standard outcome measures like NAPSI or NAS. In 14 studies, the physicians assessed the nails according to point scales. In order to compare the outcome measurements used, we incorporated as end point 'no/worse', 'moderate', and 'good' improvement. This approach was not ideal; therefore, the end points should be seen as indicative rather than definitive. Of the 18 studies assessed, 14 reported losses to follow-up or dropouts.

Five studies (Cannavo 2003; de Jong 1999; Gü mủ ș el 2011; Tosti 1998; Tzung 2008) assessed one of our primary outcomes: 'Improvement of nail psoriasis in the participant's opinion'. Only one study (Cannavo 2003) reported on quality of life as a questionnaire. Eleven studies showed separate data on nail features, and 2 trials (Scher 2001; Yu 1992) reported the outcome parameter nail growth.

Studies on cutaneous psoriasis that reported the effect on nail psoriasis as a secondary outcome of the trial did not mention differences in outcomes between participants with or without nail psoriasis. The outcome of internally-controlled studies (i.e. studies in which a lesion on one side is compared to another control lesion) measuring Patient's Global Assessment (PAGA) score, adverse effects, and dropouts could be influenced by the treatments of both sides.

Levell 1995 showed a discrepancy between the data reported in the figure and text of the original study. In this review, we reported the data presented in the text.

\section{Potential biases in the review process}

We performed our review according to the Cochrane Handbook for Systematic Reviews of Interventions. Although it was not possible to assess the likelihood of publication bias by using funnel plots, we searched for ongoing studies in the trial registers. However, we did not identify unpublished results.

The incompleteness of some of the included studies and our inability to obtain clarification of certain trial details or to resolve ambiguities in the reports may have contributed to some bias in their assessment.

\section{Agreements and disagreements with other studies or reviews}

Reich 2009 reviewed the management of nail psoriasis, also showing the efficacy of topical glucocorticosteroids and Vitamin D analogues, such as calcipotriol, in improving the signs and symptoms of nail psoriasis. We agree, as suggested by Jiaravuthisan 2007, that systemic treatments for nail psoriasis may be used in cases where cutaneous psoriasis also needs systemic intervention. Systemic treatment could be an option for those whose nail psoriasis has shown resistance to topical or radiotherapy treatment, for those with very severely affected nails, and if the condition has an adverse impact on the quality of life.

de Berker 2000, de Berker 2009, and Reich 2009 discussed the penetration of the nail treatment through the nail bed and matrix as a factor limiting efficacy. Therefore, the site of application is important to where the nail pathology lies. Treatment for the nail matrix can be administered to the nail fold. For treatment of the nail bed features, onycholytic nails must be trimmed back to the hyponychium (the area between the nail plate and the fingertip) before administering the therapy as near as possible to the nail bed. Jiaravuthisan 2007 reported that different intralesional treatment seems to be efficacious in treating the nail matrix. The burden of intralesional treatment could be pain, subungual haematomas, and short-term paraesthesia. The most common intralesional treatment for nail psoriasis is triamcinolone acetonide $2.5 \%$ to $10 \%$ (de Berker 2009). In our review, we did not include RCT evidence of intralesional treatments.

An abstract from Baerveldt 2010 reported a prospective, doubleblind, randomised, placebo internally-controlled trial, which assessed the efficacy of topically-applied ciclosporin solution 100 $\mathrm{mg} / \mathrm{ml}$ in maize oil versus maize oil twice daily. The duration of the treatment was until the achievement of complete cure or for a maximum of 16 weeks, and for the control group for a maximum of 28 weeks. The results reported no direct therapeutic efficacy for ciclosporin after 28 weeks. This is in contrast to the good improvement of Cannavo 2003 with topical ciclosporin.

The long-term use of topical glucocorticosteroids and calcipotriol are associated with adverse events like atrophy and skin irritation (de Berker 2009; Reich 2009). Occlusion of the topical therapy will enhance the intensity but may develop an increased risk for adverse effects (de Berker 2009). Tazarotene $0.1 \%$ gel has been demonstrated to provide some benefit when used under occlusion (Scher 2001). For long-term treatment, occlusion is not desirable 
because long-term management might be inconvenient for the participant and will result in poor compliance.

The data from the RCTs that used systemic ciclosporin were conflicting. Levell 1995 reported a 82\% score improvement (not significant compared to baseline) (median baseline score $=5.5$, with a median decrease in severity score of 4.5 (95.1\% CI 0 to 8$)$ within 12 weeks of ciclosporin $5.0 \mathrm{mg} / \mathrm{kg}$ treatment; however, in this study, we found a discrepancy in improvement between the presented figure and the text. Mahrle 1995 showed a mild improvement of $17.5 \%$ of the 90 participants with nail involvement, out of 137 skin psoriasis participants treated with ciclosporin 2.5 to $5.0 \mathrm{mg} / \mathrm{kg}$ for 10 weeks. The study reported a final mean dosage of $3.4 \mathrm{mg} / \mathrm{kg} /$ day and a mean daily dose of $3.02 \mathrm{mg} / \mathrm{kg} /$ day for the 137 participants with skin psoriasis (of whom 90 had nail involvement). After 24 weeks, Gü mủ ș el 2011 showed a relative reduction in NAPSI score of $37.2 \%$ with ciclosporin $5 \mathrm{mg} / \mathrm{kg} /$ day, reduced to 2.5 to $3.5 \mathrm{mg} / \mathrm{kg} /$ day after 12 weeks if side-effects were absent. Feliciani 2004 reported in a cohort study after 3 months an improvement in $47 \%$ of 21 participants with ciclosporin $3.5 \mathrm{mg} /$ $\mathrm{kg}$ compared with an improvement of $79 \%$ of 33 participants with the same dosage plus topical calcipotriol. The review by Gregoriou 2008 suggested, "Systemic ciclosporin should be considered a second-line treatment for nail psoriasis". For the other conventional systemic therapies, there were no randomised controlled trials fulfilling our inclusion criteria available. However, some of the conventional systemic therapies would be expected to be efficacious. The guidelines for biologic interventions from the British Association of Dermatologists (Smith 2009) and the review by Reich 2009 referred to infliximab as an intervention for nail psoriasis. Noiles 2009 reviewed clinical trials with infliximab for nail psoriasis. The review reported the significant improvement of infliximab for nail psoriasis as the most efficacious biologic treatment. For the other biologic agents, there was no high level of evidence, being derived from case studies or in open-label prospective trials as secondary outcomes with plaque psoriasis or psoriatic arthritis. However, the efficacy of other biologics would be expected, but comparative evidence is lacking.

The systematic review from Cassell 2006 emphasised again the difficulties in comparing and interpreting data from studies with small participant numbers, lacking appropriate controls, and with no standard outcome measures.

To heal the nail, an important factor is the growth of the nail. According to de Jong 1999, a treatment period of 12 weeks is too short to obtain an improvement of more than $50 \%$ of most of the nail signs in nail psoriasis. It takes about 6 months to regrow a fingernail completely; therefore, a treatment period of at least 24 weeks is necessary to obtain a justified impression of efficacy.

\section{A U THORS' CONCLUSIONS}

\section{Implications for practice}

The included studies in this review often showed a lot of heterogeneity and very limited evidence per treatment type (often only one study per treatment), so meta-analysis of the data was not possible. The quality of studies was low.

Clinical decision-making on the choice of intervention for nail psoriasis should be based on high-level evidence if it is available. In the absence of such high-level evidence for use of an intervention, decisions should be based on the best available evidence. This is sometimes clinical experience and may be based on an individual person's characteristics and preferences.

The studies on the biologicals infliximab $5 \mathrm{mg} / \mathrm{kg}$ (Rich 2008), golimumab $50 \mathrm{mg}$, and golimumab $100 \mathrm{mg}$ (Kavanaugh 2009) reported significant results compared to placebo with regard to the primary outcome 'Improvement of nail psoriasis'. This was after short- (until 12 weeks) and medium-term (12 to 24 weeks) treatment. After 24 weeks of treatment, infliximab $5 \mathrm{mg} / \mathrm{kg}$ and golimumab $100 \mathrm{mg}$ reported greater than $50 \%$ nail score improvement compared to placebo, which was significant. Electron beam (Kwang 1995), grenz rays (Lindelof 1989), and superficial radiotherapy (Yu 1992) reported significant results compared to placebo with regard to the primary outcome 'Improvement of nail psoriasis' after short-term treatment.

The studies with topical ciclosporin 70\% in maize oil (applied twice daily for 12 weeks, Cannavo 2003) and tazarotene cream compared to clobetasol (once daily under occlusion for 12 weeks, Rigopoulos 2007) showed $\geq 75 \%$ nail improvement compared to baseline after short-term treatment. These data were all based on one study per treatment. These studies did not use standard outcome measures to assess nail psoriasis.

Unfortunately, the medium-term studies (12 to 24 weeks of treatment) (e.g. systemic therapy) had no measure points on the shortterm (up to 12 weeks of treatment), which made comparison with the short-term studies impossible. The treatments for psoriasis nail features were also difficult to compare because the included trials often did not assess the same nail features during treatment. Furthermore, trials with systemic interventions were primarily for cutaneous psoriasis trials, where nail features were mostly not specified.

Eleven studies reported separate data on nail features (our secondary outcome parameter), of which 3 of the 4 studies discussed here showed significant results. After 90 days' treatment with hyaluronic acid and chondroitin sulphate, there was a significant improvement in onychorrhexis $(\mathrm{P}=0.039)$, onycholysis ( $\mathrm{P}$ $=0.041)$, and hyperkeratosis $(\mathrm{P}=0.041)$ in the participants (Flori 1994). After treatment with tazarotene gel, there was a significant improvement in those with onycholysis and pitting. Onycholysis improved after treatment under occlusion at weeks 4 and $12(\mathrm{P} \leq$ $0.05)$, and at week 24 without occlusion $(\mathrm{P}<0.05)$. Pitting improved under occlusion at week $24(\mathrm{P} \leq 0.05)$ (Scher 2001). Oil 
drop discolourations significantly improved after 12 weeks' treatment with calcipotriol $0.005 \%(\mathrm{P}<0.039)$ (Tzung 2008). One study (infliximab (Rich 2008)) showed a significant decrease in the occurrence of individual features over time.

The benefits of systemic interventions should be balanced against their possible harms. Powerful systemic treatments have been shown to be beneficial, but they may often not be a realistic option for people troubled with nail psoriasis because of side-effects, unless they are candidates for these systemic treatments because of their cutaneous psoriasis. Current RCTs generally do not pick up serious side-effects because of their timescale and design, which is probably why this review was only able to report mild adverse effects for systemic treatment. Some topical therapies were shown to be beneficial and seemed to cause fewer adverse effects. Radiotherapy treatments for psoriasis are not generally used in common practice.

Randomised controlled trials for psoriasis treatments that include the assessment of nail psoriasis are lacking, for example, other topical corticosteroids, acitretin, UV therapy, laser, and biologics like adalimumab and etanercept that need further research. The lack of evidence for these interventions does not mean the treatments don't improve nail psoriasis. In particular, evidence for topical treatment should be further investigated as these play a major role in common prescribing practice. Also, treatments with conflicting results need further research.

\section{Implications for research}

More RCTs on nail psoriasis are needed, assessing the efficacy and safety of possible treatments, e.g. topical treatments compared to each other, topical versus systemic therapy, conventional systemic therapy compared to biologics, biologics head-to-head.

The quality of studies should be improved. To compare studies, clinical homogeneity should be reached by clear descriptions of the populations, e.g. isolated nail psoriasis or with skin involvement, type of nail psoriasis (nail matrix and nail bed psoriasis), disease severity, treatment dosage and frequency, durations of treatment (long enough), outcome measurements (like point scales and nail scores (NAPSI, NAS); participants' reported outcomes, such as quality of life; and adverse effects), and time points of assessments, including long enough follow up to be meaningful.

Participants with nail psoriasis could have a solitary nail psoriasis problem or have psoriasis of the skin, joints with nail involvement, or both. Studies dealing with the overall impact of systemic treatments for psoriasis may report on nail psoriasis as a secondary outcome. In the future, separate trials including participants with only nail psoriasis would be welcome. These studies should describe participants' characteristics, results (with validated nail scores), adverse effects, and separate information on dropouts for those with nail psoriasis. Patient-reported outcomes, such as 'quality of life', are important outcomes because of the great impact nail psoriasis can have on daily life.

The RCTs in our review included treatment durations of 12 to 64 weeks. The duration of treatment in the included studies was often short. To regrow a nail completely takes at least six months (de Jong 1999), so to obtain clear evidence for the efficacy of an intervention, a trial with a duration of at least six months is necessary. These studies may have obtained better results if the duration had been appropriate. As shown by Igarashi 2012 and Rich 2008, at 64 weeks and 46 weeks of treatment, respectively, the nail score improvement was considerably increased compared to the short-term measure point, and it was maintained compared to the medium-term measurement. Therefore, future trials must be performed with sufficient duration to report the efficacy of the intervention. In addition, the follow up must be long enough, because follow up and the rate of relapse after treatment discontinuation is also of clinical importance.

Harmonised and validated outcome measures are necessary for evaluating nail psoriasis. There are some validation studies for the NAPSI. Aktan 2007 investigated the interobserver reliability of the NAPSI, graded by 3 dermatologists looking at 25 participants. They found a moderate to good scoring agreement with the NAPSI. Cassell 2007 showed in participants with psoriatic arthritis, a modified NAPSI (mNAPSI), with an inter-rater reliability and construct validity. A nail score (like NAPSI, mNAPSI, or NAS) is required to assess and compare the improvements of different trials. For quality criteria for outcome measures, the COSMIN (consensus-based standards for the selection of health measurement instruments) checklist can be used (Mokkink 2010).

Also, studies reported methodological heterogeneity, e.g. incomplete data about the internal validity. Future trials need to be rigorous in design, which reduces bias. High-quality descriptions of all aspects of methodology will improve the interpretation of results. This could be achieved by following the Consolidated Standards of Reporting Trials (CONSORT) statement checklist in future trials (Schulz 2010). For internally-controlled trials with topical treatments, one should be aware of the systemic impact of the carry-over effect on the compared finger or toenail.

\section{ACKNOWLEDGEMENTS}

The Cochrane Skin Group editorial base wishes to thank Luigi Naldi who was the Key Editor for this review; Jo Leonardi-Bee and Philippa Middleton who were the Statistical and Methods Editors, respectively; the clinical referees, Manuel Sánchez Regaña and David de Berker; and the consumer referee, José Ramirez.

We would like to thank Finola Delamere, who was the Trials Search Co-ordinator at the Cochrane Skin Group, Nottingham. 


\section{R E F E R E N C E S}

\section{References to studies included in this review}

\section{Baran 1999 \{published data only\}}

Baran R, Tosti A. Topical treatment of nail psoriasis with a new corticoid-containing nail lacquer formulation. Journal of Dermatological Treatment 1999;10(3):201-4.

Baran 1999a \{published data only\}

Baran R, Tosti A. Topical treatment of nail psoriasis with a new corticoid-containing nail lacquer formulation. Journal of Dermatological Treatment 1999;10(3):201-4.

\section{Cannavo 2003 \{published data only\}}

Cannavo SP, et al.Treatment of psoriatic nails with topical cyclosporin [Abstract]. 11th Congress of the European Academy of Dermatology and Venereology Prague October 2nd-6th, 2002. Journal of the European Academy of Dermatology \& Venereology 2002;16(Suppl s1):P27-89. * Cannavo SP, Guarneri F, Vaccaro M, Borgia F, Guarneri B. Treatment of psoriatic nails with topical cyclosporin: a prospective, randomized placebo-controlled study. Dermatology 2003;206(2):153-6.

de Jong 1999 \{published data only\} de Jong EM, Menke HE, van Praag MC, van De Kerkhof PC. Dystrophic psoriatic fingernails treated with $1 \% 5-$ fluorouracil in a nail penetration-enhancing vehicle: a double-blind study. Dermatology 1999;199(4):313-8.

Flori 1994 \{published data only\} Flori ML, Rubegni P, Micheli S, Andreassi L. Treatment of psoriasic onychodystrophy with a hyaluronic acid product and chondroitinsulphates [Trattamento dell'onicodistrofia psoriasica con un prodotto a base di acido ialuronico e condroitinsolfati]. Giornale Italiano di Dermatologia e Venereologia 1994;129(3):129-33.

Gú mü ș el 2011 \{published data only\}

Gumusel M, Ozdemir M, Mevlitoglu I, Bodur S. Evaluation of the efficacy of methotrexate and cyclosporine therapies on psoriatic nails: a one-blind, randomized study. Journal of the European Academy of Dermatology \& Venereology 2011; 25(9):1080-4.

\section{Igarashi 2012 \{published data only\}}

Igarashi A, Kato T, Kato M, Song M, Nakagawa H, Japanese Ustekinumab Study Group. Efficacy and safety of ustekinumab in Japanese patients with moderate-to-severe plaque-type psoriasis: long-term results from a phase $2 / 3$ clinical trial. Journal of Dermatology 2012;39(3):242-52.

Kavanaugh 2009 \{published data only\}

Kavanaugh A Mclnnes I, Mease P, Krueger GG, Gladman D, Gomez-Reino J, Papp K, et al.Golimumab, a new human tumor necrosis factor alpha antibody, administered every four weeks as a subcutaneous injection in psoriatic arthritis: twenty-four-week efficacy and safety results of a randomized, placebo-controlled study. Arthritis \& Rheumatism 2009;60(4):976-86.
Kwang 1995 \{published data only\}

Kwang TY, Nee TS, Seng KT. A therapeutic study of nail psoriasis using electron beams. Acta Dermato-Venereologica 1995;75(1):90.

\section{Levell 1995 \{published data only\}}

Levell NJ, Shuster S, Munro CS, Friedmann PS. Remission of ordinary psoriasis following a short clearance course of cyclosporin. Acta Dermato-Venereologica 1995;75(1):65-9.

Lindelof 1989 \{published data only\}

Lindelof B. Psoriasis of the nails treated with grenz rays: a double-blind bilateral trial. Acta Dermato-Venereologica 1989;69(1):80-2.

\section{Mahrle 1995 \{published data only\}}

Mahrle G, Schulze HJ, Farber L, Weidinger G, Steigleder GK. Low-dose short-term cyclosporine versus etretinate in psoriasis: improvement of skin, nail, and joint involvement. Journal of the American Academy of Dermatology 1995;32(1): 78-88.

Rich 2008 \{published data only\}

Reich K, Nestle FO, Papp K, Ortonne JP, Evans R, Guzzo $\mathrm{C}$, et al.Infliximab induction and maintenance therapy for moderate-to-severe psoriasis: a phase III, multicentre, double-blind trial. Lancet 2005;366(9494):1367-74. Reich K, Ortonne JP, Kerkmann U, Wang Y, Saurat $\mathrm{JH}$, Papp K, et al.Skin and nail responses after 1 year of infliximab therapy in patients with moderate-to-severe psoriasis: a retrospective analysis of the EXPRESS Trial. [Erratum appears in Dermatology 2011 Feb;222(1):4]. Dermatology 2010;221(2):172-8.

Reich R, Nestle F, Ortonne JP, Papp K, Evans R, Guzzo $\mathrm{C}$, et al.Infliximab produces a sustained and significant improvement in psoriasis over 50 weeks of continuous therapy. [Abstract O-10]. The 85th BAD Annual Meeting 5-8th July 2005, Glasgow, UK. British Journal of Dermatology 2005;153(Suppl 1):1-8.

* Rich P, Griffiths CE, Reich K, Nestle FO, Scher RK, Li S, et al.Baseline nail disease in patients with moderate to severe psoriasis and response to treatment with infliximab during 1 year. Journal of the American Academy of Dermatology 2008; 58(2):224-31.

Rich P, Guzzo C, Li S, Reich K. Nail psoriasis improvement is maintained in patients with moderate to severe psoriasis treated with infliximab. [Abstract P2716]. American Academy of Dermatology 65th Annual Meeting 2nd6th February 2007. Journal of the American Academy of Dermatology 2007;56(2 Suppl 2):AB178.

Rich P, Scher R, Reich K, Nestle F, Papp K, Evans R, et al.Significant response of nail psoriasis to infliximab in patients with moderate to severe psoriasis disease. [Abstract P06.43]. The 14th Congress of the European Academy of Dermatology and Venereology, 12-15th October 2005, London, UK. Journal of the European Academy of Dermatology \& Venereology 2005;19(Suppl 2): 171. 
Rigopoulos 2007 \{published data only\}

Rigopoulos D, Gregoriou S, Katsambas A. Treatment of psoriatic nails with tazarotene cream $0.1 \%$ vs. clobetasol propionate $0.05 \%$ cream: a double-blind study. Acta Dermato-Venereologica 2007;87(2):167-8.

Scher 2001 \{published data only\}

Scher R, Stiller M, Zhu Y. Tazarotene $0.1 \%$ gel in the treatment of fingernail psoriasis: A double-blind, randomized, vehicle-controlled study. [Abstract 936]. The 62nd Annual Meeting of the Society for Investigative Dermatology. Journal of Investigative Dermatology 2001;117 (2):545.

Scher R, Stiller M, Zhu Y. Tazarotene $0.1 \%$ gel in the treatment of nail psoriasis. [Abstract P0791]. 20th World Congress of Dermatology; 1-5 July 2002, Paris. 2002: $1 S 523$.

* Scher RK, Stiller M, Zhu YI. Tazarotene $0.1 \%$ gel in the treatment of fingernail psoriasis: a double-blind, randomized, vehicle-controlled study. Cutis 2001;68(5): $355-8$.

Tosti 1998 \{published data only\}

Tosti A, Piraccini BM, Cameli N, Kokely F, Plozzer C, Cannata GE, et al.Calcipotriol ointment in nail psoriasis: a controlled double-blind comparison with betamethasone dipropionate and salicylic acid. British Journal of Dermatology 1998;139(4):655-9.

Tzung 2008 \{published data only\}

Tzung TY, Chen CY, Yang CY, Lo PY, Chen YH. Calcipotriol used as monotherapy or combination therapy with betamethasone dipropionate in the treatment of nail psoriasis. Acta Dermato-Venereologica 2008;88(3):279-80.

Yu 1992 \{published data only\}

Yu RC, King CM. A double-blind study of superficial radiotherapy in psoriatic nail dystrophy. Acta DermatoVenereologica 1992;72(2):134-6.

\section{References to studies excluded from this review}

Camacho 1976 \{published data only\}

Camacho Martinez F, Armijo Moreno M, Naranjo Sintes R, Gutierrez Salmeron MT, de Dulanto F. Triamcinolone acetonide in ungual psoriasis [Acetonido de triamcinolona en psoriasis ungueal]. Actas Dermo-Sifiliograficas 1976;67 (1-2):49-54.

Cantoresi 2009 \{published data only\} Cantoresi F, Sorgi P, Arcese A, Bidoli A, Bruni F, Carnevale C, Calvieri S. Improvement of psoriatic onychodystrophy by a water-soluble nail lacquer. Journal of the European Academy of Dermatology \& Venereology 2009;23(7):832-4.

Feuerman 1973 \{published data only\} Feuerman EJ, Nir MA. Allopurinol in psoriasis--a doubleblind study. British Journal of Dermatology 1973;89(1): 83-6.

Lassus 1997 \{published data only\} Lassus A. Colloidal silicic acid for the treatment of psoriatic skin lesions, arthropathy and onychopathy. A pilot study.
The Journal of International Medical Research 1997;25(4):

206-9.

Luger 2009 \{published data only\}

Luger TA, Barker J, Lambert J, Yang S, Robertson D, Foehl J, et al.Sustained improvement in joint pain and nail symptoms with etanercept therapy in patients with moderate-to-severe psoriasis. Journal of the European Academy of Dermatology \& Venereology 2009;23(8): 896-904.

Mrowietz 1991 \{published data only\} Mrowietz U, Christophers E. Low-dose ciclosporin A (Sandimmun) in psoriasis: A multicenter dose-finding study. H+G Zeitschrift fur Hautkrankheiten 1991;66(Suppl 1):25-9.

\section{O’Daly 2009 \{published data only\}}

O’Daly JA, Lezama R, Rodriguez PJ, Silva E, Indriago NR, Pena G, et al.Antigens from Leishmania amastigotes induced clinical remission of psoriasis. Archives of Dermatological Research 2009;301(1):1-13.

\section{References to studies awaiting assessment}

\section{Abesamis-Cubillan 1997 \{published data only\}}

Abesamis-Cubillan E. Efficacy of topical calcipotriol in the treatment of nail psoriasis: A randomized doubleblind placebo controlled trial. [Abstract 1020]. The 19th World Congress of Dermatology 15-20 June 1997, Sydney, Australia. Australasian Journal of Dermatology 1997;38 (Suppl 2):21.

\section{Baerveldt 2010 \{published data only\}}

Baerveldt EM, de Jong MCH, van Rengen AM, Neumann HAM, Prens EP. Topical cyclosporin for nail psoriasis: a prospective, randomised placebo-controlled study. [Abstract] [Topicale cyclosporine bij nagelpsoriasis: een prospectieve, gerandomiseerde, placebo-gecontroleerde studie]. Nederlands Tijdschrift voor Dermatologie en Venereologie January 2010;20(1):46.

Kavanaugh 2011 \{published data only\} Kavanaugh A, McInnes I, Krueger GG, Gladman D, Zrubek J, Goldstein N, et al.High level responses in psoriatic arthritis patients treated with golimumab: Results from week 104 of the go-reveal study [Poster 254]. Rheumatology 2011 Brighton United Kingdom. Conference Start: 20110412 Conference End: 20110414. Rheumatology 2011;50(Suppl 3):iii141. [DOI: 10.1093/ rheumatology/ker034]

Kingsley 2009 \{published data only\} Kingsley GH, Kowalczyk A, Taylor H, Ibrahim F, Packham JC, McHugh NJ, et al.Methotrexate is not disease modifying in psoriatic arthritis: The MIPA trial. [Abstract] Conference: American College of Rheumatology/ Association of Rheumatology Health Professionals Annual Scientific Meeting, ACR/ARHP 10 Philadelphia, PA United States. Conference Start: 20091016 Conference End: 20091021. Arthritis \& Rheumatism 2009;60(S10):664. 
Langley 2011 \{published data only\}

Langley R, Crowley J, Unnebrink K, Goldblum O. Improvement in nail psoriasis is associated with improved efficacy outcomes in hand and/or foot psoriasis in adalimumab-treated patients: subanalysis of REACH. (Abstract P402) . Conference: 69th Annual Meeting of the American Academy of Dermatology New Orleans, LA United States. Conference Start: 20110204 Conference End: 20110208. Conference Publication. Journal of the American Academy of Dermatology 2011;64(2 Suppl 1):AB7.

Leonardi 2011 \{published data only\}

Leonardi C, Matheson R, Zachariae C, Cameron G, Li L, Edson E, et al.A Phase 2 trial of LY2439821, an antiinterleukin-17 monoclonal antibody, given subcutaneously in patients with moderate to severe psoriasis [Abstract P-17]. Conference: 6th International Congress on Psoriasis: From Gene to Clinic London United Kingdom. Conference Start: 20111201 Conference End: 20111203. British Journal of Dermatology 2011;165(6):e18-9. [DOI: 10.1111/ j.1365-2133.2011.10671.x]

\section{McInnes 2009 \{published data only\}}

McInnes I, Gladman D, Kavanaugh A, Mease P, GomezReino J, Papp K, et al.Golimumab administered every four weeks as a subcutaneous injection in psoriatic arthritis: Nail, enthesitis, and dactylitis response in the randomized, placebo-controlled, go-reveal study [Abstract 97]. Conference: British Society for Rheumatology and British Health Professionals in Rheumatology Annual Meetings 2009, Rheumatology'09 Glasgow United Kingdom. Conference Start: 20090428 Conference End: 20090501. Rheumatology 2009;48(Suppl 1):i58. [DOI: 10.1093/rheumatology/kep723]

Thaci 2010 \{published data only\}

* Thaci D, Khemis A, Kupper H, Unnebrink K. Adalimumab plus topical treatment (calcipotriol/ betamethasone) in the treatment of moderate to severe psoriasis: Effects on skin, scalp, and nails: Results from BELIEVE (Poster P3365) 68th Annual Meeting of the American Academy of Dermatology, AAD Miami, FL United States. Journal of the American Academy of Dermatology 2010;62(3 Suppl):AB139.

Thaci D, Xie J, Mulani P, Gupta S. Effects of adalimumab monotherapy versus adalimumab plus betametha-sone/ calcipotriol on patient-reported outcomes in patients with palmo-plantar, nail, or scalp psoriasis (Poster P3350) 68th Annual Meeting of American Academy of Dermatology, AAD Miami, FL United States. Journal of the American Academy of Dermatology 2010;62(3 Suppl):AB135.

\section{References to ongoing studies}

\section{EUCTR2004-004825-87-HU \{published data only\}} EUCTR2004-004825-87-HU. Efficacy and safety of 0, $1 \%, 0,5 \%$ and $1 \%$ tazarotene nail lacquer formulation versus vehicle in nail psoriasis. International, multicenter, double-blind, randomized study of four parallel groups. - Dose ranging for Tazarotene nail lacquer. www.clinicaltrialsregister.eu/ctr-search/search?query= EUCTR2004-004825-87-HU (accessed 22 March 2012).

EUCTR2006-004453-18-FR \{published data only\}

EUCTR2006-004453-18-FR. A Randomised, Open-Label Preliminary Study To Assess The Effects Of Etanercept 50 mg Once Weekly For 24 Weeks And Etanercept 50 mg Twice Weekly For 12 weeks Reducing To Etanercept 50 mg Once Weekly For 12 weeks On Nail And Skin Symptoms In Patients With Nail Psoriasis And Plaque Psoriasis. www.clinicaltrialsregister.eu/ctr-search/search? query=EUCTR2006-004453-18-FR (accessed 22 March 2012).

EUCTR2006-006569-18-FR \{published data only\} EUCTR2006-006569-18-FR. Efficacy and safety of 8\% clobetasol nail lacquer formulation versus vehicle in nail psoriasis. www.clinicaltrialsregister.eu/ctr-search/search? query=EUCTR2006-006569-18-FR (accessed 22 March 2012).

\section{EUCTR2010-019706-16-IT \{published data only\}}

EUCTR2010-019706-16-IT. A randomized, double blind, placebo controlled, parallel groups, pilot study to assess the effects of two new nail lacquers, cyclosporine $5 \%$ and calcipotriol $0.005 \%$, in the treatment of nail psoriasis ND. www.clinicaltrialsregister.eu/ctr-search/search?query= EUCTR2010-019706-16-IT (accessed 22 March 2012).

\section{NCT00581100 \{published data only\}}

NCT00581100. Effects of Etanercept on Nail Psoriasis and Plaque Psoriasis. www.clinicaltrials.gov/show/ NCT00581100 (accessed 27 April 2010).

\section{NCT00666354 \{published data only\}}

NCT00666354. Dose response and safety study of topical methotrexate for the treatment of fingernail psoriasis. www.clinicaltrials.gov/show/NCT00666354 (accessed 27 April 2010).

\section{NCT00999687 \{published data only\}} NCT00999687. Evaluation of the Efficacy and Safety of Indigo Naturalis Oil Extract on Psoriatic Nails. www.clinicaltrials.gov/show/NCT00999687 (accessed 27 April 2010).

\section{NCT01107457 \{published data only\}} NCT01107457. A Study in Patients With Moderate to Severe Psoriasis. www.clinicaltrials.gov/show/ NCT01107457 (accessed 27 April 2010).

\section{Additional references}

\section{Aktan 2007}

Aktan S, Ilknur T, Akin C, Ozkan S. Interobserver reliability of the Nail Psoriasis Severity Index. Clinical \& Experimental Dermatology 2007;32:141-44.

\section{Baran 2004}

Baran RL. A Nail Psoriasis Severity Index. British Journal of Dermatology 2004;150(3):568-9.

\section{Bolognia 2003}

Bolognia JL, Jorrizo J, Rapini R, editors. Dermatology. London: Mosby, Elsevier Health Sciences, 2003. 


\section{Cassell 2006}

Cassell S, Kavanaugh AF. Therapies for psoriatic nail disease. A systematic review. Journal of Rheumatology 2006; 33(7):1452-6.

\section{Cassell 2007}

Cassell SE, Bieber JD, Rich P, Tutuncu ZN, Lee SJ, Kalunian KC, et al.The modified Nail Psoriasis Severity Index: validation of an instrument to assess psoriatic nail involvement in patients with psoriatic arthritis. Journal of Rheumatology 2007;34:123-9.

\section{Dawber 1992}

Dawber RP, Baran R. Disorders of nails. In: Champion RH, Burton JL editor(s). Textbook of Dermatology. 5th Edition. Oxford: Blackwell Scientific Publications, 1992: 2497-2532.

\section{de Berker 2000}

de Berker D. Management of nail psoriasis. Clinical \& Experimental Dermatology 2000;25(5):357-62.

\section{de Berker 2009}

de Berker D. Management of psoriatic nail disease. Seminars in Cutaneous Medicine \& Surgery 2009;28(1):39-43.

\section{de Jong 1996}

de Jong EM, Seegers BA, Gulinck MK, Boezeman JB, van de Kerkhof PC. Psoriasis of the nails associated with disability in a large number of patients: results of a recent interview with 1,728 patients. Dermatology 1996;193(4): $300-3$.

\section{de Korte 2004}

de Korte J, Sprangers MA, Mombers FM, Bos JD. Quality of life in patients with psoriasis: a systematic literature review. Journal of Investigative Dermatology Symposium Proceedings 2004;9(2):140-7.

\section{Farber 1992}

Farber EM, Nall L. Nail psoriasis. Cutis 1992;50(3):174-8.

\section{Feliciani 2004}

Feliciani C, Zampetti A, Forleo P, Cerritelli L, Amerio P, Proietto G, et al.Nail psoriasis: combined therapy with systemic cyclosporin and topical calcipotriol. Journal of Cutaneous Medicine \& Surgery 2004;8(2):122-5.

\section{Forleo 1999}

Forleo P, Cerritelli L, Feliciani C, Koniger P, Lo Amerio P, Proietto G, et al.Nail psoriasis therapy. Review of the literature [Terapia della psoriasi ungueale. Revisione della letteratura]. Giornale Italiano di Dermatologia e Venerologia 1999;134(6):565-70.

\section{Gregoriou 2008}

Gregoriou S, Kalogeromitros D, Kosionis N, Gkouvi A, Rigopoulos D. Treatment options for nail psoriasis. Expert Review of Dermatology 2008;3(3):339-344.

Gudjonsson 2006

Gudjonsson JE, Karason A, Runarsdottir EH, Antonsdottir AA, Hauksson VB, Jonsson $\mathrm{HH}$, et al.Distinct clinical differences between HLA-Cw*0602 positive and negative psoriasis patients--an analysis of 1019 HLA-C- and HLA-
B-typed patients. Journal of Investigative Dermatology 2006; 126(4):740-5.

\section{Higgins 2011}

Higgins JPT, Green S (editors). Cochrane handbook for Systematic Reviews of Interventions. Version 5.1.0 [updated March 2011]. Available from www.cochranehandbook.org. The Cochrane Collaboration.

Jiaravuthisan 2007 Jiaravuthisan MM, Sasseville D, Vender RB, Murphy F, Muhn CY. Psoriasis of the nail: anatomy, pathology, clinical presentation, and a review of the literature on therapy. Journal of the American Academy of Dermatology 2007;57(1): $1-27$.

\section{Jones 1994}

Jones SM, Armas JB, Cohen MG, Lovell CR, Evison G, McHugh NJ. Psoriatic arthritis: outcome of disease subsets and relationship of joint disease to nail and skin disease. British Journal of Rheumatology 1994;33(9):834-9.

Juni 2001

Juni P, Altman DG, Egger M. Systematic reviews in health care: assessing the quality of controlled clinical trials. $B M J$ 2001;323(7303):42-6.

\section{Kaur 2001}

Kaur I, Saraswat A, Kumar B. Nail changes in psoriasis: a study of 167 patients. International Journal of Dermatology 2001;40(9):601-3.

\section{Mokkink 2010}

Mokkink LB, Terwee CB, Patrick DL, Alonso J, Stratford PW, Knol DL, et al.The COSMIN checklist for assessing the methodological quality of studies on measurement properties of health status measurement instruments: an international Delphi study. Quality of Life Research 2010;19 (4):539-49.

Noiles 2009

Noiles K, Vender R. Nail psoriasis and biologics. Journal of Cutaneous Medicine \& Surgery 2009;13(1):1-5.

\section{Parrish 2005}

Parrish CA, Sobera JO, Elewski BE. Modification of the Nail Psoriasis Severity Index. Journal of the American Academy of Dermatology 2005;53(4):746-7.

\section{Reich 2005}

Reich K, Nestle FO, Papp K, Ortonne JP, Evans R, Guzzo $\mathrm{C}$, et al.Infliximab induction and maintenance therapy for moderate-to-severe psoriasis: a phase III, multicentre, double-blind trial. Lancet 2005;366(9494):1367-74.

\section{Reich 2009}

Reich K. Approach to managing patients with nail psoriasis. Journal of the European Academy of Dermatology \& Venereology 2009;23(Suppl 1):15-21.

\section{Reich 2010}

Reich K, Ortonne JP, Kerkmann U, Wang Y, Saurat JH, Papp K, et al.Skin and nail responses after 1 year of infliximab therapy in patients with moderate-tosevere psoriasis: a retrospective analysis of the EXPRESS 
Trial.[Erratum appears in Dermatology. 2011 Feb;222(1):

4]. Dermatology 2010;221(2):172-8.

\section{Rich 2003}

Rich P, Scher RK. Nail Psoriasis Severity Index: a useful tool for evaluation of nail psoriasis. Journal of the American Academy of Dermatology 2003;49(2):206-12.

\section{Roberts 2010}

Roberts C, Angus JE, Williams HC, Villanueva E, Saeterdal I, Jobling R. Ustekinumab for plaque psoriasis. Cochrane Database of Systematic Reviews 2011, Issue 1. [DOI: 10.1002/14651858.CD008947]

\section{Sadek 2007}

Sadek HA, Abdel-Nasser AM, El-Amawy TA, Hassan SZ. Rheumatic manifestations of psoriasis. Clinical Rheumatology 2007;26:488-98.

\section{Salomon 2003}

Salomon J, Szepietowski JC, Proniewicz A. Psoriatic nails: a prospective clinical study. Journal of Cutaneous Medicine \& Surgery 2003;7(4):317-21.

\section{Schafer 2006}

Schafer T. Epidemiology of psoriasis. Review and the German perspective. Dermatology 2006;212(4):327-37.

\section{Scher 1990}

Scher RK. The nails. In: Roenigk HH, Maibach HI editor (s). Psoriasis. 2nd Edition. New York: Dekker, 1990:131.

\section{Schulz 2010}

Schulz KF, Altman DG, Moher D, for the CONSORT Group. CONSORT 2010 Statement: Updated guidelines for reporting parallel group randomised trials. Journal of Clinical Epidemiology 2010;63(8):834-40.

\section{Smith 2009}

Smith CH, Anstey AV, Barker JNWN, Burden AD, Chalmers RJG, Chandler DA, et al.British Association of Dermatologists' guidelines for biologic interventions for psoriasis 2009. British Journal of Dermatology 2009;161(5): 987-1019.

\section{Tham 1988}

Tham SN, Lim JJ, Tay SH, Chiew YF, Chua TN, Tan E, et al.Clinical observations on nail changes in psoriasis. Annals of the Academy of Medicine, Singapore 1988;17(4):482-5.

\section{van de Kerkhof 1998}

van de Kerkhof PC, de Hoop D, de Korte J, Kuipers MV. Scalp psoriasis, clinical presentations and therapeutic management. Dermatology 1998;197(4):326-34.

\section{Williamson 2004}

Williamson L, Dalbeth N, Dockerty JL, Gee BC, Weatherall $\mathrm{R}$, Wordsworth BP. Extended report: nail disease in psoriatic arthritis -- clinically important, potentially treatable and often overlooked. Rheumatology 2004;43(6):790-4.

* Indicates the major publication for the study 


\section{CHARACTERISTICS OF STUDIES}

\section{Characteristics of included studies [ordered by study ID]}

\section{Baran 1999}

\begin{tabular}{|c|c|}
\hline Methods & $\begin{array}{l}\text { This was a randomised, double-blind, internally placebo-controlled study } \\
\text { It was unclear if intention-to-treat analysis was conducted. }\end{array}$ \\
\hline Participants & $\begin{array}{l}\text { Inclusion criteria of the trial } \\
\text { - The trial included } 27 \text { consecutive participants with nail psoriasis ( } 8 \text { women, } 19 \\
\text { men: age range }=22 \text { to } 79 \text { years; average age }=47.0 \text { years). } \\
\text { Each participant was treated randomly with either the active formulation or the place } \\
\text { lacquer. } 1 \text { participant dropped out, and } 26 \text { participants were evaluable }\end{array}$ \\
\hline Interventions & $\begin{array}{l}\text { - } 8 \% \text { clobetasol-17-propionate in a colourless nail lacquer vehicle } \\
\text { - Placebo lacquer. } \\
\text { The participants applied the placebo lacquer to one hand and the clobetasol lacquer } \\
\text { the other hand once daily until the end of treatment. The nail lacquer film was remov } \\
\text { with a cosmetic nail varnish remover once weekly before a new application } \\
\text { The duration of treatment ranged between } 1.2 \text { and } 6.6 \text { months (average duration = } \\
\text { months) }\end{array}$ \\
\hline Outcomes & $\begin{array}{l}\text { Outcomes of the trial } \\
\text { 1. Therapeutic results on a 4-point scale: cured, improved, failure, or worsened } \\
\text { 2. Observed features: onycholysis. pitting, subungual hyperkeratosis, salmon } \\
\text { patches, splinter haemorrhages, ridging, transverse grooves, onychomadesis, and } \\
\text { periungual psoriasis }\end{array}$ \\
\hline
\end{tabular}

Notes There was a 1-month wash-out period for participants who had been treated with calcipotriol or steroid cream

\begin{tabular}{|c|c|c|}
\hline Bias & Authors' judgement & Support for judgement \\
\hline $\begin{array}{l}\text { Random sequence generation (selection } \\
\text { bias) }\end{array}$ & Unclear risk & $\begin{array}{l}\text { Quote: "Each participant was treated ran- } \\
\text { domly." }\end{array}$ \\
\hline Allocation concealment (selection bias) & Unclear risk & $\begin{array}{l}\text { Comment: The paper provided insufficient } \\
\text { details. }\end{array}$ \\
\hline $\begin{array}{l}\text { Blinding (performance bias and detection } \\
\text { bias) } \\
\text { Clinician/ Investigator }\end{array}$ & Low risk & Quote: “...double-blind study.” \\
\hline
\end{tabular}

Blinding (performance bias and detection Low risk

Quote: “...double-blind study.” bias)

Participants 


\begin{tabular}{|c|c|c|}
\hline $\begin{array}{l}\text { Blinding (performance bias and detection } \\
\text { bias) } \\
\text { Outcome assessor }\end{array}$ & Low risk & $\begin{array}{l}\text { Quote: “...double-blind study.” } \\
\text { Comment: The blinded clinician was prob- } \\
\text { ably the assessor. }\end{array}$ \\
\hline $\begin{array}{l}\text { Incomplete outcome data (attrition bias) } \\
\text { All outcomes }\end{array}$ & Low risk & $\begin{array}{l}\text { Quote: " } 27 \text { consecutive participants with } \\
\text { nail psoriasis were included, one dropped } \\
\text { out during the study. At the end of the } \\
\text { study, } 26 \text { participants were evaluable." }\end{array}$ \\
\hline Selective reporting (reporting bias) & Low risk & $\begin{array}{l}\text { Comment: The trial reported all prespeci- } \\
\text { fied outcomes. }\end{array}$ \\
\hline Other bias & Low risk & $\begin{array}{l}\text { Comment: This was free of other sources } \\
\text { of bias. }\end{array}$ \\
\hline
\end{tabular}

\section{Baran 1999a}

Methods

This was a double-blind, internally placebo-controlled study. In the methods of the trial, no randomisation is mentioned. We assume the study was randomised because the comparable trial in the same publication (Baran 1999) was randomised.

It was unclear if intention-to-treat analysis was conducted.

Participants

\section{Inclusion criteria of the trial}

- The trial included 18 participants who had fingernail psoriasis affecting both hands (all of the participants were men; age range $=22$ to 79 years; average age $=53.7$ years).

During the study, 3 participants dropped out, and 15 participants were evaluable

\begin{tabular}{l|l}
\hline Interventions & $\begin{array}{l}-8 \% \text { clobetasol-17-propionate in a colourless nail lacquer vehicle } \\
- \text { Placebo lacquer }\end{array}$ \\
$\begin{array}{l}\text { The participants applied the placebo lacquer to } 1 \text { hand and the clobetasol lacquer to the } \\
\text { other hand once daily in the first week and from the second week onwards twice or } 3 \\
\text { times weekly. The nail lacquer film was removed with a cosmetic nail varnish remover } \\
\text { once weekly before a new application } \\
\text { The duration of treatment ranged between } 5.1 \text { and } 8.9 \text { months (average duration }=7 \\
\text { months) }\end{array}$ \\
\hline Outcomes of the trial \\
\hline $\begin{array}{l}\text { Outcomes } \\
2 . \text { Observed features: onycholysis. pitting, subungual hyperkeratosis, salmon } \\
\text { patches, splinter haemorrhages, ridging, transverse grooves, onychomadesis, and } \\
\text { periungual psoriasis }\end{array}$ \\
\hline Notes & $\begin{array}{l}\text { The trial required participants who had been treated with intralesional steroids to have } \\
\text { a wash-out period of more than } 2 \text { months }\end{array}$ \\
\hline
\end{tabular}

\section{Risk of bias}




\begin{tabular}{|c|c|c|}
\hline Bias & Authors' judgement & Support for judgement \\
\hline $\begin{array}{l}\text { Random sequence generation (selection } \\
\text { bias) }\end{array}$ & Unclear risk & $\begin{array}{l}\text { Quote: "Each participant was treated ran- } \\
\text { domly." }\end{array}$ \\
\hline Allocation concealment (selection bias) & Unclear risk & $\begin{array}{l}\text { Comment: The paper provided insufficient } \\
\text { details. }\end{array}$ \\
\hline $\begin{array}{l}\text { Blinding (performance bias and detection } \\
\text { bias) } \\
\text { Clinician/ Investigator }\end{array}$ & Low risk & Quote: “...double-blind study.” \\
\hline $\begin{array}{l}\text { Blinding (performance bias and detection } \\
\text { bias) } \\
\text { Participants }\end{array}$ & Low risk & Quote: “...double-blind study.” \\
\hline $\begin{array}{l}\text { Blinding (performance bias and detection } \\
\text { bias) } \\
\text { Outcome assessor }\end{array}$ & Low risk & $\begin{array}{l}\text { Quote: “...double-blind study.” } \\
\text { Comment: The blinded clinician was prob- } \\
\text { ably the assessor. }\end{array}$ \\
\hline $\begin{array}{l}\text { Incomplete outcome data (attrition bias) } \\
\text { All outcomes }\end{array}$ & Low risk & $\begin{array}{l}\text { Quote: "18 participants who had finger- } \\
\text { nail psoriasis affecting both hands were in- } \\
\text { cluded, three dropped out during the study. } \\
\text { At the end of the study, } 15 \text { participants were } \\
\text { evaluable." }\end{array}$ \\
\hline Selective reporting (reporting bias) & Low risk & $\begin{array}{l}\text { Comment: All of the outcomes were re- } \\
\text { ported. }\end{array}$ \\
\hline Other bias & Low risk & $\begin{array}{l}\text { Comment: This was free of other sources } \\
\text { of bias. }\end{array}$ \\
\hline
\end{tabular}

\section{Cannavo 2003}

\begin{tabular}{ll} 
Methods & $\begin{array}{l}\text { This was a randomised, placebo-controlled study. } \\
\text { The blinding was unclear. } \\
\text { It was unclear if intention-to-treat analysis was conducted. }\end{array}$ \\
\hline Participants & $\begin{array}{l}\text { Inclusion criteria of the trial } \\
\text { - The study enrolled } 16 \text { men affected by moderate plaque-type psoriasis and } \\
\text { involvement of at least } 4 \text { nails of the hands (pitting, onycholysis, crumbling of the nail } \\
\text { plate, subungual hyperkeratosis, and oil drop change). The age range was } 46 \text { to } 80 \text { years } \\
\text { (mean age }=61.06 \pm 10.08) .4 \text { to } 10 \text { nails per participant were affected (median }=7 \text { ). } \\
\text { The mean age of participants in group A was } 62.88 \pm 10.53 . \text { The mean age of participants } \\
\text { in group B was } 59.25 \pm 9.95\end{array}$
\end{tabular}


Cannavo 2003 (Continued)

\begin{tabular}{|c|c|c|}
\hline Interventions & \multicolumn{2}{|c|}{$\begin{array}{l}\text { - Oil solution containing } 70 \% \text { of an oral preparation of ciclosporin (Sandimmun } \\
\text { Neoral }{ }^{\circledR} \text { oral solution) (total } 70 \mathrm{mg} / 100 \mathrm{ml} \text { ) and } 30 \% \text { of maize oil, which was applied } \\
\text { on the nails twice daily for a period of } 12 \text { weeks } \\
\text { - The control group were treated with maize oil only, which was applied twice daily } \\
\text { for a period of } 12 \text { weeks } \\
8 \text { weeks after the last visit, a follow-up visit was performed to evidence the presence of } \\
\text { relapses }\end{array}$} \\
\hline Outcomes & \multicolumn{2}{|c|}{$\begin{array}{l}\text { Outcomes of the trial } \\
\text { 1. Clinical severity score }(0=\text { absent, } 3=\text { severe) for onycholysis, hyperkeratosis, } \\
\text { pitting, crumbling, and oil drop } \\
\text { 2. Participants' severity score: 'minimal', 'moderate', 'severe', or 'very severe' } \\
\text { 3. Participants' assessment of lesions bothering them: 'not at all', 'a little', } \\
\text { 'moderately', or 'very much' } \\
\text { 4. PAGA (global therapeutic efficacy): 'excellent', 'good', 'moderate', 'no } \\
\text { improvement', or 'aggravation' }\end{array}$} \\
\hline Notes & \multicolumn{2}{|c|}{$\begin{array}{l}\text { There was a wash-out period of } 12 \text { weeks for participants allocated systemic therapy } \\
\text { No local or systemic side-effect was detectable, and the compliance was excellent }\end{array}$} \\
\hline \multicolumn{3}{|l|}{ Risk of bias } \\
\hline Bias & Authors' judgement & Support for judgement \\
\hline $\begin{array}{l}\text { Random sequence generation (selection } \\
\text { bias) }\end{array}$ & Low risk & $\begin{array}{l}\text { Quote: “...dividing into two groups using } \\
\text { block randomisation. In each block of four, } \\
\text { two participants were randomly assigned to } \\
\text { a group and two to the other." }\end{array}$ \\
\hline Allocation concealment (selection bias) & Unclear risk & $\begin{array}{l}\text { Comment: The paper provided insufficient } \\
\text { details. They used a block randomisation of } \\
\text { small blocks (4) in a, probably, unblinded } \\
\text { trial }\end{array}$ \\
\hline $\begin{array}{l}\text { Blinding (performance bias and detection } \\
\text { bias) } \\
\text { Clinician/ Investigator }\end{array}$ & Unclear risk & $\begin{array}{l}\text { Quote: "All participants were evaluated by } \\
\text { the same dermatologists." } \\
\text { Comment: The paper provided insufficient } \\
\text { details about blinding of dermatologists }\end{array}$ \\
\hline $\begin{array}{l}\text { Blinding (performance bias and detection } \\
\text { bias) } \\
\text { Participants }\end{array}$ & Unclear risk & $\begin{array}{l}\text { Comment: The paper provided insufficient } \\
\text { details about the blinding of participants }\end{array}$ \\
\hline $\begin{array}{l}\text { Blinding (performance bias and detection } \\
\text { bias) } \\
\text { Outcome assessor }\end{array}$ & Unclear risk & $\begin{array}{l}\text { Comment: The paper provided insufficient } \\
\text { details about blinding }\end{array}$ \\
\hline
\end{tabular}

Interventions for nail psoriasis (Review) 
Cannavo 2003 (Continued)

\begin{tabular}{l|l|l}
\hline $\begin{array}{l}\text { Incomplete outcome data (attrition bias) } \\
\text { All outcomes }\end{array}$ & Unclear risk & $\begin{array}{l}\text { Comment: There was no mention of miss- } \\
\text { ing outcome data. }\end{array}$ \\
\hline $\begin{array}{l}\text { Selective reporting (reporting bias) } \\
\text { Other bias }\end{array}$ & Low risk & $\begin{array}{l}\text { Comment: The trial reported all of the ex- } \\
\text { pected outcomes. }\end{array}$ \\
\hline
\end{tabular}

de Jong 1999

Methods

This was a randomised, double-blind, internally-controlled study

Intention-to-treat analysis was performed.

Participants

Inclusion criteria of the trial

- The trial included 57 adult participants ( 2 x 57 hands) with dystrophic fingernail psoriasis. (There were 36 men and 21 women; age range $=21$ to 77 years; mean age $=$ 45.8 years). The duration of fingernail psoriasis had a mean of 9.9 years (range $=0$ to 46 years).

- A minimum NAS score of 5 was required for inclusion.

Exclusion criteria of the trial

- The trial tested participants for onychomycosis by means of a $\mathrm{KOH}$ test and mycological culture, and they were excluded if positive.

Interventions

Left hand versus right hand treated with either of the following:

- 1\% 5-fluorouracil in Belanyx lotion; or

- Vehicle Belanyx lotion

The intervention was applied once daily and covered with a plaster for 12 weeks, with a follow-up period of 4 weeks

Outcomes

\section{Outcomes of the trial}

1. Changes in NAS scores of a comparable target nail of each hand, according to a 5point rating scale $(0=$ none, $4=$ very severe $)$. Assessed NAS parameter were as follows: extent of the nail pitting area ( $0 \%$ to $100 \%)$, in steps of $25 \%$ + number of pits ( 0 to > 15 ), the average of which was defined as nail pitting; subungual keratosis ( 0 to $>3 \mathrm{~mm}$ : measured from nail bed to thickest part); onycholysis ( $0 \%$ to $100 \%)$; and oil spots $(0 \%$ to $100 \%$ )

2. Changes in severity score, investigators' opinion: 5 -point rating scale $(0=$ none, 4 = very severe)

3. Changes in severity score, participants' opinion: 5 -point rating scale $(0=$ none, 4 = very severe)

\section{Notes}

-

Risk of bias

Bias

Authors' judgement

Support for judgement

Interventions for nail psoriasis (Review)

Copyright @ 2013 The Cochrane Collaboration. Published by John Wiley \& Sons, Ltd. 


\begin{tabular}{|c|c|c|}
\hline $\begin{array}{l}\text { Random sequence generation (selection } \\
\text { bias) }\end{array}$ & Low risk & Quote: “...randomised trial.” \\
\hline Allocation concealment (selection bias) & Unclear risk & $\begin{array}{l}\text { Comment: The paper provided insufficient } \\
\text { details. }\end{array}$ \\
\hline $\begin{array}{l}\text { Blinding (performance bias and detection } \\
\text { bias) } \\
\text { Clinician/ Investigator }\end{array}$ & Low risk & Quote: “...double-blind study.” \\
\hline $\begin{array}{l}\text { Blinding (performance bias and detection } \\
\text { bias) } \\
\text { Participants }\end{array}$ & Low risk & Quote: “...double-blind study.” \\
\hline $\begin{array}{l}\text { Blinding (performance bias and detection } \\
\text { bias) } \\
\text { Outcome assessor }\end{array}$ & Low risk & $\begin{array}{l}\text { Quote: “...double-blind study.” } \\
\text { Comment: The blinded investigator was } \\
\text { probably the assessor. }\end{array}$ \\
\hline $\begin{array}{l}\text { Incomplete outcome data (attrition bias) } \\
\text { All outcomes }\end{array}$ & Low risk & $\begin{array}{l}\text { Comment: There were no missing outcome } \\
\text { data. }\end{array}$ \\
\hline Selective reporting (reporting bias) & Low risk & $\begin{array}{l}\text { Comment: The trial reported all the ex- } \\
\text { pected outcomes. }\end{array}$ \\
\hline Other bias & Low risk & $\begin{array}{l}\text { Comment: This was free of other sources } \\
\text { of bias. }\end{array}$ \\
\hline
\end{tabular}

\section{Flori 1994}

Methods

Participants

Interventions
This was a randomised, double-blind, placebo-controlled study

It was unclear if intention-to-treat analysis was conducted.

\section{Inclusion criteria of the trial}

- The trial included 30 participants in total, who were divided into 2 groups of 15 participants. (There were 16 men and 14 women; age range $=18$ to 74 years. The active treatment group contained 10 men and 5 women, with a mean age of 42.5 years. The placebo group contained 6 men and 9 women, with a mean age of 41.8 years.) There were no dropouts or withdrawals during the study.

Exclusion criteria of the trial

- Participants were tested for onychomycosis at first visit and excluded if positive.

- The trial excluded participants treated with steroids, retinoids, or PUVA/UVB in the previous months.

- Hyaluronic acid with chondroitin sulphate (containing also vitamin A, vitamin B6, and vitamin E (Kevis nails))

- Placebo

Both active and placebo treatment were applied as a gel and micro-emulsion. The gel was applied in the morning and the micro-emulsion in the evening, $100 \mathrm{mg}$ by finger, 
Flori 1994 (Continued)

during 90 days. Every application was preceded with topical creme, which contained betamethasone $0.2 \%$ and $2 \%$ aminoglycoside antibiotic

\begin{tabular}{|c|c|c|}
\hline Outcomes & \multicolumn{2}{|c|}{$\begin{array}{l}\text { Outcomes of the trial } \\
\text { 1. Pitting, onicoressi, Beau's lines, onycholysis, and subungual hyperkeratosis } \\
\text { assessed with a 4-point-scale: } 0=\text { no lesion, } 1=\text { light lesion, } 2=\text { medium lesion, and } 3= \\
\text { serious lesion }\end{array}$} \\
\hline Notes & - & \\
\hline \multicolumn{3}{|l|}{ Risk of bias } \\
\hline Bias & Authors' judgement & Support for judgement \\
\hline $\begin{array}{l}\text { Random sequence generation (selection } \\
\text { bias) }\end{array}$ & Low risk & $\begin{array}{l}\text { Quote: "Participants were sequenced in a } \\
\text { randomisation scheme." }\end{array}$ \\
\hline Allocation concealment (selection bias) & Unclear risk & $\begin{array}{l}\text { Comment: The paper provided insufficient } \\
\text { details. }\end{array}$ \\
\hline $\begin{array}{l}\text { Blinding (performance bias and detection } \\
\text { bias) } \\
\text { Clinician/ Investigator }\end{array}$ & Low risk & Quote: “...double-blind study.” \\
\hline $\begin{array}{l}\text { Blinding (performance bias and detection } \\
\text { bias) } \\
\text { Participants }\end{array}$ & Low risk & Quote: “...double-blind study.” \\
\hline $\begin{array}{l}\text { Blinding (performance bias and detection } \\
\text { bias) } \\
\text { Outcome assessor }\end{array}$ & Low risk & $\begin{array}{l}\text { Quote: “...double-blind study.” } \\
\text { Comment: The blinded investigator was } \\
\text { probably the assessor. }\end{array}$ \\
\hline $\begin{array}{l}\text { Incomplete outcome data (attrition bias) } \\
\text { All outcomes }\end{array}$ & Low risk & $\begin{array}{l}\text { Quote: "All participants completed the en- } \\
\text { tire treatment course." } \\
\text { Comment: The study reported no drop- } \\
\text { outs. }\end{array}$ \\
\hline Selective reporting (reporting bias) & High risk & $\begin{array}{l}\text { Onychodystrophy toenails were reported } \\
\text { in the placebo group. The treated group re- } \\
\text { ported no toenails. There were no results } \\
\text { for the placebo toenails }\end{array}$ \\
\hline Other bias & Unclear risk & $\begin{array}{l}\text { Puropharma supplied the Kevis nails deliv- } \\
\text { ery. }\end{array}$ \\
\hline
\end{tabular}


Participants

Interventions

\section{Inclusion criteria of the trial}

- The study included 37 consecutive psoriatic participants with nail involvement aged between 25 and 68 years of either gender.

34 participants completed the 6-month study. Diagnosis of psoriatic nail was based on the presence of diagnostic psoriatic nail signs on fingernails. Psoriatic participants with nail involvement had psoriatic lesions on more than $10 \%$ of their total body surface area (BSA), a minimum PASI of 10 , and a NAPSI score of 10 or greater

Participants had stopped all topical therapy at least 4 weeks before and all systemic therapies for at least 6 months before initiating the study protocol

\section{Exclusion criteria of the trial}

- The study excluded participants with positive findings from native or culture for fungi.

- Methotrexate was administered at $15 \mathrm{mg}$ single dose weekly (subcutaneously) with folic acid $5 \mathrm{mg}$ daily except on the days of administration of methotrexate. If no side-effects occurred, it was applied for the first 3 months. In the second 3 months, the dose was planned to be decreased to $10 \mathrm{mg} /$ week.

- Ciclosporin $5 \mathrm{mg} / \mathrm{kg}$ daily (divided into 2 doses) was applied. In case of absence of side-effects, it was planned to apply this dose for the first 3 months. In the second 3 months, the dose was planned to be decreased to 2.5 to $3.5 \mathrm{mg} / \mathrm{kg} /$ day. The treatment period lasted 24 weeks, and follow up was for at least 3 months after the end of treatment.

Outcomes

Outcome measures were evaluated at baseline and at weeks 4, 8, 12, 16, 20, and 24 using the NAPSI. In addition, nail matrix and bed scores in hand and foot were evaluated separately before and after the treatment in the 2 groups

\section{Outcomes of the trial}

1. Using the NAPSI score, the participants' responses were classified at the end of the treatments as no improvement ( $<5 \%$ improvement), mild improvement $(>5 \%$ to $50 \%$ improvement), moderate improvement (> 50\% to 99\%), and complete improvement (100\% improvement).

2. At each visit, the physician performed a global assessment, which is a general evaluation of a psoriatic nail, using a scale of 0 to 10 , with a score of 0 indicating the worst involvement of nail and a score of 10 for the absence of nail involvement. Similar evaluation was performed by the participants as the participant's global score.

3. All participants were monitored for adverse effects at each visit using a standardised questionnaire and followed up for at least 3 months after the end of treatment.

Notes

During the study and the follow-up period, additional therapy was restricted to the use of emollients that were applied once daily in the evening

Risk of bias

Bias

Authors' judgement

\section{Support for judgement}


Random sequence generation (selection Low risk bias)

Allocation concealment (selection bias) Low risk

Blinding (performance bias and detection Unclear risk bias)

Clinician/ Investigator
Quote: "Randomized assignment of either of the two treatments was performed by asking the patients to throw a dice."

Randomised assignment of either of the 2 treatments was performed by asking the participants to throw a dice without knowing the underlying allocation criteria (numbers 1 to 3 = ciclosporin; numbers 4 to $6=$ methotrexate)

Quote: “...a one-blind study. Outcome measures were evaluated by an independent observer (MÖ). At each visit, the physician (MÖ) performed a global assessment."

Comment: It was unclear if the physician was blinded. It was unclear if the physician was the same person as the independent/ blinded observer

Quote: “...a one-blind study.”

Comment: The participants were not blinded for the treatment

bias)

Participants

Blinding (performance bias and detection Unclear risk bias)

Outcome assessor

Quote: “...a one-blind study. The scores were determined by a blinded observer. Outcome measures were evaluated by an independent observer (MÖ). At each visit, the physician (MÖ) performed a global assessment."

Comment: It was unclear if the independent/blinded observer was the physician, who probably was not blinded

Incomplete outcome data (attrition bias) Low risk All outcomes

Selective reporting (reporting bias)

Low risk
Quote: "Of the 37 participants, 34 completed the study. 1 participant discontinued treatment before the end of the treatment in the methotrexate group because of elevation of liver transaminase. Of the ciclosporin withdrawals, 2 participants developed elevation in serum creatinine and lipids. These 3 participants were excluded from the statistical analysis."

Comment: These dropouts were $<20 \%$ and present in both study arms

Comment: The expected outcomes were reported. 
Igarashi 2012

Methods

Participants
This was a randomised, double-blind, placebo-controlled study

It was unclear if intention-to-treat analysis was conducted.

\section{Inclusion criteria of the trial}

- A total of 160 participants with moderate-to-severe plaque-type psoriasis (at least 6 months, with PASI of 12 or higher) entered the study. 158 participants were randomly assigned, of whom $102(64.6 \%)$ participants had nail psoriasis. (There were $83 \%$ men and $17 \%$ women; mean age $=46$ years.

- Participants were randomised 2:2:1 to receive ustekinumab $45 \mathrm{mg}$ or $90 \mathrm{mg}$ by subcutaneous injection at weeks 0 and 4 , and every 12 weeks, or placebo at weeks 0 and 4, with a cross-over to ustekinumab 45 or $90 \mathrm{mg}$ at week 12 , and treatment at weeks 16, 28, 40, and 52. At week 28, participants with less than 50\% improvement in PASI discontinued the study agent. The study consisted of a placebo-controlled period (weeks 0 to 12), an active treatment period (weeks 12 to 64), and a follow-up period (week 64 to 72 ).

\section{Outcomes}

Adverse effects and other used outcomes were reported for the whole group, not specifically for nail psoriasis

Participants had not received systemic therapies or phototherapies within the previous 4 weeks or topical therapies within the previous 2 weeks. Participants with latent TB diagnosed during screening could be treated with an anti-TB agent (i.e. isoniazid (INH) ) for at least 3 weeks prior to randomisation

\section{Risk of bias}


Igarashi 2012 (Continued)

\begin{tabular}{l|l|l}
\hline Bias & Authors' judgement & Support for judgement \\
\hline $\begin{array}{l}\text { Random sequence generation (selection } \\
\text { bias) }\end{array}$ & Low risk & $\begin{array}{l}\text { Quote: “...double blind study, participants } \\
\text { were randomised 2:2:1.” } \\
\text { Comment: This was probably done. }\end{array}$ \\
\hline $\begin{array}{l}\text { Allocation concealment (selection bias) } \\
\begin{array}{l}\text { Blinding (performance bias and detection } \\
\text { bias) } \\
\text { Clinician/ Investigator }\end{array}\end{array}$ & Low risk & $\begin{array}{l}\text { Comment: The paper provided insufficient } \\
\text { details. }\end{array}$ \\
\hline
\end{tabular}

Blinding (performance bias and detection Low risk

bias)

Participants

Quote: “...double blind study.”

Blinding (performance bias and detection Low risk bias)

Outcome assessor

Quote: “...double blind study.”

Comment: The blinded investigator was probably the assessor.

Incomplete outcome data (attrition bias) Unclear risk All outcomes

Quote: "Of the 193 participants screened, 160 participants were randomised and 158 were treated. Two participants [were] withdrawn before treatment. The primary population for the efficacy analysis consisted of 157 participants, as 1 patient was excluded due to lack of any efficacy data after receiving a single dose of placebo. During treatment and follow up, 21 participants discontinued the study, of whom 12 participants discontinued because of adverse effects."

Comment: Specific data about the discontinuation of psoriasis participants with nail symptoms were not reported. There were dropouts reported of the total randomised participants

Selective reporting (reporting bias) Low risk

Other bias
Unclear risk
Comment: The expected outcomes were reported.

Sponsor: The study was supported by Janssen Pharmaceutical K.K., a part of the Johnson \& Johnson family companies. The authors reported conflict of interest Baseline participant demographics and disease characteristics were comparable 
Igarashi 2012 (Continued)

among the treatment groups

Kavanaugh 2009

Methods

This was a randomised, double-blind, placebo-controlled study

Intention-to-treat analysis was performed.

Participants

Inclusion criteria of the trial

- 405 participants were randomised.

- Participants enrolled in the study had active psoriatic arthritis, from whom 287

had nail psoriasis.

Interventions

- Participants were randomised in a blinded manner (1:1.3:1.3) to receive subcutaneous injections of placebo, golimumab $50 \mathrm{mg}$, or golimumab $100 \mathrm{mg}$ at weeks $0,4,8,12,16$, and 20 . Randomisation was stratified by baseline methotrexate use (in the placebo group $48 \%$ used methotrexate, $49 \%$ from the $50 \mathrm{mg}$ Golimumab group, and $47 \%$ from the $100 \mathrm{mg}$ Golimumab group. These percentages are from the whole group ( 405 participants)). At week 16, participants with $<10 \%$ improvement from baseline in both the swollen and tender joints counts entered early escape, with dose escalation from placebo to golimumab $50 \mathrm{mg}$ or from golimumab $50 \mathrm{mg}$ to golimumab $100 \mathrm{mg}$ (no specific numbers for nail psoriasis; 79 participants had a dose escalation). Follow up began at week 24; all participants received golimumab (no information about the dose) and continued to receive subcutaneous treatment every 4 weeks. The last evaluation was performed at week 24 .

Outcomes

Outcomes of the trial

1. The Nail Psoriasis severity index (NAPSI) was used to assess the severity of a target fingernail, representing the worst nail psoriasis at baseline.

2. Fingernail psoriasis was also evaluated using the physician's global assessment of psoriatic nail disease, where $1=$ absent and $5=$ very severe.

3. Comparisons were made for individual golimumab dose groups versus placebo. No comparisons between golimumab $50 \mathrm{mg}$ and golimumab $100 \mathrm{mg}$ were made.

4. Safety evaluations included adverse events, routine laboratory analysis, and the presence of antibodies to golimumab.

Notes Stable doses of methotrexate, NSAIDs, and corticosteroids were allowed Adverse events were reported for the whole group, not specifically for nail psoriasis

\section{Risk of bias}

Bias

Random sequence generation (selection Low risk bias)
Authors' judgement

\section{Support for judgement}

Quote: "Participants were randomised in a blinded manner (1:1.3:1.3)."

Comment: This was probably done. 
Kavanaugh 2009 (Continued)

\begin{tabular}{|c|c|c|}
\hline Allocation concealment (selection bias) & Low risk & $\begin{array}{l}\text { Quote: “...by a centralized interactive voice } \\
\text { response system.” } \\
\text { Comment: This was probably done. }\end{array}$ \\
\hline $\begin{array}{l}\text { Blinding (performance bias and detection } \\
\text { bias) } \\
\text { Clinician/ Investigator }\end{array}$ & Low risk & Quote: “...double blind study.” \\
\hline $\begin{array}{l}\text { Blinding (performance bias and detection } \\
\text { bias) } \\
\text { Participants }\end{array}$ & Low risk & Quote: “...double-blind study.” \\
\hline
\end{tabular}

Blinding (performance bias and detection Low risk bias)

Outcome assessor

Quote: “...double blind study.”

Comment: The blinded investigator was probably the assessor.

Incomplete outcome data (attrition bias) Unclear risk All outcomes

Quote: “16 weeks: 10/113 participants in placebo group discontinued treatment (four due to adverse events, two had unsatisfactory efficacy, one lost to follow up and three other). 9/292 participants in the golimumab group discontinued treatment (four had adverse events, one unsatisfactory efficacy, one lost to follow up and three other)

24 weeks: two out of 103 participants in placebo group discontinued (no reason is given). Four out of 283 participants in the golimumab group discontinued (two because of adverse events, two no reason is given)."

Comment: Specific data about the dropouts of psoriasis participants with nail symptoms were not reported. There were dropouts reported of the total randomised participants with psoriatic arthritis

Selective reporting (reporting bias)

Low risk

All of the expected outcomes were reported.

Other bias

High risk

Centocor Research \& Development Inc. and Schering-Plough were involved in the study design and the interpretation of data Stable doses of methotrexate, NSAIDs, and corticosteroids were allowed

There were no relevant differences between the groups.

Interventions for nail psoriasis (Review) 


\begin{tabular}{ll} 
Methods & $\begin{array}{l}\text { This was a randomised, internally placebo-controlled study. } \\
\text { Blinding was unclear. } \\
\text { It was unclear if intention-to-treat analysis was conducted. }\end{array}$ \\
\hline Participants & $\begin{array}{l}\text { Inclusion criteria of the trial } \\
-12 \text { participants with symmetrical nail psoriasis were enrolled in the study. }\end{array}$ \\
\hline Interventions & $\begin{array}{l}\text { - Active treatment was randomly allocated to the affected nails of } 1 \text { hand, while the } \\
\text { other } 1 \text { served as control. } \\
\text { The nails and nailbeds were treated with an electron beam (7 mega electron volts). A } \\
\text { total of } 6 \text { Gy was given in } 8 \text { fractions over } 8 \text { weeks (1 fraction of } 0.75 \text { per week) }\end{array}$ \\
\hline $\begin{array}{l}\text { Follow-up assessment was performed 3, } 6 \text {, and } 12 \text { months after treatment } \\
\text { Outcomes }\end{array}$ & $\begin{array}{l}\text { Outcomes of the trial } \\
\text { 1. Photographs of the involved nails of both hands were obtained prior to electron } \\
\text { beam therapy and at each follow-up visit. Each of the nails were graded as follows: } \\
\text { grade } 1: \text { pits, furrows, transverse depressions, onycholysis; grade } 2: \text { subungual } \\
\text { hyperkeratosis, thickening and crumbling of nail plate, oil drop, discolourations, and } \\
\text { splinter haemorrhages; and grade 3: proximal nail fold involvement, distal arthropathy. } \\
2 . \text { At each follow up, the nails were graded and scored as follows: cured without } \\
\text { residual nail abnormalities, markedly improved with residual lesions, moderately } \\
\text { improved, slightly improved, and no change. }\end{array}$ \\
\hline
\end{tabular}

Notes

None of the participants received systemic treatment and did not apply any topical medication or clip their nail while on follow up

The only local side-effect was a temporary deep brownish-black discolouration of all the electron beam-treated nails

\section{Risk of bias}

\begin{tabular}{|c|c|c|}
\hline Bias & Authors' judgement & Support for judgement \\
\hline $\begin{array}{l}\text { Random sequence generation (selection } \\
\text { bias) }\end{array}$ & Low risk & $\begin{array}{l}\text { Quote: "Active treatment was randomly al- } \\
\text { located to the affected nails of one hand, } \\
\text { while the other one served as control." } \\
\text { Comment: This was probably done. }\end{array}$ \\
\hline Allocation concealment (selection bias) & Unclear risk & $\begin{array}{l}\text { Comment: The paper provided insufficient } \\
\text { details. }\end{array}$ \\
\hline $\begin{array}{l}\text { Blinding (performance bias and detection } \\
\text { bias) } \\
\text { Clinician/ Investigator }\end{array}$ & Unclear risk & $\begin{array}{l}\text { Comment: There was no information } \\
\text { about blinding of the clinician }\end{array}$ \\
\hline
\end{tabular}

Blinding (performance bias and detection Unclear risk bias)

Participants
Comment: There was no information about blinding of the participants 
Kwang 1995 (Continued)

Blinding (performance bias and detection Unclear risk

bias)

Outcome assessor
Comment: There was no information about blinding of the outcome assessor

Incomplete outcome data (attrition bias) Low risk

There were no missing outcome data.

All outcomes

$\begin{array}{lll}\text { Selective reporting (reporting bias) } \quad \text { Low risk } & \text { All of the expected outcomes were reported }\end{array}$

Other bias Unclear risk

There was no information about the baseline characteristics.

\section{Levell 1995}

Methods

This was a randomised, actively-controlled study.

The trial was not blinded.

It was unclear if intention-to-treat analysis was conducted.

Participants

Interventions

\section{Inclusion criteria of the trial}

- A total of 60 participants with plaque psoriasis entered the study (33 women, 27 men: age range $=18$ to 67 years; age range for ciclosporin = 18 to 61 years; age range for dithranol $=20$ to 67 years). Of them, 29 participants had psoriatic nail disease. Exclusion criteria of the trial

- Systematic treatment for psoriasis taken less than 2 weeks before the study

- Oral ciclosporin was given as 2 daily doses of $2.5 \mathrm{mg} / \mathrm{kg}$ until 2 weeks after the psoriasis had cleared.

- After a suberythemal dose of UVB, dithranol ( $2 \%$ to $8 \%$ with $0.5 \%$ salicylic acid in emulsifying ointment) was applied daily for 15 minutes and then washed off.

The Ingram regimen, using dithranol in Lassar's paste, was used for participants not improving on the short contact regime. Treatment was considered a failure and stopped if there were any residual lesions after 16 weeks of either treatment

Participants were treated for 16 weeks until clear (the complete absence of visible or palpable lesions of psoriasis). All participants who cleared were followed up until relapse or until 8 months had elapsed. Visits for assessment were made twice before the treatment began and every 2 weeks thereafter until the rash was cleared and, after clearance, monthly until relapse or for 8 months

Outcomes

\section{Outcomes of the trial}

1. Severity score from 0 to 2 points for individual nail involvement

2. Psoriasis of the nails was assessed as improved, unchanged, or worsened.

Notes

Systematic treatment for psoriasis was not allowed for the last 2 weeks before starting the treatment

Adverse events included minimal toxicity (ciclosporin), burning (dithranol with salicylic acid and UVB), high blood pressure (ciclosporin), increasing serum creatinine (ciclosporin), increasing serum urate (ciclosporin and dithranol with salicylic acid and UVB), and increasing serum magnesium (ciclosporin) 
Levell 1995 (Continued)

There was a wash-out period of 2 weeks for systematic therapy

\section{Risk of bias}

\begin{tabular}{|c|c|c|}
\hline Bias & Authors' judgement & Support for judgement \\
\hline $\begin{array}{l}\text { Random sequence generation (selection } \\
\text { bias) }\end{array}$ & Low risk & $\begin{array}{l}\text { Quote: "The participants were randomised } \\
\text { by a code." } \\
\text { Comment: This was probably done. }\end{array}$ \\
\hline Allocation concealment (selection bias) & Low risk & $\begin{array}{l}\text { Quote: “...the code being available only to } \\
\text { a hospital pharmacist who was otherwise } \\
\text { uninvolved with the study." }\end{array}$ \\
\hline $\begin{array}{l}\text { Blinding (performance bias and detection } \\
\text { bias) } \\
\text { Clinician/ Investigator }\end{array}$ & High risk & $\begin{array}{l}\text { Quote: "The study was an open ran- } \\
\text { domised comparison." } \\
\text { Comment: The trial did not use blinding. }\end{array}$ \\
\hline $\begin{array}{l}\text { Blinding (performance bias and detection } \\
\text { bias) } \\
\text { Participants }\end{array}$ & High risk & $\begin{array}{l}\text { Quote: "The study was an open ran- } \\
\text { domised comparison." } \\
\text { Comment: The trial did not use blinding. }\end{array}$ \\
\hline $\begin{array}{l}\text { Blinding (performance bias and detection } \\
\text { bias) } \\
\text { Outcome assessor }\end{array}$ & High risk & $\begin{array}{l}\text { Quote: "The study was an open ran- } \\
\text { domised comparison." } \\
\text { Comment: The trial did not use blinding. }\end{array}$ \\
\hline $\begin{array}{l}\text { Incomplete outcome data (attrition bias) } \\
\text { All outcomes }\end{array}$ & High risk & $\begin{array}{l}\text { Of the participants with nail psoriasis, } 3 \text { out } \\
\text { of } 13 \text { participants in the ciclosporin group } \\
\text { and } 1 \text { out of } 16 \text { participants in the dithra- } \\
\text { nol with salicylic acid and UVB group } \\
\text { withdrew before further assessment (rea- } \\
\text { sons were difficulty in attending daily, ob- } \\
\text { jecting to the frequent assessment, and dys- } \\
\text { pepsia) } \\
\text { There was little information about the nail } \\
\text { psoriasis group and scoring }\end{array}$ \\
\hline Selective reporting (reporting bias) & High risk & $\begin{array}{l}\text { Quote: "The Ingram regimen, using } \\
\text { dithranol in Lassar's paste, was used for par- } \\
\text { ticipants not improving on the short con- } \\
\text { tact regimen." } \\
\text { Comment: No information was given } \\
\text { about the number of participants and re- } \\
\text { sults regarding who needed this cross-over } \\
\text { There was a discrepancy in the article be- } \\
\text { tween the improvement score showed in } \\
\text { the figure and the text }\end{array}$ \\
\hline
\end{tabular}

Interventions for nail psoriasis (Review) 
Levell 1995 (Continued)

\begin{tabular}{|c|c|c|}
\hline Other bias & High risk & $\begin{array}{l}\text { Sandoz Pharmaceuticals sponsored the } \\
\text { study. } \\
\text { Ciclosporin was given until } 2 \text { weeks after } \\
\text { the psoriasis had cleared }\end{array}$ \\
\hline
\end{tabular}

\section{Lindelof 1989}

Methods

Participants

Interventions
This was a randomised, double-blind, internally-controlled study. There was cross-over to active treatment for the placebo-treated group after 10 weeks

It was unclear if intention-to-treat analysis was conducted.

Inclusion criteria of the trial
$\begin{aligned} & \text { Participants } 24 \text { participants with psoriasis of the nails of both hands; age range }=29 \text { to } 75 \\ & \text { years. The psoriatic nails had various degrees of severity, ranging from nails of normal } \\ & \text { thickness with pits to very thickened hyperkeratotic nails. }\end{aligned}$

Outcomes

Notes
- Each participant received 5 Gy of grenz rays given on 10 occasions at intervals of 1 week. The psoriatic nail of 1 hand received active treatment; the other hand was treated with placebo (the apparatus hummed without irradiation).

The grenz ray machine factors were $10 \mathrm{kV}, 10 \mathrm{~mA}$, half-value layer $0.02 \mathrm{~mm} \mathrm{Al}$, halfvalue depth in tissue $0.5 \mathrm{~mm}$, focus skin distance $10 \mathrm{~cm}$. Active treatment was given to the former placebo-treated hands after 10 weeks. The participants were then followed for 6 months

\section{Outcomes of the trial}

1. Clinical evaluation was done before the grenz ray therapy and after the 10th treatment. Photographs of the involved nails of both hands were obtained prior to the grenz ray treatment. The nails were examined for signs of psoriasis, i.e. pitting, onycholysis, oil drops, subungual hyperkeratosis, onychorrhexis, and psoriatic involvement of the proximal nail fold. After 10 weeks, the improvement of each of the psoriatic nail signs was judged, and an overall improvement was scored for each hand. The nails were scored as follows: almost complete recovery, moderate improvement, slight improvement, and no improvement. No carry-over effect was present at crossover from placebo to active treatment.

The participant had been untreated for at least 6 months before the start of the study 5 participants showed slight pigmentation of the grenz ray treated nail fold. No other local or systematic adverse reactions were noted

\section{Risk of bias}

\begin{tabular}{lll} 
Bias & Authors' judgement & Support for judgement \\
\hline $\begin{array}{l}\text { Random sequence generation (selection } \\
\text { bias) }\end{array}$ & Low risk & $\begin{array}{l}\text { Quote: '...double blind trial, participants } \\
\text { were randomly allocated.” } \\
\text { Comment: This was probably done. }\end{array}$
\end{tabular}


Lindelof 1989 (Continued)

\begin{tabular}{|c|c|c|}
\hline Allocation concealment (selection bias) & Unclear risk & $\begin{array}{l}\text { Comment: No information about ran- } \\
\text { domisation of the hands was available }\end{array}$ \\
\hline $\begin{array}{l}\text { Blinding (performance bias and detection } \\
\text { bias) } \\
\text { Clinician/ Investigator }\end{array}$ & Low risk & $\begin{array}{l}\text { Quote: "...double blind trial, neither the } \\
\text { participant nor the evaluating doctor knew } \\
\text { which side had received active grenz ray } \\
\text { therapy." }\end{array}$ \\
\hline $\begin{array}{l}\text { Blinding (performance bias and detection } \\
\text { bias) } \\
\text { Participants }\end{array}$ & Low risk & $\begin{array}{l}\text { Quote: “...double blind study, neither the } \\
\text { participant nor the evaluating doctor knew } \\
\text { which side had received active grenz ray } \\
\text { therapy." } \\
\text { Comment: Placebo was administered by al- } \\
\text { lowing the apparatus to hum without irra- } \\
\text { diation }\end{array}$ \\
\hline $\begin{array}{l}\text { Blinding (performance bias and detection } \\
\text { bias) } \\
\text { Outcome assessor }\end{array}$ & Low risk & $\begin{array}{l}\text { Quote: “...double blind study, neither the } \\
\text { participant nor the evaluating doctor knew } \\
\text { which side had received active grenz ray } \\
\text { therapy." } \\
\text { Comment: The blinded doctor was the } \\
\text { outcome assessor. }\end{array}$ \\
\hline $\begin{array}{l}\text { Incomplete outcome data (attrition bias) } \\
\text { All outcomes }\end{array}$ & Low risk & $\begin{array}{l}2 \text { participants failed to participate through- } \\
\text { out the study, because of illness in their } \\
\text { families }\end{array}$ \\
\hline Selective reporting (reporting bias) & High risk & $\begin{array}{l}\text { The nail signs were not separately discussed } \\
\text { in the results. }\end{array}$ \\
\hline Other bias & Unclear risk & $\begin{array}{l}\text { There was no information about the base- } \\
\text { line characteristics. }\end{array}$ \\
\hline
\end{tabular}

Mahrle 1995

Methods

Participants
This was a randomised (2 ciclosporin, 1 etretinate), active controlled, cross-over study The blinding was unclear.

It was unclear if intention-to-treat analysis was conducted.

\section{Inclusion criteria of the trial}

- 210 participants with moderate to severe chronic plaque type psoriasis were randomised, of whom a total of 137 participants had nail symptoms. There were 90 nail psoriasis participants in the ciclosporin group, and 47 participants in the etretinate group. There were no data available for the number of nail psoriasis participants assigned to which groups in which phases (after cross-over).

- Specific data about the age and sex of the psoriasis participants with nail involvements were not reported separately, even for the dropouts and adverse events data. 
Mahrle 1995 (Continued)

\begin{tabular}{|c|c|}
\hline Interventions & $\begin{array}{l}\text { - Ciclosporin } \\
\text { - Etretinate } \\
\text { The initial dosage for ciclosporin was } 2.5 \mathrm{mg} / \mathrm{kg} / \text { day and } 0.5 \mathrm{mg} / \mathrm{kg} / \text { day for etretinate, } \\
\text { which could be individually adjusted to } 5.0 \text { and } 0.75 \mathrm{mg} / \mathrm{kg} / \text { day, respectively, depending } \\
\text { on the response reduction of the PASI score during the first } 10 \text { weeks (phase } 1 \text { ). The } \\
\text { daily dose was administered in divided doses in the morning and evening } \\
\text { After } 10 \text { weeks (phase } 1 \text { ), the study continued with a cross-over (phase } 2 \text { ). Because no } \\
\text { wash-out was required, there was a carry-over effect in the second phase. That is why we } \\
\text { only analysed the first } 10 \text { weeks (phase } 1 \text { ) }\end{array}$ \\
\hline Outcomes & $\begin{array}{l}\text { Outcomes of the trial } \\
\text { 1. 4-point scale nail involvement (there was no definition of the 4-point scale } \\
\text { assessment of nail psoriasis) }\end{array}$ \\
\hline Notes & $\begin{array}{l}\text { There was } 4 \text { weeks' wash-out for systemic therapy and } 1 \text { week for topical treatment } \\
\text { before entering the study } \\
\text { With regard to concomitant medication, only salicylic acid-containing emollients were } \\
\text { allowed during the study. During the follow-up weeks, any antipsoriatic therapy except } \\
\text { ciclosporin was allowed } \\
\text { There was a carry-over effect from phase } 1 \text { to } 2 \text {; it was unclear if a wash-out was applied } \\
\text { between these phases. Even after contacting the author about the missing data, we did } \\
\text { not receive any more information }\end{array}$ \\
\hline
\end{tabular}

Risk of bias

Bias

Authors' judgement

Support for judgement

Random sequence generation (selection Low risk

bias)

Quote: “...randomly allocated (2:1); after the first phase ( 10 weeks) ciclosporin group were again randomly (1:1) allocated."

Allocation concealment (selection bias) Unclear risk

Comment: The paper provided insufficient details.

Blinding (performance bias and detection Unclear risk bias)

Comment: The paper provided insufficient details about the blinding of the clinician

Clinician/ Investigator

Blinding (performance bias and detection Unclear risk bias)

Participants

Blinding (performance bias and detection Unclear risk bias)

Outcome assessor

Incomplete outcome data (attrition bias) Unclear risk
All outcomes
Comment: The paper provided insufficient details about the blinding of the participants

Comment: The paper provided insufficient details about the blinding of the outcome assessor

Comment: Specific data about the dropouts of psoriasis participants with nail 
Mahrle 1995 (Continued)

symptoms were not reported. There were dropouts reported of the total randomised psoriasis participants. There were no data about the participants' cross-over to the other therapy

Selective reporting (reporting bias) Low risk

Comment: The expected outcomes were reported.

Other bias

High risk

Sandoz AG sponsored the study.

With regard to concomitant medication, salicylic acid-containing emollients were allowed during the study

Rich 2008

Methods

This was a randomised, double-blind study, placebo-controlled study (data came from the EXPRESS study)

It was unclear if intention-to-treat analysis was conducted.

Participants

\section{Inclusion criteria of the trial}

- Of 378 enrolled participants with moderate to severe psoriasis, 305 had nails involved (217 men and 88 women).

- Participants were eligible if they had a diagnosis of at least 6 months, PASI $>12$, and psoriasis $>10 \%$ of body surface area.

Interventions

- Infliximab $5 \mathrm{mg} / \mathrm{kg}$ iv at weeks 0,2 , and 6 , and every 8 weeks through to week 46

- Placebo at weeks 0,2 , and 6, and every 8 weeks through to week 24, crossing over in a double-blind fashion to infliximab $5 \mathrm{mg} / \mathrm{kg}$ at weeks 24,26 , and 30 , and every 8 weeks through week 46

Eligible participants were allocated in a 4:1 ratio to receive infliximab $5 \mathrm{mg} / \mathrm{kg}$ or placebo. The follow-up period was 4 weeks

\section{Outcomes \\ Outcomes of the trial}

1. Nail psoriasis was assessed at weeks 10, 24, 38, and 50 with the Nail Psoriasis Severity Index (NAPSI). A target nail that represented the most severe nail psoriasis at baseline was scored with the NAPSI; no carry-over effect was present at cross-over from placebo to active treatment.

Notes

All systematic treatments and phototherapies were stopped a month before treatment; topical treatment was stopped 2 weeks before starting the study treatment Adverse events were not specifically reported for nail psoriasis

\section{Risk of bias}


Rich 2008 (Continued)

\begin{tabular}{|c|c|c|}
\hline $\begin{array}{l}\text { Random sequence generation (selection } \\
\text { bias) }\end{array}$ & Low risk & $\begin{array}{l}\text { Quote: "Participants were randomly allo- } \\
\text { cated in a } 4: 1 \text { ratio using a minimisation } \\
\text { algorithm with biased coin assignment by } \\
\text { means of an interactive voice response sys- } \\
\text { tem." } \\
\text { Comment: This was probably done. }\end{array}$ \\
\hline Allocation concealment (selection bias) & Low risk & $\begin{array}{l}\text { Quote: "This information was distributed } \\
\text { to the unblinded pharmacist, who then pre- } \\
\text { pared the study drug." } \\
\text { Comment: This was probably done. }\end{array}$ \\
\hline $\begin{array}{l}\text { Blinding (performance bias and detection } \\
\text { bias) } \\
\text { Clinician/ Investigator }\end{array}$ & Low risk & $\begin{array}{l}\text { Quote: “...double blind study. The inves- } \\
\text { tigators, study site personnel and partici- } \\
\text { pants remained blinded until the database } \\
\text { lock at week } 50 . "\end{array}$ \\
\hline $\begin{array}{l}\text { Blinding (performance bias and detection } \\
\text { bias) } \\
\text { Participants }\end{array}$ & Low risk & $\begin{array}{l}\text { Quote: “...double blind study, the inves- } \\
\text { tigators, study site personnel and partici- } \\
\text { pants remained blinded until the database } \\
\text { lock at week } 50 . "\end{array}$ \\
\hline $\begin{array}{l}\text { Blinding (performance bias and detection } \\
\text { bias) } \\
\text { Outcome assessor }\end{array}$ & Low risk & $\begin{array}{l}\text { Quote: "...double blind study, the inves- } \\
\text { tigators, study site personnel and partici- } \\
\text { pants remained blinded until the database } \\
\text { lock at week } 50 . "\end{array}$ \\
\hline $\begin{array}{l}\text { Incomplete outcome data (attrition bias) } \\
\text { All outcomes }\end{array}$ & Unclear risk & $\begin{array}{l}\text { 3/305 participants with nail psoriasis were } \\
\text { missing: The study did not provide reasons } \\
\text { for missing data }\end{array}$ \\
\hline Selective reporting (reporting bias) & Low risk & All of the expected outcomes were reported. \\
\hline Other bias & Unclear risk & $\begin{array}{l}\text { Centocor Inc, Malvern, } \mathrm{Pa} \text {, and Schering- } \\
\text { plough, and Kenilworth, NJ supported the } \\
\text { study } \\
\text { The } 2 \text { groups were homogeneous for all pa- } \\
\text { rameters. }\end{array}$ \\
\hline
\end{tabular}

Rigopoulos 2007

Methods

This was a randomised, double-blind, actively-controlled study

It was unclear if intention-to-treat analysis was conducted.

Participants

Inclusion criteria of the trial

- The study included 46 psoriatic participants with nail symptoms.

Interventions for nail psoriasis (Review)

Copyright @ 2013 The Cochrane Collaboration. Published by John Wiley \& Sons, Ltd. 
Rigopoulos 2007 (Continued)

\begin{tabular}{ll} 
Interventions & $\begin{array}{l}\text { - The first group applied tazarotene } 0.1 \% \text { cream (Zorac®) to the affected nail } \\
\text { plates, surrounding nail folds, and periungual skin under occlusion at bed time for } 12 \\
\text { weeks. } \\
\text { - The second group applied clobetasol propionate } 0.05 \% \text { cream (Butavate) in the } \\
\text { same way. } \\
\text { Occlusion was performed after application of the cream using common transparent } \\
\text { membrane obtained through general stores }\end{array}$ \\
\hline Outcomes & $\begin{array}{l}\text { Outcomes of the trial } \\
\text { Nail Psoriasis Severity Index (NAPSI) to grade the following parameters } \\
\text { independently: pitting, onycholysis, subungual hyperkeratosis, and salmon patches. } \\
\text { Follow-up evaluation was performed } 12 \text { weeks after the end of the therapy }\end{array}$ \\
\hline Notes & $\begin{array}{l}\text { A } 12 \text {-week wash-out period was allowed for topical and systematic medications } \\
3 \text { of } 16 \text { participants in the tazarotene group reported adverse events: desquamation and } \\
\text { erythema of nail fold skin, periungual irritation, paronychia, and irritation of the skin } \\
\text { of the toe or finger distanced from the nail area. } 1 \text { of } 14 \text { participants in the clobetasol } \\
\text { group reported a sensation of burning on the nail fold skin }\end{array}$ \\
\hline
\end{tabular}

Risk of bias

\begin{tabular}{|c|c|c|}
\hline Bias & Authors' judgement & Support for judgement \\
\hline $\begin{array}{l}\text { Random sequence generation (selection } \\
\text { bias) }\end{array}$ & Low risk & $\begin{array}{l}\text { Quote: "The participants were randomly } \\
\text { assigned by a computer." } \\
\text { Comment: This was probably done. }\end{array}$ \\
\hline Allocation concealment (selection bias) & Low risk & $\begin{array}{l}\text { Quote: “...assignment by a computer." } \\
\text { Comment: This was probably done. }\end{array}$ \\
\hline $\begin{array}{l}\text { Blinding (performance bias and detection } \\
\text { bias) } \\
\text { Clinician/ Investigator }\end{array}$ & Low risk & $\begin{array}{l}\text { Quote: “...double blind study, investigators } \\
\text { were blinded regarding the agent applied } \\
\text { by each participant.” }\end{array}$ \\
\hline $\begin{array}{l}\text { Blinding (performance bias and detection } \\
\text { bias) } \\
\text { Participants }\end{array}$ & Low risk & Quote: “...double blind study.” \\
\hline $\begin{array}{l}\text { Blinding (performance bias and detection } \\
\text { bias) } \\
\text { Outcome assessor }\end{array}$ & Low risk & $\begin{array}{l}\text { Quote: “...double blind study.” } \\
\text { Comment: The blinded investigator was } \\
\text { probably the outcome assessor }\end{array}$ \\
\hline $\begin{array}{l}\text { Incomplete outcome data (attrition bias) } \\
\text { All outcomes }\end{array}$ & High risk & $\begin{array}{l}\text { There were } 16 \text { dropouts ( } 7 \text { in the tazarotene } \\
\text { group, and } 9 \text { in the clobetasol group): } 10 / \\
16 \text { had urgent need for systemic therapy; } 4 \\
\text { of } 16 \text { failed to keep to the follow-up sched- } \\
\text { ule; and } 2 \text { had missing outcome data }\end{array}$ \\
\hline
\end{tabular}

Interventions for nail psoriasis (Review) 
Rigopoulos 2007 (Continued)

\begin{tabular}{|c|c|c|}
\hline Selective reporting (reporting bias) & Low risk & All of the expected outcomes were reported. \\
\hline Other bias & Unclear risk & $\begin{array}{l}\text { There was no information about baseline } \\
\text { characteristics. } \\
\text { Both agents were given in identical con- } \\
\text { tainers. }\end{array}$ \\
\hline
\end{tabular}

Scher 2001

Methods

This was a randomised, double-blind, vehicle-controlled study

It was unclear if intention-to-treat analysis was conducted.

Participants

Inclusion criteria of the trial

- The trial included a total of 31 adults ( $71 \%$ men, $29 \%$ women) with at least 2 fingernails that had at least 3 of the following characteristics: pitting, onycholysis, subungual hyperkeratosis, leuconychia, nail plate crumbling/loss, splinter haemorrhages, or nail bed discolourations. The mean age of the participant was 43 years old.

21 participants received tazarotene, and 10 participants received vehicle. Most participants were Caucasian (25)

\section{Exlusion criteria of the trial}

- Participants were excluded if either of their 2 target fingernails had positive results with a potassium hydroxide stain or dermatophyte/fungal culture. During the study, there were no dropouts or losses to follow up.

Interventions

- Tazarotene $0.1 \%$ gel

- Vehicle gel

Participants were randomised to receive either of the above, which they applied each evening for up to 24 weeks to 2 target fingernails: 1 under occlusion and 1 unoccluded

Outcomes

\section{Outcomes of the trial}

1. Pitting, onycholysis, subungual hyperkeratosis, leuconychia, nail plate crumbling/ loss, splinter haemorrhages, or nail bed discolourations were assessed on a 7-point scale $(0=$ none, $1=$ mild, $2=$ mild to moderate, $3=$ moderate, $4=$ moderate to severe, $5=$ severe, 6 = very severe) for 24 weeks.

2. Nail growth: by marking each target fingernail each visit with a transverse groove parallel to the lunula, measured using an electronic calliper

Notes

Occlusion was with polyethylene film/sheeting.

No other medications were allowed on the fingernails.

There was a wash-out period of 4 weeks for topical fingernail medications and investigational drugs, 6 weeks for intralesional corticosteroids and UVB or psoralen plus UVA phototherapy, and 12 weeks for systemic antipsoriatic medications

Risk of bias

Bias

Authors' judgement

Support for judgement

Interventions for nail psoriasis (Review)

Copyright $\odot 2013$ The Cochrane Collaboration. Published by John Wiley \& Sons, Ltd. 


\begin{tabular}{|c|c|c|}
\hline $\begin{array}{l}\text { Random sequence generation (selection } \\
\text { bias) }\end{array}$ & Unclear risk & Quote: “...randomised trial.” \\
\hline Allocation concealment (selection bias) & Unclear risk & $\begin{array}{l}\text { Comment: The paper provided insufficient } \\
\text { details. }\end{array}$ \\
\hline $\begin{array}{l}\text { Blinding (performance bias and detection } \\
\text { bias) } \\
\text { Clinician/ Investigator }\end{array}$ & Low risk & Quote: “...double blind study.” \\
\hline $\begin{array}{l}\text { Blinding (performance bias and detection } \\
\text { bias) } \\
\text { Participants }\end{array}$ & Low risk & Quote: “...double blind study.” \\
\hline $\begin{array}{l}\text { Blinding (performance bias and detection } \\
\text { bias) } \\
\text { Outcome assessor }\end{array}$ & Low risk & $\begin{array}{l}\text { Quote: “...double blind study.” } \\
\text { Comment: The blinded investigator was } \\
\text { probably the outcome assessor }\end{array}$ \\
\hline $\begin{array}{l}\text { Incomplete outcome data (attrition bias) } \\
\text { All outcomes }\end{array}$ & Low risk & Comment: There were no dropouts. \\
\hline Selective reporting (reporting bias) & Low risk & $\begin{array}{l}\text { The trial reported all of the expected out- } \\
\text { comes. }\end{array}$ \\
\hline Other bias & Unclear risk & Allergan, Inc provided financial support. \\
\hline
\end{tabular}

\section{Tosti 1998}

Methods

This was a randomised, double-blind actively-controlled study

It was unclear if intention-to-treat analysis was conducted.

Participants

\section{Inclusion criteria of the trial}

- Participants were eligible if over 18 years of age, of either sex, with severe subungual hyperkeratosis ( $>1 \mathrm{~mm}$ for fingernails, $>2.5 \mathrm{~mm}$ for toenails).

- A total of 58 participants were enrolled. (There were 35 men and 23 women; mean age $=51.8$ years.) 29 participants received topical calcipotriol -16 men and 13 women; mean age $=50.7$ years - of whom 13 participants ( 47 nails) had fingernail psoriasis, and 20 participants (109 nails) had toenail psoriasis. The mean duration of nail psoriasis in these participants was 8.3 years. 29 participants $(19$ men and 10 women; mean age $=53$ years) received topical betamethasone dipropionate and salicylic acid, of whom 16 participants (82 nails) had fingernail psoriasis, and 24 participants (161 nails) had toenail psoriasis. The mean duration of nail psoriasis in these participants was 7.1 years.

- A total of 29 participants had psoriasis of the fingernails, and 44 participants had toenail psoriasis.

- 2 participants assigned to receive calcipotriol presented exclusion criteria and were not considered in the assessment of efficacy; 12 (4 with calcipotriol and 8 with betamethasone) failed to attend the visit and were considered as dropouts. 
Tosti 1998 (Continued)

\section{Exclusion criteria of the trial}

- Onychomycosis

- Pregnant or breast-feeding women

- Known hypersensitivity to the study molecule

- Receiving vitamin D-based therapies or other topical or systemic treatments

- Severe renal or hepatic insufficiency

Interventions

- Calcipotriol ointment $(50 \mu \mathrm{g} / \mathrm{g})$ or betamethasone dipropionate $(64 \mathrm{mg} / \mathrm{g})$ and salicylic acid $(0.03 \mathrm{~g} / \mathrm{g})$ ointment, twice daily for at last 3 months. Participants who showed a $50 \%$ or more reduction in the baseline hyperkeratotic thickness at least in 1 nail (responders) were offered continuation of treatment for 2 further months.

Participants who completed the 5 months of treatment were then followed for 1 month after discontinuation.

Outcomes

\section{Outcomes of the trial}

1. Nail thickness (nail plate + hyperkeratotic nail bed) in $\mathrm{mm}$ using a calliper

2. Responders ( $\geq 50 \%$ reduction after 3 months, further treatment for 2 months and 1 month follow up)

3. Participant's opinion about acceptability of treatment using a 5-point scale: $0=$ nil, 1 = poor, 2 = fair, 3 = good, 4 = excellent

Notes

The trial was conducted in accordance with the principles of the Declaration of Helsinki

Risk of bias

\begin{tabular}{|c|c|c|}
\hline Bias & Authors' judgement & Support for judgement \\
\hline $\begin{array}{l}\text { Random sequence generation (selection } \\
\text { bias) }\end{array}$ & Unclear risk & Quote: “...randomised study.” \\
\hline Allocation concealment (selection bias) & Unclear risk & $\begin{array}{l}\text { Comment: The paper provided insufficient } \\
\text { details. }\end{array}$ \\
\hline $\begin{array}{l}\text { Blinding (performance bias and detection } \\
\text { bias) } \\
\text { Clinician/ Investigator }\end{array}$ & Low risk & Quote: “...double blind study.” \\
\hline
\end{tabular}

Blinding (performance bias and detection Low risk bias)

Quote: “...double blind study.”

Participants

Blinding (performance bias and detection Low risk bias)

Outcome assessor

Incomplete outcome data (attrition bias) High risk All outcomes
Quote: “...double blind study.”

Comment: The blinded investigator was probably the outcome assessor

2/29 calcipotriol participants presented exclusion criteria, and 12 participants ( 4 of 29 calcipotriol-treated participants and 8 of 29 betamethasone + salicylic acid-treated 
Tosti 1998 (Continued)

\begin{tabular}{|c|c|c|}
\hline & & $\begin{array}{l}\text { participants) failed to attend the visits dur- } \\
\text { ing the trial and were considered as drop- } \\
\text { outs } \\
\text { Responders ( } \geq 50 \% \text { reduction after } 3 \\
\text { months, further treatment for } 2 \text { months } \\
\text { and } 1 \text { month follow up); fingernails: } 8 \text { ( } 28 \\
\text { nails) calcipotriol, } 10 \text { ( } 38 \text { nails) betametha- } \\
\text { sone; toenails: } 7 \text { ( } 51 \text { nails) calcipotriol, } 12 \\
\text { ( } 58 \text { nails) betamethasone }\end{array}$ \\
\hline Selective reporting (reporting bias) & Low risk & $\begin{array}{l}\text { Comment: All of the outcomes were re- } \\
\text { ported. }\end{array}$ \\
\hline Other bias & High risk & $\begin{array}{l}\text { Quote: “...partially supported by Prodotti } \\
\text { Formenti SRL, Milan, Italy." } \\
\text { "The baseline subungual hyperkeratotic } \\
\text { thickness of the responder groups was } \\
\text { not homogeneous for calcipotriol and be- } \\
\text { tamethasone treatment for fingernails as } \\
\text { well as toenails." }\end{array}$ \\
\hline
\end{tabular}

Tzung 2008

Methods

This was a randomised, investigator-blinded, actively-controlled study

It was unclear if intention-to-treat analysis was conducted.

Participants

\section{Inclusion criteria of the trial}

- A total of 40 participants of at least 20 years of age with fingernail psoriasis were allocated randomly to 2 groups (A and B) for 12 weeks of treatment. 32 participants completed the study ( 7 women and 25 men). 5 participants in group A and 3 in group B dropped out for reasons unrelated to the treatment.

Interventions

- Group A: calcipotriol $0.005 \%$ plus betamethasone dipropionate $0.05 \%$ ointment (Daivobet ${ }^{\circledR}$ ), once daily for 12 weeks

- Group B: calcipotriol $0.005 \%$ ointment (Daivonex), twice daily for 12 weeks

Outcomes

\section{Outcomes of the trial}

1. NAPSI: nail matrix (4) and nail bed (4) involvement. Target nail was evaluated every 4 weeks (lower score $=$ improvement)

2. Investigator's Global Assessment (IGA) ( 0 = worse; $1=$ no change; 2,3 , and $4=$ slight, moderate, and marked improvement, respectively; 5 = clearance)

3. PAGA at end of the study ( $0=$ worse; $1=$ no change; 2,3 , and $4=$ slight, moderate, and marked improvement, respectively; 5 = clearance)

Notes

There were no conflicts of interest.

\section{Risk of bias}


Tzung 2008 (Continued)

\begin{tabular}{|c|c|c|}
\hline Bias & Authors' judgement & Support for judgement \\
\hline $\begin{array}{l}\text { Random sequence generation (selection } \\
\text { bias) }\end{array}$ & Unclear risk & Quote: “...randomised trial.” \\
\hline Allocation concealment (selection bias) & Unclear risk & $\begin{array}{l}\text { Comment: The paper provided insufficient } \\
\text { details. }\end{array}$ \\
\hline $\begin{array}{l}\text { Blinding (performance bias and detection } \\
\text { bias) } \\
\text { Clinician/ Investigator }\end{array}$ & Low risk & Quote: “...an investigator-blinded trial.” \\
\hline $\begin{array}{l}\text { Blinding (performance bias and detection } \\
\text { bias) } \\
\text { Participants }\end{array}$ & High risk & $\begin{array}{l}\text { Quote: “...an investigator-blinded trial.” } \\
\text { Comment: The participants were not } \\
\text { blinded to the treatment. }\end{array}$ \\
\hline $\begin{array}{l}\text { Blinding (performance bias and detection } \\
\text { bias) } \\
\text { Outcome assessor }\end{array}$ & Low risk & $\begin{array}{l}\text { Quote: “...an investigator-blinded trial.” } \\
\text { Comment: The blinded investigator was } \\
\text { probably the assessor. }\end{array}$ \\
\hline $\begin{array}{l}\text { Incomplete outcome data (attrition bias) } \\
\text { All outcomes }\end{array}$ & Low risk & $\begin{array}{l}40 \text { participants were randomised; } 32 \text { par- } \\
\text { ticipants completed the study. } 5 \text { partici- } \\
\text { pants in group A and } 3 \text { in group B dropped } \\
\text { out for reasons unrelated to the treatment }\end{array}$ \\
\hline Selective reporting (reporting bias) & Low risk & $\begin{array}{l}\text { All of the study's prespecified (primary and } \\
\text { secondary) outcomes that were of interest } \\
\text { were reported in the prespecified way }\end{array}$ \\
\hline Other bias & Low risk & This was free of other sources of bias. \\
\hline
\end{tabular}

\section{Yu 1992}

\begin{tabular}{|c|c|}
\hline Methods & $\begin{array}{l}\text { This was a randomised, double-blind, internally-controlled study } \\
\text { It was unclear if intention-to-treat analysis was conducted. }\end{array}$ \\
\hline Participants & $\begin{array}{l}\text { Inclusion criteria of the trial } \\
\text { - The trial included } 10 \text { participants with severe psoriatic nail dystrophy involving } \\
\text { all fingernails. Of these } 10 \text { participants, } 2 \text { defaulted and were excluded before } \\
\text { radiotherapy commenced. (There were } 7 \text { men and } 1 \text { woman; age range = } 42 \text { to } 68 \\
\text { years; mean age }=55 \text { years.) }\end{array}$ \\
\hline Interventions & $\begin{array}{l}\text { - Superficial radiotherapy was administered to the distal phalanx of each individual } \\
\text { finger of a randomly preselected hand. } 3 \text { fractionated doses of } 150 \mathrm{cGy} \text { were } \\
\text { administered every } 2 \text { weeks to a total of } 450 \mathrm{cGy} \text { per fortnight }(90 \mathrm{kV}, 5 \mathrm{~mA} \text {, half-value } \\
\text { layer } 1.00 \mathrm{~mm} \text {, focus skin distance } 100 \mathrm{~mm}) \text {. } \\
\text { - The control hand was treated with 'sham' radiotherapy. } \\
\text { The participants' nails were assessed at }-10,0,10,15 \text {, and } 20 \text { weeks (total of } 30 \text { weeks) }\end{array}$ \\
\hline
\end{tabular}


They intend to keep these participants under review every third month over a period of 2 years in order to watch for a delayed response

$\begin{array}{ll}\text { Outcomes } & \begin{array}{l}\text { Outcomes of the trial } \\ 1 . \text { Visual assessment: each nail was scored using a rating scale }(0=\text { normal, } 1= \\ \text { slightly affected, } 2=\text { moderately affected, } 3=\text { severely affected }) \text { for pitting, onycholysis, } \\ \text { subungual hyperkeratosis, and destruction of the nail plate. Range of scoring points: } 0 \\ \text { to } 12 \\ \text { 2. Rate of nail growth: in mm per week using an electronic calliper } \\ \text { 3. Nail thickness using an electronic calliper }\end{array}\end{array}$

\section{Risk of bias}

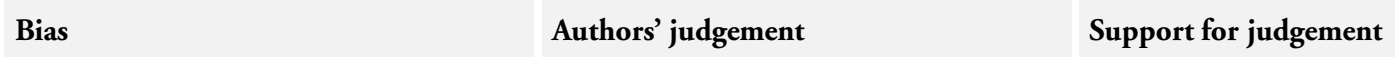

Random sequence generation (selection Low risk bias)

Blinding (performance bias and detection Unclear risk bias)

Clinician/ Investigator
Allocation concealment (selection bias) Unclear risk

Quote: "Superficial radiotherapy was administered to a randomly preselected hand.

Comment: This was probably done.

Comment: The paper provided insufficient details.

Quote: “...double blind trial, neither the participants nor the assessor were aware which side was being active treated until the end of the trial."

Comment: It was unclear if the investigator was the blinded assessor

Blinding (performance bias and detection Low risk
Blinding (performance bias and detection Low risk bias)

Participants bias)

Outcome assessor

Incomplete outcome data (attrition bias) Low risk All outcomes

Selective reporting (reporting bias) Low risk

Quote: “...double blind trial, neither the participants nor the assessor were aware which side was being active treated until the end of the trial."

Comment: 'Sham radiotherapy' was administered to the control hand

Quote: “...double blind trial, neither the participants nor the assessor were aware which side was being active treated until the end of the trial."

2 participants defaulted and were excluded before radiotherapy
The trial reported all of the expected outcomes. 


$\begin{array}{lll}\text { Other bias } & \text { Unclear risk } & \begin{array}{l}\text { There was no information about the base- } \\ \text { line characteristics. }\end{array}\end{array}$

\section{Characteristics of excluded studies [ordered by study ID]}

\begin{tabular}{ll}
\hline Study & Reason for exclusion \\
\hline Camacho 1976 & This was not a randomised controlled trial. \\
\hline Cantoresi 2009 & This was not a randomised controlled trial. \\
\hline Feuerman 1973 & No nails or nail psoriasis score were used. \\
\hline Lassus 1997 & Data were missing for primary and secondary outcomes of this review. Extraction of suitable data was not possible \\
\hline Luger 2009 & $\begin{array}{l}\text { Participants in the 2 treatment groups were analysed together; there was no specification between them. There was } \\
\text { no adequate control group, and the number of participants was not correct. There were not enough data provided } \\
\text { about which intervention was better }\end{array}$ \\
\hline Mrowietz 1991 & There were not enough data for nail psoriasis participants on the primary and secondary outcomes of this review \\
\hline O’Daly 2009 & There were no nail psoriasis participants in the study. \\
\hline
\end{tabular}

\section{Characteristics of studies awaiting assessment [ordered by study ID]}

\section{Abesamis-Cubillan 1997}

Methods This was a randomised, double-blind, placebo-controlled trial

\section{Participants Inclusion criteria of the trial}

- The trial included 14 psoriasis participants with concomitant nail psoriasis. 8 participants with a total of 75 dystrophic nails were assigned to the calcipotriol group; 6 participants with 60 nails involved were given placebo.

\begin{tabular}{ll}
\hline Interventions & - Topical calcipotriol \\
& $\bullet$ Placebo (white petrolatum)
\end{tabular}

\section{Outcomes Outcomes of the trial}

1. A clinical visual rating scale was devised to grade the severity of the nails $(0=$ normal, $1=$ slightly affected, $2=$ moderately affected, 3 = severely affected) for each of the following features: pitting, grooves, subungual hyperkeratosis, and onycholysis.

2. Adverse events were assessed in both the treatment group and placebo group.

Notes We emailed the Prinicpal Investigator (PI), but received no response 
Baerveldt 2010

Methods This was a prospective, double-blind, randomised, internally-controlled trial

\begin{tabular}{l|l}
\hline Participants & $\begin{array}{l}\text { Inclusion criteria of the trial } \\
\text { - Adults with fingernail psoriasis of both hands for at least } 6 \text { months } \\
\text { - A minimum of at least } 2 \text { affected nails on the left hand and the right hand, and the number of affected nails } \\
\text { may have differed by } 1 \text { nail at the maximum on the left hand compared with those on the right hand } \\
\text { - The dose of oral medication before the start had to have been constant for } 8 \text { weeks, and it would be reasonably } \\
\text { expected that the dose would not be altered during the treatment phase of the study. } \\
\text { - The trial evaluated } 30 \text { participants with a baseline NAPSI of } 18.3 \text { in the ciclosporin group and } 16.9 \text { at the } \\
\text { placebo group (with a maximum score of } 40) \text {. }\end{array}$ \\
\hline Interventions & $\begin{array}{l}\text { The duration of the treatment was until complete cure or for a maximum of } 16 \text { weeks, with the control group treated } \\
\text { for a maximum of } 28 \text { weeks. The follow up was for } 12 \text { weeks after stopping the treatment }\end{array}$ \\
\hline Outcomes & $\begin{array}{l}\text { Outcomes of the trial } \\
\text { - Nail Psoriasis Severity Index (NAPSI) }\end{array}$ \\
\hline Notes & \begin{tabular}{l}
6 participants dropped out because of non-compliance, protocol violation, or the start of systemic therapy \\
\hline
\end{tabular}
\end{tabular}

Kavanaugh 2011

\begin{tabular}{l|l}
\hline Methods & This was a randomised, placebo-controlled trial (GO-REVEAL study) \\
\hline Participants & $\begin{array}{l}\text { Inclusion criteria of the trial } \\
\text { The trial lasted for } 104 \text { weeks, and it included } 405 \text { participants }\end{array}$ \\
\hline Interventions & $\begin{array}{l}\text { - Subcutaneous placebo (group 1) } \\
\text { - Golimumab } 50 \mathrm{mg} \text { (group 2) }\end{array}$ \\
$\begin{array}{l}\text { The interventions were administered every } 4 \text { weeks. At week 16, participants with inadequate response entered early } \\
\text { escape. Group } 1 \text { crossed over to golimumab } 50 \mathrm{mg} \text { at week 24. In open-label extension, participants could be dose- } \\
\text { escalated, from golimumab } 50 \text { mg to } 100 \mathrm{mg}\end{array}$ \\
\hline Outcomes & $\begin{array}{l}\text { Outcomes of the trial } \\
\text { 1. Improvement of target fingernail psoriasis } \\
\text { 2. Adverse effects }\end{array}$ \\
\hline Notes & \begin{tabular}{l} 
This was a conference publication. \\
\hline
\end{tabular} \\
\hline
\end{tabular}


Kingsley 2009

\begin{tabular}{l|l} 
Methods & $\begin{array}{l}\text { This was a multicentre, randomised, double-blind, placebo-controlled trial, which lasted } 6 \text { months (the MIPA } \\
\text { (methotrexate in active psoriatic arthritis) trial). } \\
\text { The trial conducted intention-to-treat analysis. }\end{array}$ \\
\hline Participants & $\begin{array}{l}\text { Inclusion criteria of the trial } \\
\bullet \text { Participants with active psoriatic arthritis }\end{array}$ \\
\hline Interventions & $\begin{array}{l}\bullet \text { Oral methotrexate (15 mg/week) } \\
\bullet \text { Placebo }\end{array}$ \\
\hline Outcomes & $\begin{array}{l}\text { Outcomes of the trial } \\
\text { 1. Improvement of nail score }\end{array}$ \\
\hline Notes & $\begin{array}{l}\text { The trial reported dropouts. } \\
\text { This was a conference publication. }\end{array}$ \\
\hline
\end{tabular}

Langley 2011

Methods This was a randomised, placebo-controlled trial. This abstract used data from the 28-week phase IV trial, REACH (randomized, placebo-controlled evaluation of adalimumab for treatment of adults with moderate to severe chronic plaque psoriasis involving hands, feet, or both; NCT00735787).

$\begin{array}{ll}\text { Participants } & \text { Inclusion criteria of the trial } \\ \bullet \text { Participants with moderate to severe chronic plaque psoriasis involving hands, feet, or both }\end{array}$

Interventions $\quad$ Adalimumab

- Placebo

Participants were randomised 2:1 to adalimumab (80 mg at week $0,40 \mathrm{mg}$ every other week from weeks 1 to 27) or placebo (placebo at weeks 1 to $15,80 \mathrm{mg}$ adalimumab at week $16,40 \mathrm{mg}$ every other week from weeks 17 to 27)

Outcomes Outcomes of the trial

1. Nail Psoriasis Severity Index (NAPSI)

Notes This was an abstract conference publication.

Leonardi 2011

Methods This was a randomised, placebo-controlled, phase II, double-blind trial

Intention-to-treat analysis was carried out (last observation carried forward)

Participants Inclusion criteria of the trial

- 142 participants with moderate to severe plaque psoriasis

Interventions

- Subcutaneous injections of $10,25,75$, or $150 \mathrm{mg}$ of LY2439821 (LY), a humanized anti-interleukin (IL)-17 monoclonal antibody

- Placebo at weeks 0, 2, 4, 8, 12, and 16

Efficacy measures and safety were monitored through week 20 .

Interventions for nail psoriasis (Review)

Copyright @ 2013 The Cochrane Collaboration. Published by John Wiley \& Sons, Ltd. 


\section{Leonardi 2011 (Continued)}

\begin{tabular}{l|l} 
Outcomes & Outcomes of the trial \\
\cline { 2 - 2 } & $\begin{array}{l}\text { 1. Nail Psoriasis Severity Index (NAPSI) } \\
\text { 2. Adverse effects }\end{array}$ \\
\hline Notes & This was a conference publication.
\end{tabular}

McInnes 2009

\begin{tabular}{|c|c|}
\hline Methods & This was a randomised, placebo-controlled trial (GO-REVEAL study), with 405 participants \\
\hline Participants & $\begin{array}{l}\text { Inclusion criteria of the trial } \\
\text { - Psoriatic arthritis participants with } 3 \text { swollen and } 3 \text { tender joints and active plaque psoriasis (at least } 1 \text { lesion at } \\
\text { least } 2 \mathrm{~cm} \text { in diameter) }\end{array}$ \\
\hline Interventions & $\begin{array}{l}\text { - Subcutaneous placebo } \\
\text { - Golimumab } 50 \mathrm{mg} \\
\text { - Golimumab } 100 \mathrm{mg} \\
\text { The interventions were administered every } 4 \text { weeks. }\end{array}$ \\
\hline Outcomes & $\begin{array}{l}\text { Outcomes of the trial } \\
\text { 1. The single worst psoriasis-affected nail (target) was assessed using the Nail Psoriasis Severity Index (NAPSI). } \\
\text { 2. The Nail Physician's Global Assessment (PGA; } 1 \text { to } 5 ; 1=\text { absence of; } 5=\text { very severe) evaluated all fingernails. }\end{array}$ \\
\hline Notes & This was a conference publication. \\
\hline
\end{tabular}

Thaci 2010

Methods This was a randomised, vehicle-controlled trial, which lasted 16 weeks

Participants were treated in the phase IIIb, multicentre European study BELIEVE

Participants Inclusion criteria of the trial

- BELIEVE study: Participants with moderate to severe psoriasis who had failed, been intolerant of, or had contraindications to more than 2 systemic therapies

Interventions - Adalimumab $80 \mathrm{mg}$ at week 0 , and $40 \mathrm{mg}$ every other week from weeks 1 to 15

- Either topical vehicle or topical calcipotriol/betamethasone (C/B) (once daily for 4 weeks, and thereafter as needed (PRN: pro re nata); face, scalp, and nails excluded).

\section{Outcomes Outcomes of the trial}

1. Nails were assessed by NAPSI of the hands (range $=0$ to 80 ) at baseline, week 8 , and week 16 .

Notes

This was a poster presentation.

Interventions for nail psoriasis (Review) 


\section{Characteristics of ongoing studies [ordered by study ID]}

\section{EUCTR2004-004825-87-HU}

Trial name or title Efficacy and safety of $0.1 \%, 0.5 \%$ and $1 \%$ tazarotene nail lacquer formulation versus vehicle in nail psoriasis. International, multicenter, double-blind, randomized study of four parallel groups. - Dose ranging for tazarotene nail lacquer

Methods This is a double-blind, randomised study of 4 parallel groups, assessing the application of $0.1 \%, 0.5 \%$, or $1 \%$ tazarotene fingernail lacquer 6-month daily in fingernail psoriasis

$\begin{array}{ll}\text { Participants } & \begin{array}{l}\text { Inclusion criteria of the trial } \\ \text { - Participants are aged } 18 \text { years or over with a history of cutaneous psoriasis. Participants have at least } 4 \\ \text { nails with a minimal severity level defined as onycholysis of at least } 25 \% \text { or subungual hyperkeratosis at least } \\ 2 \mathrm{~mm} .\end{array}\end{array}$

\begin{tabular}{lll} 
Interventions & - Application of $0.1 \%, 0.5 \%$, or $1 \%$ tazarotene fingernail lacquer for 6 months daily \\
\hline
\end{tabular}

\begin{tabular}{|c|c|}
\hline Outcomes & Primary outcomes of the trial \\
\hline & $\begin{array}{l}\text { 1. Main objective: to assess the efficacy of a } 6 \text {-month daily application of } 0.1 \%, 0.5 \% \text {, or } 1 \% \text { tazarotene } \\
\text { fingernail lacquer in fingernail psoriasis, using Expert Physician Global Assesment (EPGA) corresponding to } \\
\text { a blinded assessment of photographs using a } 6 \text {-point scale } \\
\text { 2. Primary end point(s): Blinded Expert Global Assesment (EPGA) from photographs at } 6 \text { months on a } \\
\text { 6-point scale: } 1=\text { clear, } 2=\text { excellent, } 3=\text { good, } 4=\text { fair, } 5=\text { poor, } 6=\text { worse }\end{array}$ \\
\hline
\end{tabular}

\section{Secondary outcomes of the trial}

1. To assess the efficacy every 6 weeks using Baran's Total Clinical Score and Investigator Physician Global Assessment (IPGA)

2. To assess the efficacy of a 3-month daily application using EPGA

3. To assess relapse at 3 months after the end of the treatment

4. To assess local and general safety of the test product at each visit

5. To collect the participant self-assessment at 3 and 6 months

Starting date 22 April 2005

Contact information Pierre Fabre Dermatology represented by Institut de Recherche Pierre Fabre

Notes Status: not recruiting

\section{EUCTR2006-004453-18-FR}

Trial name or title A Randomised, Open-Label Preliminary Study To Assess The Effects Of Etanercept 50 mg Once Weekly For 24 Weeks And Etanercept 50 mg Twice Weekly For 12 weeks Reducing To Etanercept 50 mg Once Weekly For 12 weeks On Nail And Skin Symptoms In Patients With Nail Psoriasis And Plaque Psoriasis

Methods

This is a randomised, open-label study assessing the effects of etanercept $50 \mathrm{mg}$ once weekly for 24 weeks and etanercept $50 \mathrm{mg}$ twice weekly for 12 weeks reducing to etanercept $50 \mathrm{mg}$ once weekly for 12 weeks on nail and skin symptoms in participants with nail psoriasis and plaque psoriasis 


\section{EUCTR2006-004453-18-FR (Continued)}

\begin{tabular}{|c|c|}
\hline Participants & $\begin{array}{l}\text { Inclusion criteria of the trial } \\
\text { - Participants are } 18 \text { years of age or older at time of consent and have active, stable plaque psoriasis } \\
\text { defined by the following criteria: } \\
\quad \text { O Body surface area (BSA) } \geq 10 \% \text { at screening and baseline; } \\
\quad \text { PASI }>10 \text { at screening and baseline; } \\
\quad \text { PGA of psoriasis status of moderate or worse (moderate, marked, or severe) at screening and } \\
\text { baseline; or } \\
\quad \text { DLQI }>10 \text { at baseline } \\
\text { - Participants have active fingernail psoriasis as defined as target fingernail NAPSI } \geq 2 \text { and overall NAPSI } \\
>\text { 14. The target nail is defined as the nail with most severe overall grading at baseline. } \\
\text { - Participants had failure of at least } 1 \text { systemic psoriasis therapy for nail psoriasis, are eligible to receive } \\
\text { biologic therapy for psoriasis in accordance to local guidelines, are able to store injectable test article } \\
\text { between } 2^{\circ} \text { and } 8^{\circ} \mathrm{C} \text {, and are able and willing to self-inject test article or have a designee who can do so }\end{array}$ \\
\hline Interventions & $\begin{array}{l}\text { - Etanercept } 50 \mathrm{mg} \text { once weekly for } 24 \text { weeks or etanercept } 50 \mathrm{mg} \text { twice weekly for } 12 \text { weeks reducing to } \\
\text { etanercept } 50 \mathrm{mg} \text { once weekly for } 12 \text { weeks }\end{array}$ \\
\hline Outcomes & $\begin{array}{l}\text { Primary outcomes of the trial } \\
\text { - Main objective: to estimate the Nail Psoriasis Severity Index (NAPSI) in the target fingernail for both } \\
\text { treatment regimens over } 24 \text { weeks } \\
\text { - Primary end point(s): change from baseline in NAPSI for target fingernail over } 24 \text { weeks } \\
\text { Secondary outcomes of the trial } \\
\text { - To estimate the overall NAPSI for both treatment regimens over } 24 \text { weeks } \\
\text { - To estimate the proportion of participants achieving a } 50 \% \text { and } 75 \% \text { improvement in NAPSI in the } \\
\text { target fingernail and overall NAPSI at } 12 \text { and } 24 \text { weeks } \\
\text { - To estimate the Psoriasis Area and Severity Index (PASI) scores over } 24 \text { weeks } \\
\text { - To estimate the proportion of participants achieving a } 50 \% \text { and } 75 \% \text { improvement in PASI scores at } \\
12 \text { and } 24 \text { weeks } \\
\text { - To estimate the Physician Global Assessment (PGA) of Psoriasis over } 24 \text { weeks } \\
\text { - To estimate patient Dermatology Life Quality Index (DLQI) over } 24 \text { weeks } \\
\text { - To estimate Physician and Patient Global Assessment of Nail Psoriasis Disease Activity Visual } \\
\text { Analogue Scale (VAS) over } 24 \text { weeks } \\
\text { - To evaluate the safety and tolerability of the treatment regimens over } 24 \text { weeks } \\
\text { - To explore the utility of a novel fingernail grading assessment tool over } 24 \text { weeks }\end{array}$ \\
\hline Starting date & 7 June 2007 \\
\hline Contact information & Wyeth Pharmaceuticals (France) \\
\hline Notes & Status: Authorised - recruitment may be ongoing or finished \\
\hline
\end{tabular}


Trial name or title Efficacy and safety of $8 \%$ clobetasol nail lacquer formulation versus vehicle in nail psoriasis

Thethods is a randomised, double-blind, placebo-controlled trial assessing the efficacy of a 6-month daily applica-
tion of $8 \%$ clobetasol nail lacquer versus vehicle in fingernail psoriasis using the dynamic physician (blinded
expert) global assessment (EPGA), the dynamic physician (investigator) global assessment (IPGA), and the
patient global self assessment

Participants $\begin{aligned} & \text { Inclusion criteria of the trial } \\ & \text { - Participants are } 18 \text { years or older, men or women, and ambulatory participants. They have a history of } \\ & \text { having - for the last } 6 \text { months - bilateral fingernail psoriatic involvement on both hands. } \\ & \text { - At least } 1 \text { fingernail with psoriatic involvement per hand, at least } 1 \text { nail per hand (target nail) with an } \\ & \text { onycholysis area }>25 \% \text {, a subungual hyperkeratosis }>2 \mathrm{~mm} \text {, or both. The target nail should be on the same } \\ & \text { finger of each hand. }\end{aligned}$

Interventions

- 6-month daily application of $8 \%$ clobetasol nail lacquer

- Vehicle

\begin{tabular}{|c|c|}
\hline \multirow[t]{11}{*}{ Outcomes } & Primary outcomes of the trial \\
\hline & - Main objective: to assess the efficacy of a 6-month daily application of $8 \%$ clobetasol nail lacquer \\
\hline & versus vehicle in fingernail psoriasis using the dynamic physician (blinded expert) global assessment (EPGA \\
\hline & , the dynamic physician (investigator) global assessment (IPGA), and the patient global self assessment \\
\hline & - Primary end point(s): dynamic PGA: 1) dEPGA (dynamic expert PGA), 2) dIPGA (dynamic \\
\hline & investigator PGA); Static PGA: 1) sEPGA (static expert PGA), 2) sIPGA (static investigator PGA) \\
\hline & - Total clinical score assessing onycholysis, hyperkeratosis, healthy nail, number of cured nails, healthy \\
\hline & hands, number of cured hands, patients global self assessment, tolerance to clobetasol dosage, plasmatic \\
\hline & clobetasol measurement at baseline and 3 and 6 months \\
\hline & $\begin{array}{l}\text { Secondary outcomes of the trial } \\
\text { - To assess local and general safety of } 8 \% \text { clobetasol fingernail lacquer }\end{array}$ \\
\hline & - To assess systemic exposure of clobetasol after 6 months' treatment \\
\hline
\end{tabular}

Starting date $\quad 19$ January 2007

Contact information Pierre Fabre Dermatology represented by Institut de Recherche Pierre Fabre

Notes $\quad$ Status: Authorised - recruitment may be ongoing or finished

\section{EUCTR2010-019706-16-IT}

Trial name or title A randomized, double blind, placebo controlled, parallel groups, pilot study to assess the effects of two new nail lacquers, cyclosporine $5 \%$ and calcipotriol $0.005 \%$, in the treatment of nail psoriasis - ND

Methods This is a randomised, double-blind, placebo-controlled, parallel-group pilot study assessing the application of 2 new nail lacquers, ciclosporin $5 \%$ and calcipotriol $0.005 \%$

Participants

\section{Inclusion criteria of the trial}

- Participants are men and women aged 18 to 80 years, who have a clinical diagnosis of mild to moderate psoriasis (BSA involvement $=10 \%$ or PASI $=10$ ), have nail psoriasis (fingernails) of the nail matrix, the nail bed affecting at least 1 nail, or both. There is presence of at least 1 clinical sign of nail 


\section{EUCTR2010-019706-16-IT (Continued)}

psoriasis of the matrix (pitting, leukonychia, red spots in lunula, nail plate crumbling), of the nail bed (salmon patch, onycholysis, hyperkeratosis, and splinter haemorrhage), or both in at least 1 nail.

\begin{tabular}{l|l}
\hline Interventions & - Topical ciclosporin $5 \%$ \\
& $\bullet$ Calcipotriol $0.005 \%$
\end{tabular}

\section{Outcomes Primary outcomes of the trial}

1. Main objective: to evaluate the changes of clinical signs of nail bed and of the nail matrix of the nails affected by psoriasis by means of NAPSI score at the end of treatment, at each study visit, and at the followup visit (12 weeks after the end of treatment)

2. To evaluate the changes of nail thickness of the affected nails by means of $20 \mathrm{MHz}$ ultrasound at the end of treatment, at each study visit, and at the end of the follow-up period ( 12 weeks after the end of treatment)

3. Evaluation of the safety profile of P-3072 and P-3073 at the end of treatment and at each study visit by means of adverse effects monitoring

4. To evaluate the changes in participants' quality of life at the end of treatment, at each study visit, and at the end of the follow-up period ( 12 weeks after the end of treatment)

5. To evaluate the changes in pain due to nail psoriasis

6. To evaluate the changes in discomfort due to nail psoriasis

7. To evaluate participants' opinion on the product (effectiveness and acceptability) at the end of treatment

8. Primary end point(s):

- Changes in clinical signs of the nail bed (salmon patch, onycholysis, hyperkeratosis, and splinter haemorrhage) and of the nail matrix (pitting, leukonychia, red spots in lunula, and nail plate crumbling) of the affected nails evaluated by means of NAPSI score at the end of treatment, at each study visit, and at the follow-up visit

- Changes of nail thickness of the affected nails evaluated by means of $20 \mathrm{MHz}$ ultrasound at the end of treatment, at each study visit, and at the end of the follow-up period

- Evaluation of the safety profile of P-3072 and P-3073 at each study visit by means of adverse effect monitoring

- Changes in participants' quality of life by means of NPQ10 (Nail Psoriasis Quality of Life) and

DLQI (Dermatology Life Quality Index) questionnaires evaluated at each study visit

- Changes of pain due to nail psoriasis by means of a VAS (Visual Analogue Scale)

- Changes of discomfort due to nail psoriasis by means of a VAS (Visual Analogue Scale)

- Participants' opinion on the product effectiveness and on its acceptability evaluated at each study visit by means of participants' diaries

- Blood and nail concentration of ciclosporin and calcipotriol at the end of treatment, at each study visit, and at the end of the follow-up period 
Trial name or title Randomised, Open-label Preliminary Study to Assess the Effects of 2 Regimens of Etanercept on Nail and Skin Symptoms in Patients With Nail Psoriasis and Plaque Psoriasis

\begin{tabular}{ll} 
Methods & This is an open-label randomised controlled trial. \\
& $\begin{array}{l}\text { The study will assess the effects of the } 2 \text { etanercept regimens on fingernail psoriasis over } 24 \text { weeks among } \\
\text { participants with both skin and fingernail involvement who have previously failed at least } 1 \text { therapy for nail } \\
\text { psoriasis } \\
\text { The end point of } 24 \text { weeks was chosen to allow sufficient time for normal nail growth }\end{array}$ \\
Participants & $\begin{array}{l}\text { Inclusion criteria of the trial } \\
\text { psoriasis therapy for nail psoriasis }\end{array}$ \\
\hline Interventions & - Etanercept
\end{tabular}

\begin{tabular}{|c|c|}
\hline Outcomes & $\begin{array}{l}\text { Outcomes of the trial } \\
\text { 1. Change from baseline in NAPSI for target fingernail over } 24 \text { weeks } \\
\text { 2. Proportion of subjects achieving NAPSI } 50 \text { and NAPSI } 75 \text { for target fingernail and an overall NAPSI } \\
\text { at } 12 \text { and } 24 \text { weeks } \\
\text { 3. Change from baseline in the Physician and Patient Assessment of Nail Psoriasis Activity VAS to } 24 \\
\text { weeks } \\
\text { 4. Change from baseline using novel assessment tool (physician fingernail grading assessment) over } 24 \\
\text { weeks }\end{array}$ \\
\hline Starting date & September 2007 \\
\hline Contact information & Medical Monitor, Study Director, Wyeth \\
\hline Notes & Status: Completed \\
\hline
\end{tabular}

\section{NCT00666354}

Trial name or title Phase IIB Dose Response and Safety Study of Topical Formulations of Methotrexate (MQX-5902, MQX5904 and MQX-5906) in the Treatment of Fingernail Psoriasis

Methods This is a multicentre, randomised, double-blind, efficacy and safety study evaluating improvements in the appearance of the target fingernail measured monthly for 4 months. The trial will also assess safety, i.e., the frequency and severity of adverse events in the treatment of participants with fingernail psoriasis, measured monthly for 5 months

\begin{tabular}{l|l} 
Participants & $\frac{\text { Inclusion criteria of the trial }}{\bullet} 83$ participants, 18 to 75 years of age and either sex
\end{tabular}

Interventions

- Active comparator 1 = methotrexate (other names: MQX-5906)

Dosing: $0.01 \mathrm{~g}$ of topical amphimatrix containing $0.05 \%$ methotrexate per affected nail and adjacent skin folds applied daily for 3 months

- Active comparator 2 = methotrexate (other names: MQX-5902)

Dosing: $0.01 \mathrm{~g}$ of topical amphimatrix containing $0.25 \%$ methotrexate per affected nail and adjacent skin 


\section{NCT00666354 (Continued)}

folds applied daily for 3 months

- Active comparator 3 = methotrexate (other names: MQX-5904)

Dosing: $0.01 \mathrm{~g}$ of topical amphimatrix containing $1.0 \%$ methotrexate per affected nail and adjacent skin folds applied daily for 3 months

The total duration of follow-up is 1 month.

\begin{tabular}{|c|c|}
\hline Outcomes & $\begin{array}{l}\text { Primary outcomes of the trial } \\
\text { 1. Evaluate improvements in the appearance of the target fingernail, utilising photography for imaging } \\
\text { and independent photograph evaluators, measured monthly for } 4 \text { months } \\
\text { 2. Assess safety, i.e., the frequency and severity of adverse events associated with MQX-5902, MQX-5904, } \\
\text { and MQX-5906 in the treatment of participants with fingernail psoriasis, measured monthly for } 5 \text { months } \\
\text { Secondary outcomes of the trial } \\
\text { The following will be measured monthly for } 4 \text { months. } \\
\text { 1. The improvement in the appearance of the control fingernail as determined by independent evaluators } \\
\text { 2. The improvement of the target fingernail as measured by the investigator using the mNAPSI (a } \\
\text { modification of the Nail Psoriasis Severity Index) } \\
\text { 3. A comparison of the improvement of the mNAPSI of the target and control fingernails } \\
\text { 4. Information on the relative changes in nail psoriasis severity of the other affected fingernails } \\
\text { 5. A comparison of nail growth of the target and control fingernails as determined from nail notch } \\
\text { movement measured on nail photographs }\end{array}$ \\
\hline Starting date & 01 October 2007 \\
\hline Contact information & $\begin{array}{l}\text { Professor Neil McHugh } \\
\text { Royal National Hospital for Rheumatic Diseases } \\
\text { Upper Borough Walls, Bath } \\
\text { United Kingdom } \\
\text { BA1 1RL } \\
\text { MediQuest Therapeutics, Inc. (USA) sponsored the trial (email: info@mqti.com; phone: +1 } 4253989580 \text { ) }\end{array}$ \\
\hline Notes & Status: Completed \\
\hline
\end{tabular}

\section{NCT00999687}

Trial name or title Evaluation of the Efficacy and Safety of Indigo Naturalis Oil Extract on Psoriatic Nails

Methods This is a phase II/phase III, randomised, placebo-controlled, single-blind trial

Participants

\section{Inclusion criteria of the trial}

- Participants aged 18 to 75 years old with fingernail psoriasis

- Failure of topical or systemic Chinese herbal antipsoriasis therapy for fingernail psoriasis, or both

Interventions

- Indigo naturalis oil extract

- Placebo

The interventions were administered for 24 weeks. 


\section{NCT00999687 (Continued)}

\begin{tabular}{l|l}
\hline Outcomes & $\begin{array}{l}\text { Outcomes of the trial } \\
\text { 1. Change from baseline in modified NAPSI for target fingernail over 24 weeks } \\
\text { 2. Comparison of improvement of modified NAPSI of the indigo naturalis oil agent-treated and control } \\
\text { fingernails }\end{array}$ \\
\hline Starting date & September 2009 \\
\hline Contact information & $\begin{array}{l}\text { Yin-Ku Lin, MD, PhD } \\
\text { Principal Investigator } \\
\text { Chang Gung Memorial Hospital }\end{array}$ \\
\hline Notes & Status: Enrolling by invitation \\
\hline
\end{tabular}

\section{NCT01107457}

\begin{tabular}{l|l} 
Trial name or title & $\begin{array}{l}\text { A Dose-Ranging And Efficacy Study of LY2439821 (An Anti-IL-17 Antibody) In Patients With Moderate- } \\
\text { To-Severe Psoriasis }\end{array}$ \\
\hline Methods & $\begin{array}{l}\text { This is a randomised, placebo-controlled, double-blind trial } \\
\text { Participants will be evaluated for treatment efficacy at multiple visits, and the primary end point will be } \\
\text { evaluated at week 16. Participants will be followed an additional } 16 \text { to } 24 \text { weeks (32 to } 40 \text { weeks in total) after } \\
\text { the completion of dosing in order to continue safety monitoring and to determine the duration of treatment } \\
\text { efficacy }\end{array}$ \\
\hline Participants & $\begin{array}{l}\text { Inclusion criteria of the trial } \\
\text { LY2439821 groups or to placebo (approximately } 25 \text { participants per group). } \\
\text { - Plaque psoriasis covering at least } 10 \% \text { body surface area and a PASI score of } 12\end{array}$ \\
\hline Interventions & $\begin{array}{l}\text { - LY2439821 } 10 \mathrm{mg}, 25 \mathrm{mg}, 75 \mathrm{mg} \text {, and } 150 \mathrm{mg} \text { (biological) } \\
\text { - Placebo (drug) }\end{array}$ \\
\hline
\end{tabular}

Outcomes

\section{Outcomes of the trial}

1. Change from baseline through 32 weeks in Nail Psoriasis Severity Index (NAPSI) in participants with nail psoriasis

\begin{tabular}{ll}
\hline Starting date & April 2010 \\
\hline Contact information & $\begin{array}{l}\text { Eli Lilly \& Co. } \\
\text { Study Director: phone CTLILLY }(+18772854559) \text { or phone }+13176154559\end{array}$ \\
\hline Notes & Status: This trial is not yet recruiting. \\
\hline
\end{tabular}


DATA AND ANALYSES

Comparison 1. (Systemic) ciclosporin $2.5 \mathrm{mg} / \mathrm{kg}$ vs topical dithranol + salicylic acid + UVB

\begin{tabular}{lcccc} 
Outcome or subgroup title & $\begin{array}{c}\text { No. of } \\
\text { studies }\end{array}$ & $\begin{array}{c}\text { No. of } \\
\text { participants }\end{array}$ & Statistical method & Effect size \\
\hline $\begin{array}{c}1 \text { Participants with at least } 50 \% \\
\text { nail score improvement after } \\
\text { short-term treatment duration }\end{array}$ & 1 & Risk Ratio (M-H, Random, 95\% CI) & Subtotals only \\
\hline
\end{tabular}

Comparison 2. (Topical) ciclosporin $70 \%$ in maize oil vs maize oil

\begin{tabular}{lcccc} 
Outcome or subgroup title & $\begin{array}{c}\text { No. of } \\
\text { studies }\end{array}$ & $\begin{array}{c}\text { No. of } \\
\text { participants }\end{array}$ & Statistical method & Effect size \\
\hline $\begin{array}{c}1 \text { Participants with at least } 50 \% \\
\text { nail score improvement after } \\
\text { short-term treatment duration }\end{array}$ & 1 & Risk Ratio (M-H, Random, 95\% CI) & Subtotals only \\
\hline
\end{tabular}

Comparison 3. (Topical) calcipotriol $0.005 \%$ vs calcipotriol $0.005 \%+0.05 \%$ betamethasone dipropionate

\begin{tabular}{lcccc} 
Outcome or subgroup title & $\begin{array}{c}\text { No. of } \\
\text { studies }\end{array}$ & $\begin{array}{c}\text { No. of } \\
\text { participants }\end{array}$ & Statistical method & Effect size \\
\hline $\begin{array}{c}1 \text { Participants with at least } 50 \% \\
\text { nail score improvement after } \\
\text { short-term treatment duration }\end{array}$ & 1 & Risk Ratio (M-H, Random, 95\% CI) & Subtotals only \\
\hline
\end{tabular}

Comparison 4. Topical - Systemic - Radiotherapy

\begin{tabular}{|c|c|c|c|c|}
\hline Outcome or subgroup title & $\begin{array}{l}\text { No. of } \\
\text { studies }\end{array}$ & $\begin{array}{c}\text { No. of } \\
\text { participants }\end{array}$ & Statistical method & Effect size \\
\hline $\begin{array}{l}1 \text { Participants with adverse effects } \\
\text { (AE) }\end{array}$ & 15 & & Risk Ratio (M-H, Random, 95\% CI) & Totals not selected \\
\hline 1.1 Topical therapy & 7 & & Risk Ratio (M-H, Random, 95\% CI) & $0.0[0.0,0.0]$ \\
\hline 1.2 Systemic therapy & 5 & & Risk Ratio (M-H, Random, 95\% CI) & $0.0[0.0,0.0]$ \\
\hline 1.3 Radiotherapy & 3 & & Risk Ratio (M-H, Random, 95\% CI) & $0.0[0.0,0.0]$ \\
\hline
\end{tabular}


Comparison 5. (Topical) calcipotriol $50 \mathrm{ug} / \mathrm{g}$ vs betamethasone dipropionate $64 \mathrm{mg} / \mathrm{g}+$ salicylic acid $0.03 \mathrm{~g} / \mathrm{g}$

\begin{tabular}{|c|c|c|c|c|}
\hline Outcome or subgroup title & $\begin{array}{l}\text { No. of } \\
\text { studies }\end{array}$ & $\begin{array}{c}\text { No. of } \\
\text { participants }\end{array}$ & Statistical method & Effect size \\
\hline $\begin{array}{l}1 \text { Participants with at least } 50 \% \\
\text { nail score improvement after } \\
\text { short-term treatment duration }\end{array}$ & 1 & & Risk Ratio (M-H, Random, 95\% CI) & Subtotals only \\
\hline $\begin{array}{l}2 \text { Nail score improvement after } \\
\text { short-term treatment duration }\end{array}$ & 1 & & Mean Difference (IV, Random, 95\% CI) & Subtotals only \\
\hline
\end{tabular}

Comparison 6. (Systemic) ustekinumab $45 \mathrm{mg}$ versus placebo

\begin{tabular}{lcccc} 
Outcome or subgroup title & $\begin{array}{c}\text { No. of } \\
\text { studies }\end{array}$ & $\begin{array}{c}\text { No. of } \\
\text { participants }\end{array}$ & Statistical method & Effect size \\
\hline $\begin{array}{c}1 \text { Nail score improvement after } \\
\text { short-term treatment duration }\end{array}$ & 1 & Mean Difference (IV, Random, 95\% CI) & Subtotals only \\
\hline
\end{tabular}

Comparison 7. (Systemic) ustekinumab $90 \mathrm{mg}$ versus placebo

\begin{tabular}{lcccc} 
Outcome or subgroup title & $\begin{array}{c}\text { No. of } \\
\text { studies }\end{array}$ & $\begin{array}{c}\text { No. of } \\
\text { participants }\end{array}$ & Statistical method & Effect size \\
\hline $\begin{array}{c}1 \text { Nail score improvement after } \\
\text { short-term treatment duration }\end{array}$ & 1 & Mean Difference (IV, Random, 95\% CI) & Subtotals only \\
\hline
\end{tabular}

Comparison 8. (Systemic) ustekinumab $45 \mathrm{mg}$ versus $90 \mathrm{mg}$

\begin{tabular}{|c|c|c|c|c|}
\hline Outcome or subgroup title & $\begin{array}{l}\text { No. of } \\
\text { studies }\end{array}$ & $\begin{array}{c}\text { No. of } \\
\text { participants }\end{array}$ & Statistical method & Effect size \\
\hline $\begin{array}{l}1 \text { Nail score improvement after } \\
\text { short-term treatment duration }\end{array}$ & 1 & & Mean Difference (IV, Random, 95\% CI) & Subtotals only \\
\hline
\end{tabular}


Comparison 9. (Systemic) methotrexate versus ciclosporin

\begin{tabular}{|c|c|c|c|c|}
\hline Outcome or subgroup title & $\begin{array}{l}\text { No. of } \\
\text { studies }\end{array}$ & $\begin{array}{c}\text { No. of } \\
\text { participants }\end{array}$ & Statistical method & Effect size \\
\hline $\begin{array}{l}1 \text { Nail score improvement after } \\
\text { medium-term treatment } \\
\text { duration }\end{array}$ & 1 & & Mean Difference (IV, Random, 95\% CI) & Subtotals only \\
\hline
\end{tabular}

Analysis I.I. Comparison I (Systemic) ciclosporin $2.5 \mathrm{mg} / \mathrm{kg}$ vs topical dithranol + salicylic acid + UVB, Outcome I Participants with at least $50 \%$ nail score improvement after short-term treatment duration.

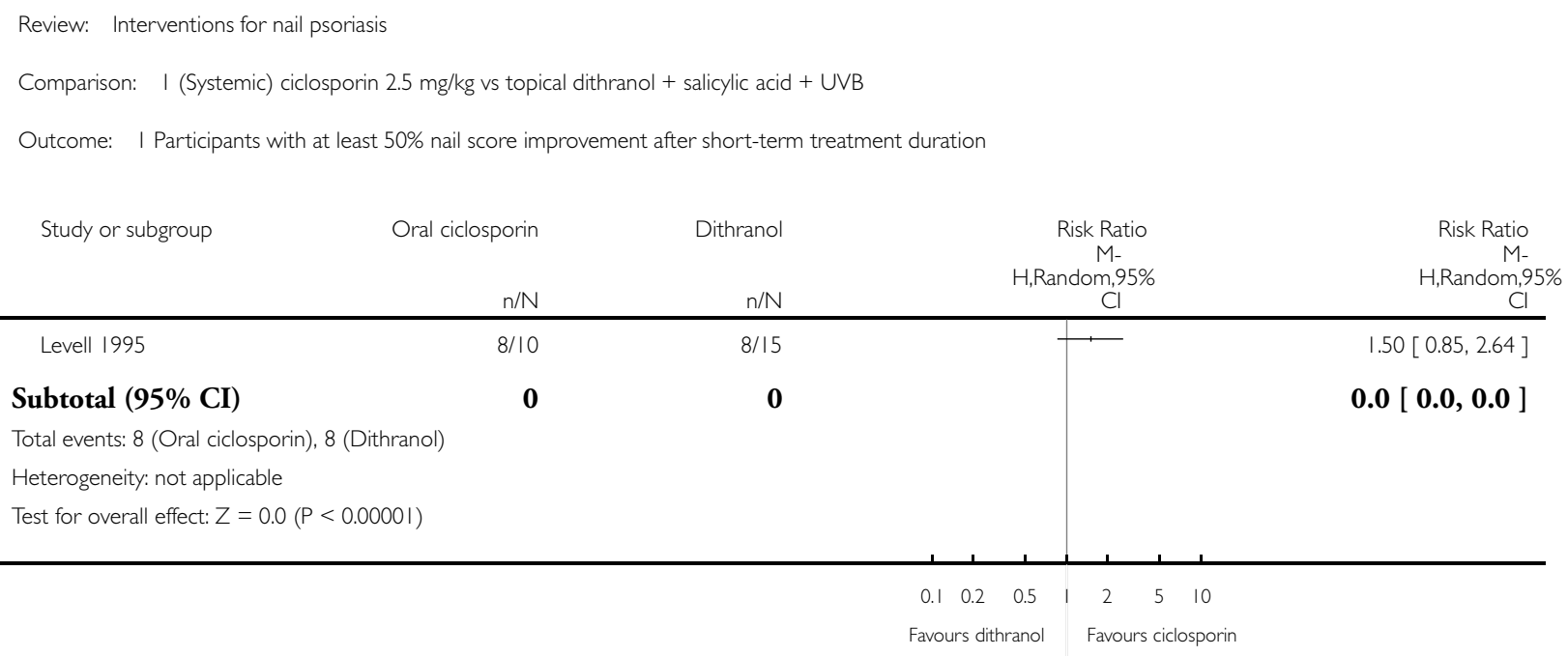


Analysis 2.I. Comparison 2 (Topical) ciclosporin $\mathbf{7 0 \%}$ in maize oil vs maize oil, Outcome I Participants with at least $\mathbf{5 0 \%}$ nail score improvement after short-term treatment duration.

Review: Interventions for nail psoriasis

Comparison: 2 (Topical) ciclosporin $70 \%$ in maize oil vs maize oil

Outcome: I Participants with at least 50\% nail score improvement after short-term treatment duration

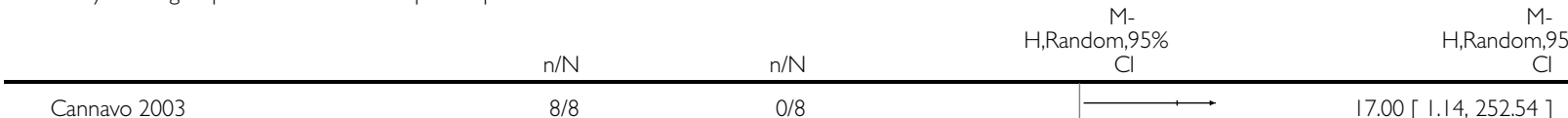

Cannavo 2003

Subtotal (95\% CI)

Total events: 8 (Top ciclosporin 70\%), 0 (Maize oil)

Heterogeneity: not applicable

Test for overall effect: $Z=0.0(P<0.0000$ I $)$

$8 / 8 \quad 0 / 8$

$17.00[1.14,252.54]$

$\mathbf{0}$

0

$0.0[0.0,0.0]$

0

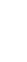

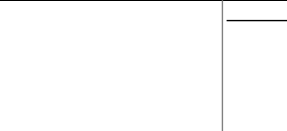

$10 \quad 50$

Favours maize oil

Favours top. ciclosporin

Analysis 3.I. Comparison 3 (Topical) calcipotriol $\mathbf{0 . 0 0 5} \%$ vs calcipotriol $\mathbf{0 . 0 0 5} \%+\mathbf{0 . 0 5} \%$ betamethasone dipropionate, Outcome I Participants with at least 50\% nail score improvement after short-term treatment duration.

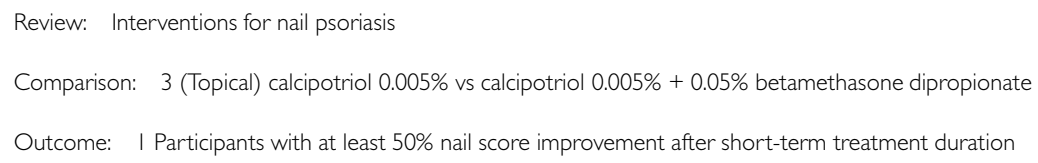

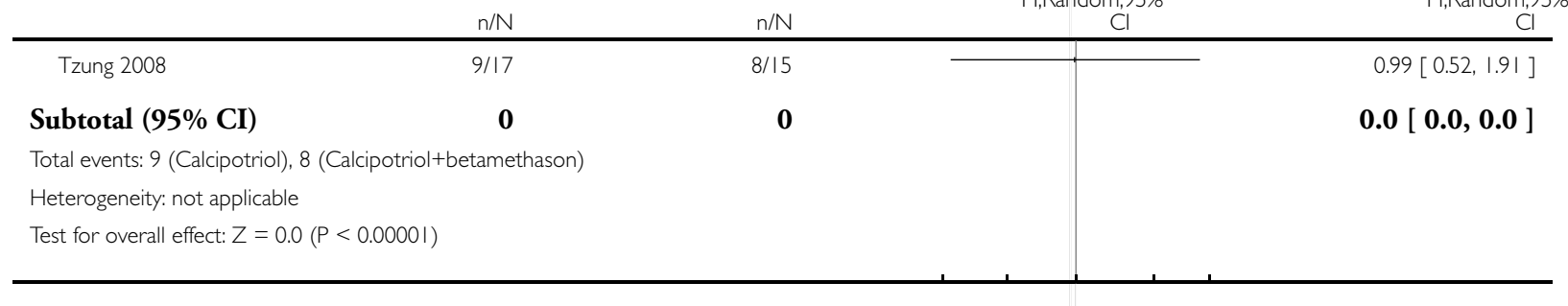


Analysis 4.I. Comparison 4 Topical - Systemic - Radiotherapy, Outcome I Participants with adverse effects (AE).

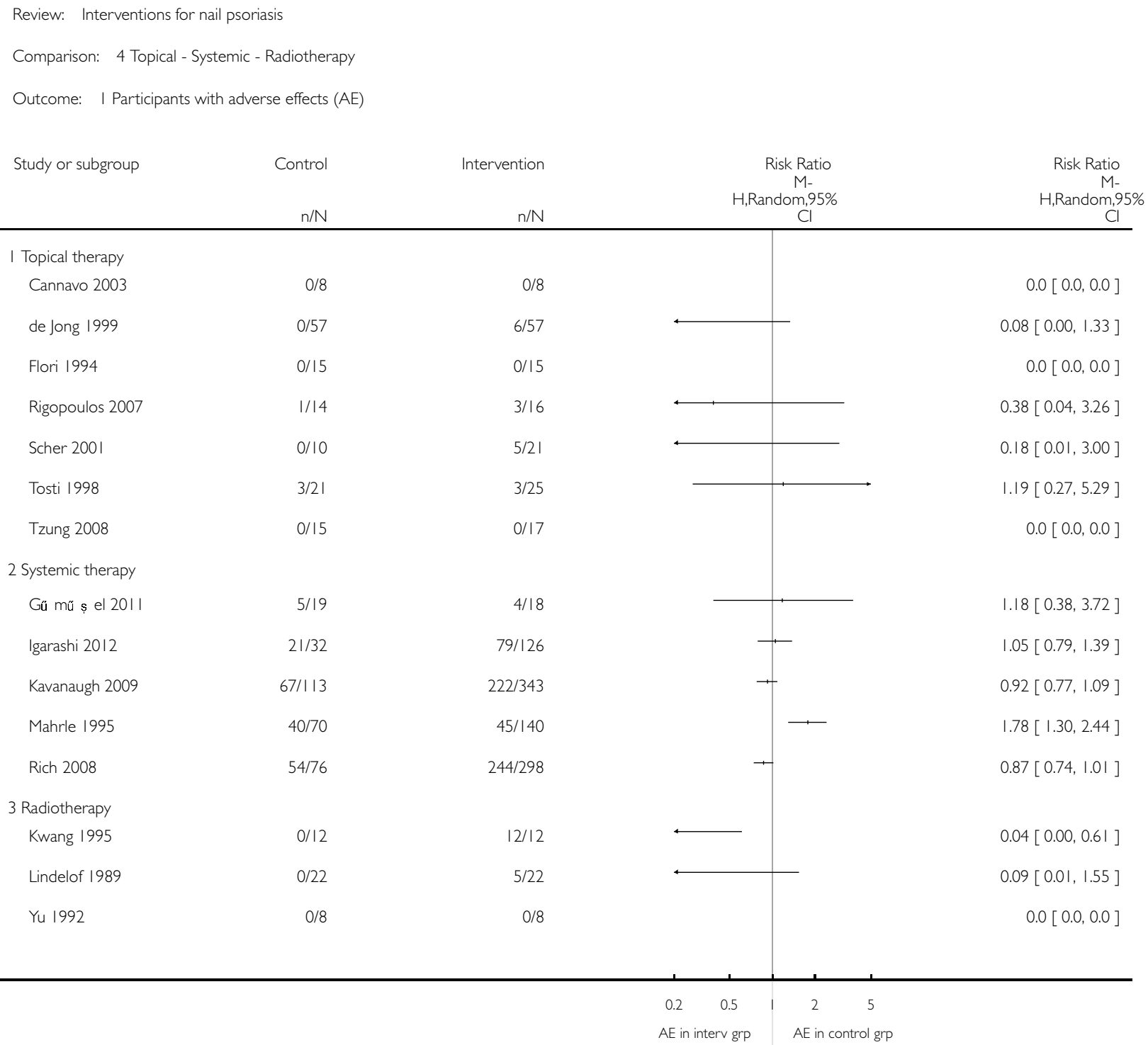


Analysis 5.I. Comparison 5 (Topical) calcipotriol $50 \mathrm{ug} / \mathrm{g}$ vs betamethasone dipropionate $64 \mathrm{mg} / \mathrm{g}+\mathrm{salicylic}$ acid $0.03 \mathrm{~g} / \mathrm{g}$, Outcome I Participants with at least $\mathbf{5 0 \%}$ nail score improvement after short-term treatment duration.

Review: Interventions for nail psoriasis

Comparison: 5 (Topical) calcipotriol 50 ug/g vs betamethasone dipropionate 64 mg/g + salicylic acid 0.03 g/g

Outcome: I Participants with at least 50\% nail score improvement after short-term treatment duration

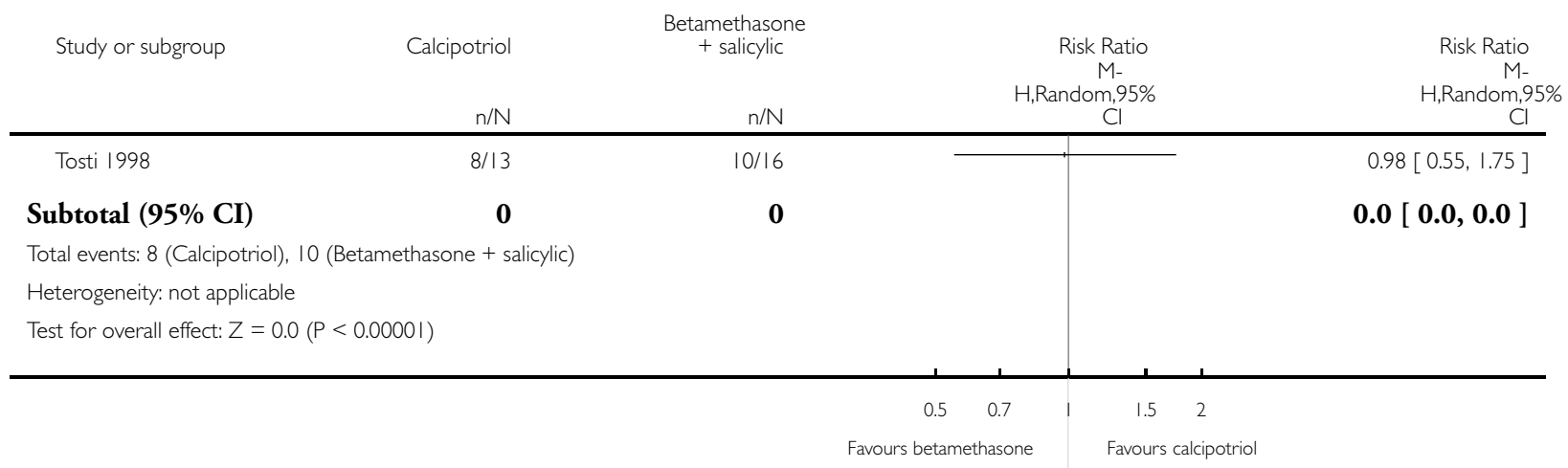

Analysis 5.2. Comparison 5 (Topical) calcipotriol $50 \mathrm{ug} / \mathrm{g}$ vs betamethasone dipropionate $64 \mathrm{mg} / \mathrm{g}+\mathrm{salicylic}$ acid $\mathbf{0 . 0 3} \mathbf{g} / \mathrm{g}$, Outcome 2 Nail score improvement after short-term treatment duration.

Review: Interventions for nail psoriasis

Comparison: 5 (Topical) calcipotriol 50 ug/g vs betamethasone dipropionate 64 mg/g + salicylic acid 0.03 g/g

Outcome: 2 Nail score improvement after short-term treatment duration

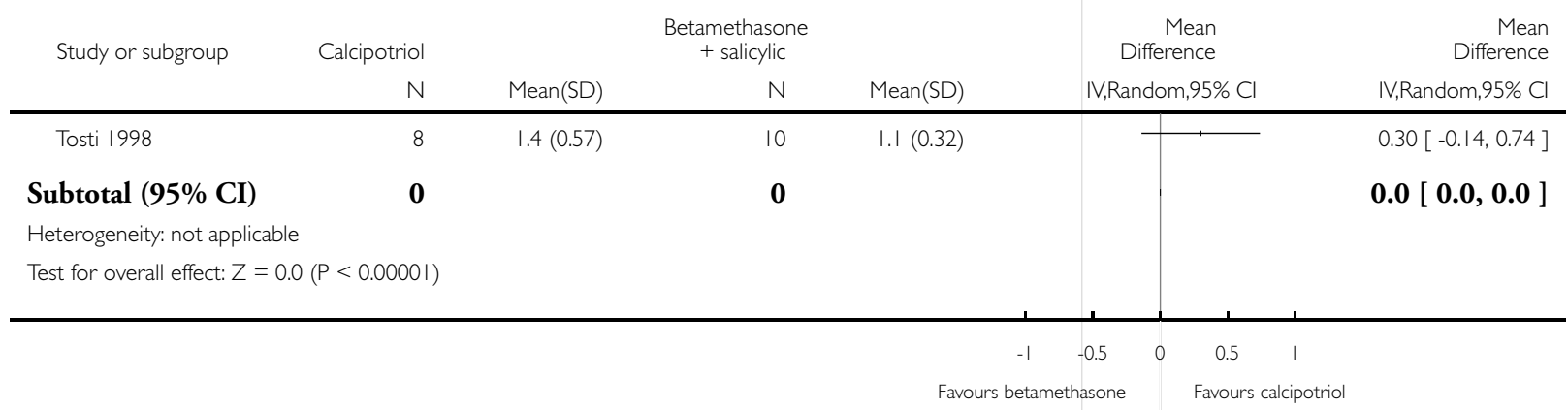

Interventions for nail psoriasis (Review)

Copyright @ 2013 The Cochrane Collaboration. Published by John Wiley \& Sons, Ltd. 
Analysis 6.I. Comparison 6 (Systemic) ustekinumab 45 mg versus placebo, Outcome I Nail score improvement after short-term treatment duration.

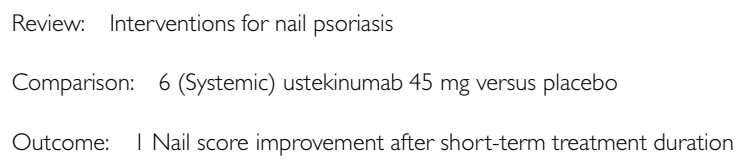

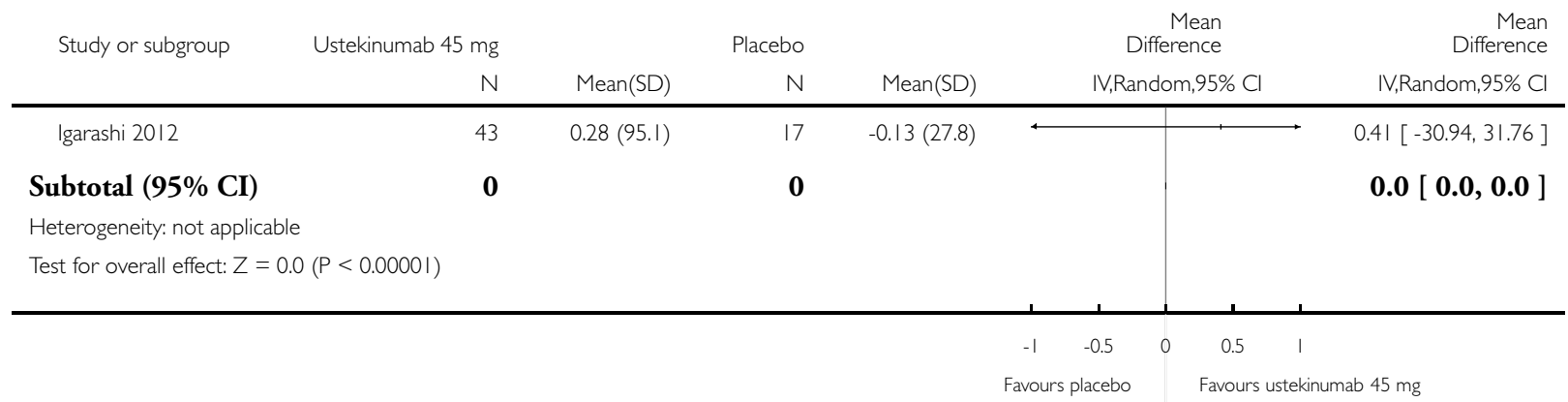

Analysis 7.I. Comparison 7 (Systemic) ustekinumab $90 \mathrm{mg}$ versus placebo, Outcome I Nail score improvement after short-term treatment duration.

Review: Interventions for nail psoriasis

Comparison: 7 (Systemic) ustekinumab 90 mg versus placebo

Outcome: I Nail score improvement after short-term treatment duration

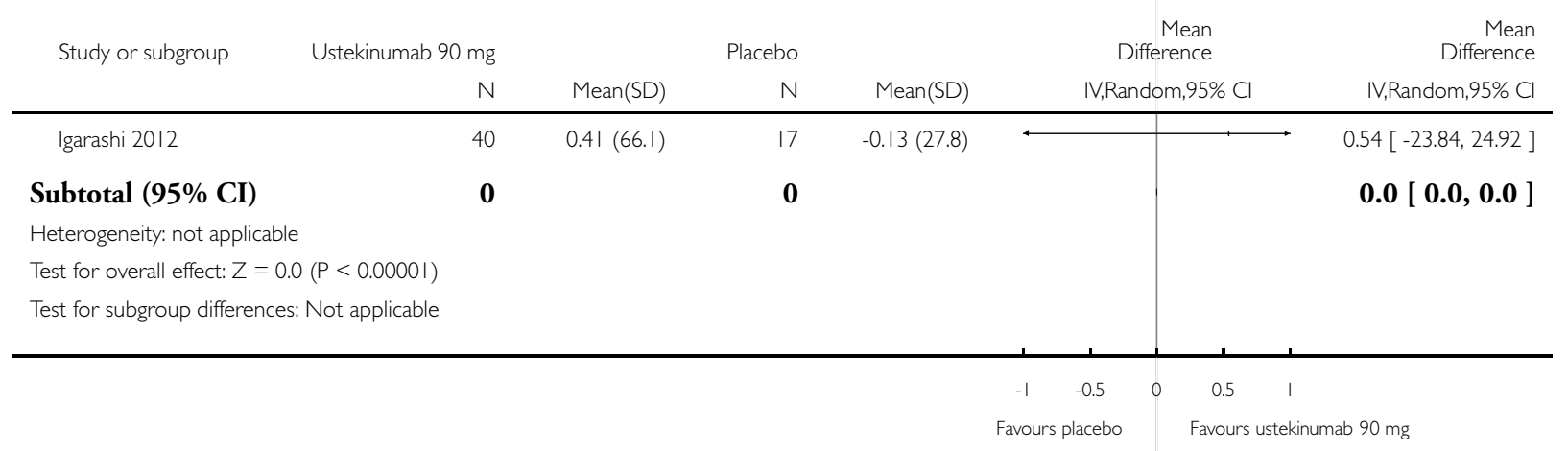


Analysis 8. I. Comparison 8 (Systemic) ustekinumab $45 \mathrm{mg}$ versus $90 \mathrm{mg}$, Outcome I Nail score improvement after short-term treatment duration.

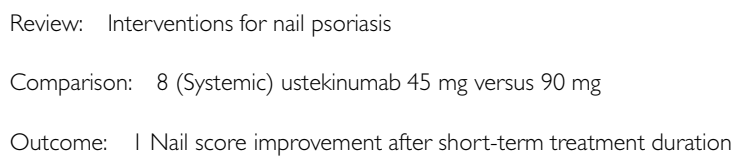

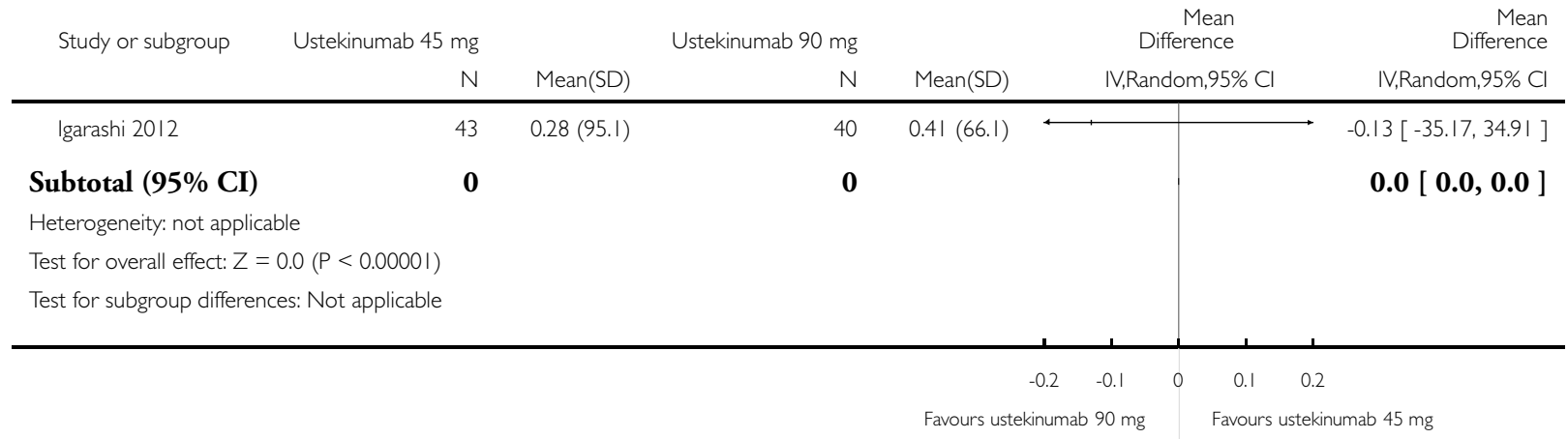

\section{Analysis 9.1. Comparison 9 (Systemic) methotrexate versus ciclosporin, Outcome I Nail score improvement after medium-term treatment duration.}

Review: Interventions for nail psoriasis

Comparison: 9 (Systemic) methotrexate versus ciclosporin

Outcome: I Nail score improvement after medium-term treatment duration

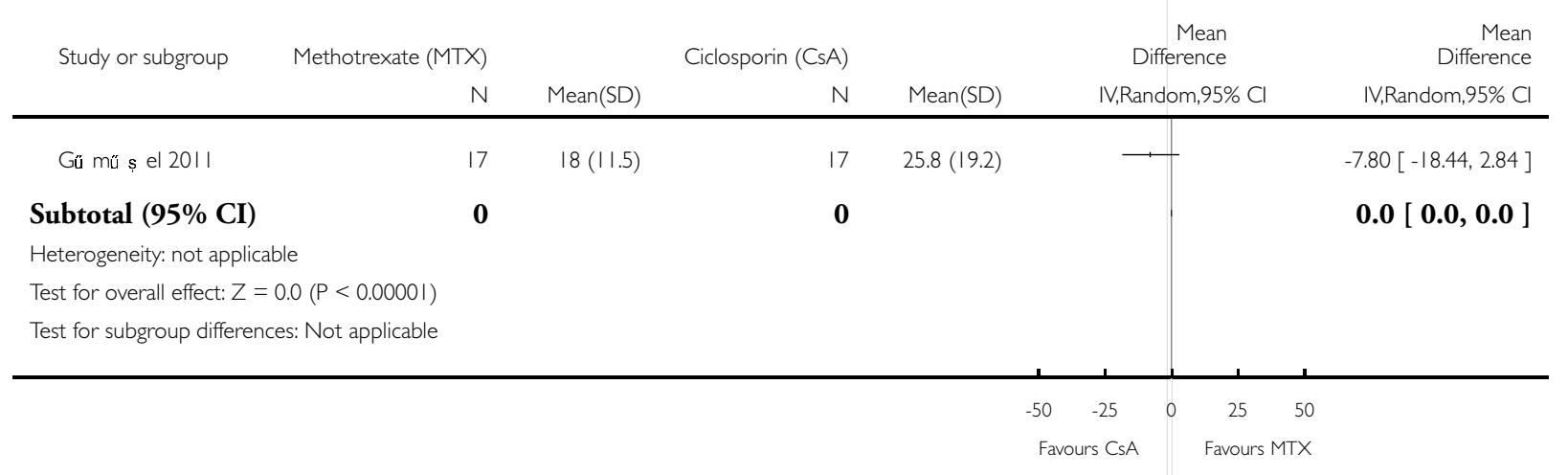


ADDITIONAL TABLES

Table 1. Glossary of terms

\begin{tabular}{|c|c|}
\hline Term & Definition \\
\hline Arthritis-psoriatica & $\begin{array}{l}\text { Inflammation of } 1 \text { or more joints (oligo- or poly-arthritis) closely } \\
\text { associated with skin psoriasis, nail changes, or both }\end{array}$ \\
\hline Carry-over effect & $\begin{array}{l}\text { The treatment effect will be affected, depending upon the order } \\
\text { in which they were received. Carry-over treatment effect across } \\
\text { periods }\end{array}$ \\
\hline Distal portion of the nail matrix & $\begin{array}{l}\text { The closest part of the nail matrix (ground substance of the nail) } \\
\text { to the body }\end{array}$ \\
\hline Erythematous & Flushing of the skin due to dilatation of the blood capillaries \\
\hline Exocytosis & The appearance of migrating inflammatory cells in the epidermis \\
\hline Koebner phenomenon & Lesions appearing on lines of trauma or other triggers \\
\hline Lunula & Nail moon \\
\hline Nail dystrophy & Destruction of the nail plate \\
\hline Onicolisi/Onycholysis & Separation or loosening of part or all of a nail from its bed \\
\hline Onicoressi & Fragile nails with thin longitudinal tracks \\
\hline Onycholysis & Separation or loosening of part or all of a nail from its bed \\
\hline Onychomadesis & Loosening of the nail from the nail bed \\
\hline Onychorrhexis & Longitudinal grooves that can split to the nail bed \\
\hline Parakeratotic foci & $\begin{array}{l}\text { Parts of the horny layer of the upper skin in which cells still contain } \\
\text { nuclei }\end{array}$ \\
\hline $\begin{array}{l}\text { Parakeratosis pustulosa, acropustulosis keratotica, acroder- } \\
\text { matitis continua of Hallopeau }\end{array}$ & Other nail diseases partly resembling nail psoriasis \\
\hline Paronychia & An inflamed swelling of the nail fold \\
\hline Psoriasis & $\begin{array}{l}\text { A chronic inflammatory skin disease characterised by thickened } \\
\text { patches, inflamed, red skin covered with thick, silvery scales }\end{array}$ \\
\hline Salmon patches & A dyschromia/discolouration of the nails resembling an oil patch \\
\hline
\end{tabular}

Interventions for nail psoriasis (Review) 
Table 1. Glossary of terms (Continued)

Subungal hyperkeratosis or subungual keratosis

Thickening of the outer horny layer of the skin underneath the nail

Table 2. Abbreviations

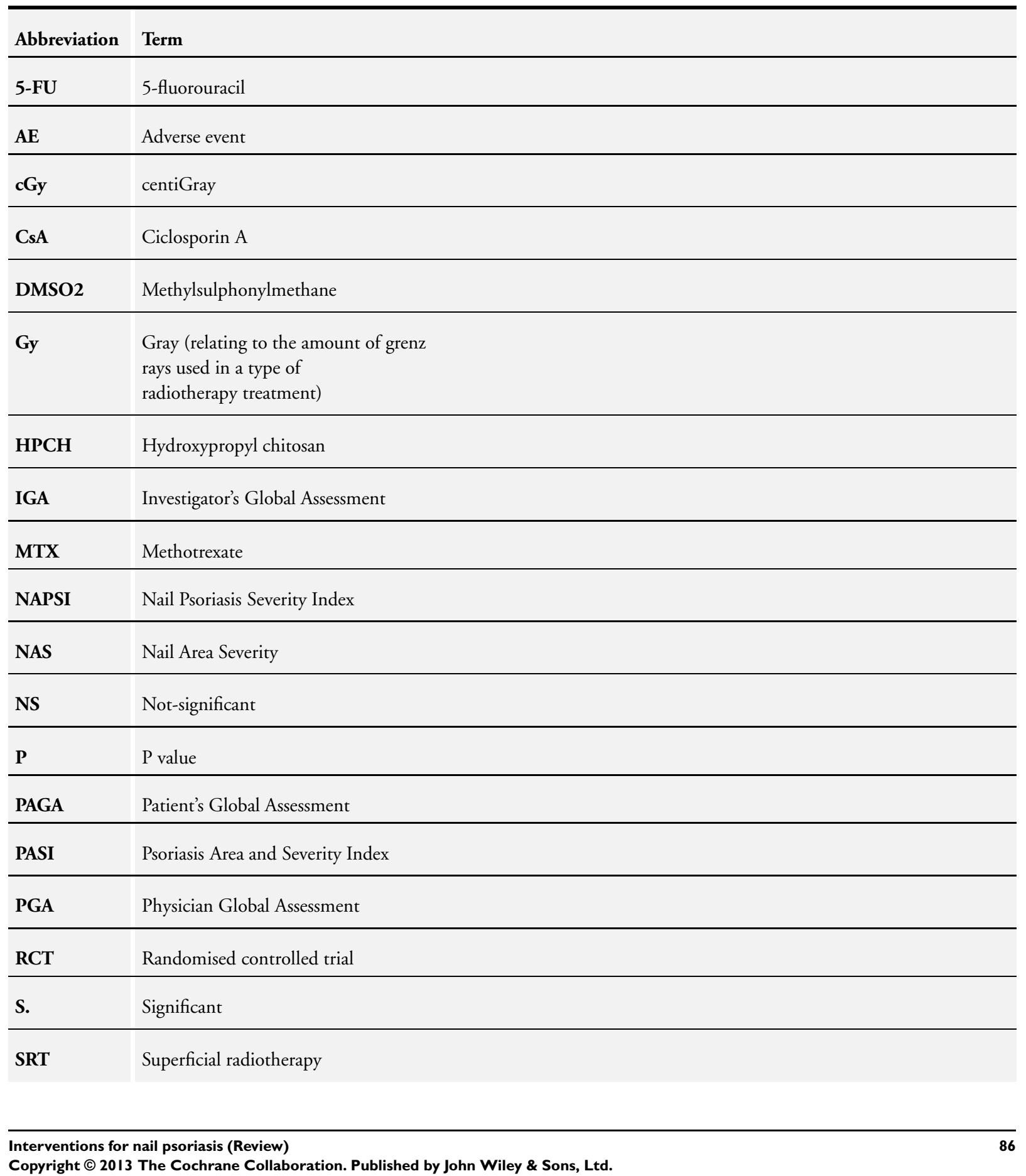


Table 2. Abbreviations (Continued)

VS Versus

Table 3. Basic characteristics

\begin{tabular}{|c|c|c|c|c|c|c|c|c|c|c|c|}
\hline Author & Year & $\begin{array}{l}\text { Inter- } \\
\text { vention }\end{array}$ & $\begin{array}{l}\text { Com- } \\
\text { parison }\end{array}$ & $\begin{array}{l}\text { Applica- } \\
\text { tion }\end{array}$ & $\begin{array}{l}\text { Treat- } \\
\text { ment } \\
\text { dura- } \\
\text { tion }\end{array}$ & $\begin{array}{l}\text { Follow- } \\
\text { up }\end{array}$ & $\mathbf{N}$ & $\begin{array}{l}\text { Inter- } \\
\text { nally- } \\
\text { con- } \\
\text { trolled } \\
\text { study }\end{array}$ & $\begin{array}{l}\text { Primary } \\
\text { outcome }\end{array}$ & $\begin{array}{l}\text { Sec- } \\
\text { ondary } \\
\text { outcome }\end{array}$ & $\begin{array}{l}\text { Level of } \\
\text { evidence }\end{array}$ \\
\hline \multicolumn{12}{|c|}{ Topical therapy } \\
\hline Baran & 1999 & $\begin{array}{l}\text { Topical } \\
8 \% \text { clo- } \\
\text { betasol }\end{array}$ & $\begin{array}{l}\text { Placebo } \\
\text { lacquer }\end{array}$ & $\begin{array}{l}\text { Once } \\
\text { daily }\end{array}$ & $\begin{array}{l}1,2 \text { to } 6, \\
6 \\
\text { months, } \\
\text { aver- } \\
\text { age } 2,5 \\
\text { months }\end{array}$ & No & 18 & Yes & 1 & 3 & B \\
\hline Baran & 1999a & $\begin{array}{l}\text { Topical } \\
8 \% \text { clo- } \\
\text { betasol }\end{array}$ & $\begin{array}{l}\text { Placebo } \\
\text { lacquer }\end{array}$ & $\begin{array}{l}\text { 1st week } \\
\text { once } \\
\text { daily, } \\
\text { onwards } \\
2 \text { or } 3 \\
\text { times } \\
\text { weekly }\end{array}$ & $\begin{array}{l}5, \\
1 \text { to } 8,9 \\
\text { months, } \\
\text { aver- } \\
\text { age } 7,0 \\
\text { months }\end{array}$ & No & 27 & Yes & 1 & 3 & B \\
\hline $\begin{array}{l}\text { Can- } \\
\text { navo }\end{array}$ & 2003 & $\begin{array}{l}\text { Topical } \\
\text { ci- } \\
\text { closporin } \\
70 \% \text { in } \\
\text { maize oil }\end{array}$ & Maisoil & $\begin{array}{l}\text { Twice } \\
\text { daily }\end{array}$ & $\begin{array}{l}12 \text { weeks } \\
\text { (3 } \\
\text { months) }\end{array}$ & 8 weeks & 16 & No & 1,3 & $1,2,3$ & A2 \\
\hline de Jong & 1999 & $\begin{array}{l}1 \% \quad 5- \\
\text { fluo- } \\
\text { rouracil } \\
\text { in Be- } \\
\text { lanyx }{ }^{\circledR} \\
\text { lotion }\end{array}$ & $\begin{array}{l}\text { Be- } \\
\text { lanyx® } \\
\text { lotion }\end{array}$ & $\begin{array}{l}\text { Once } \\
\text { daily, } \\
\text { under } \\
\text { occlu- } \\
\text { sion }\end{array}$ & $\begin{array}{l}12 \text { weeks } \\
(3 \\
\text { months) }\end{array}$ & 4 weeks & 57 & Yes & $1,2,3$ & 1,3 & $\mathrm{~A} 2$ \\
\hline Flori & 1994 & $\begin{array}{l}\text { Hyaluroni, } \\
\text { acid + } \\
\text { chon- } \\
\text { droitin } \\
\text { sul- } \\
\text { phates }\end{array}$ & Placebo & $\begin{array}{l}\text { Gel in } \\
\text { the } \\
\text { morn- } \\
\text { ing, mi- } \\
\text { cro } \\
\text { emul- } \\
\text { sion at } \\
\text { night }\end{array}$ & $\begin{array}{l}90 \text { days } \\
(3 \\
\text { months })\end{array}$ & No & 30 & No & 1 & 1,3 & A2/B \\
\hline
\end{tabular}


Table 3. Basic characteristics

(Continued)

\begin{tabular}{|c|c|c|c|c|c|c|c|c|c|c|c|}
\hline $\begin{array}{l}\text { Rigopou- } \\
\text { los }\end{array}$ & 2007 & $\begin{array}{l}\text { Tazarotene } \\
0.1 \% \\
\text { cream }\end{array}$ & $\begin{array}{l}\text { Clobeta- } \\
\text { sol pro- } \\
\text { pionate } \\
0.05 \%\end{array}$ & $\begin{array}{l}\text { Once } \\
\text { daily un- } \\
\text { der oc- } \\
\text { clusion }\end{array}$ & $\begin{array}{l}12 \text { weeks } \\
\text { ( } 3 \\
\text { months) }\end{array}$ & 12 weeks & 46 & No & 2 & 1,3 & $\mathrm{~A} 2$ \\
\hline Scher & 2001 & $\begin{array}{l}\text { Tazarotene } \\
0.1 \% \text { gel }\end{array}$ & $\begin{array}{l}\text { Vehicle } \\
\text { gel }\end{array}$ & $\begin{array}{l}\text { Once } \\
\text { daily, } \\
\text { one tar- } \\
\text { get } \\
\text { nail un- } \\
\text { der oc- } \\
\text { clusion }\end{array}$ & $\begin{array}{l}24 \text { weeks } \\
\text { (6 } \\
\text { months) }\end{array}$ & No & 31 & No & 1 & 1,3 & $\mathrm{~A} 2 / \mathrm{B}$ \\
\hline Tosti & 1998 & $\begin{array}{l}\text { Cal- } \\
\text { cipotriol } \\
50 \mathrm{ug} / \mathrm{g}\end{array}$ & $\begin{array}{l}\text { Be- } \\
\text { tametha- } \\
\text { son } \\
\text { dipropi- } \\
\text { onate } 64 \\
\mathrm{mg} / \\
\mathrm{g}+\text { sali- } \\
\text { cylic acid } \\
0.03 \mathrm{~g} / \mathrm{g}\end{array}$ & $\begin{array}{l}\text { Twice } \\
\text { daily }\end{array}$ & $\begin{array}{l}3 \text { to } 5 \\
\text { months }\end{array}$ & 1 month & 58 & No & 3 & 1,3 & B \\
\hline Tzung & 2008 & $\begin{array}{l}\text { Cal- } \\
\text { cipotriol } \\
0.005 \%\end{array}$ & $\begin{array}{l}\text { Cal- } \\
\text { cipotriol } \\
0.005 \% \\
+\quad \text { be- } \\
\text { tametha- } \\
\text { sone } \\
\text { dipropi- } \\
\text { onate } 0 . \\
05 \%\end{array}$ & $\begin{array}{l}\text { Cal- } \\
\text { cipotriol } \\
\text { twice } \\
\text { daily } \\
\text { with be- } \\
\text { tametha- } \\
\text { sone } \\
\text { once } \\
\text { daily }\end{array}$ & $\begin{array}{l}12 \text { weeks } \\
(3 \\
\text { months) }\end{array}$ & No & 40 & No & $1,2,3$ & 1,3 & B \\
\hline \multicolumn{12}{|c|}{ Systemic therapy } \\
\hline $\begin{array}{l}\text { Gü mũ } \\
\text { ș el }\end{array}$ & 2011 & $\begin{array}{l}\text { Methotrex } \\
\text { ate } 15 \\
\text { mg }\end{array}$ & $\begin{array}{l}\text { Ci- } \\
\text { closporin } \\
5 \mathrm{mg} / \mathrm{kg}\end{array}$ & $\begin{array}{l}\text { MTX: } \\
\text { sin- } \\
\text { gle dose } \\
\text { weekly } \\
\text { subcuta- } \\
\text { neous. } \\
\text { After } 3 \\
\text { months } \\
\text { de- } \\
\text { crease to } \\
10 \text { mg/ } \\
\text { week } \\
\text { CsA: }\end{array}$ & 24 weeks & 12 weeks & 37 & No & $1,2,3$ & 1 & A2 \\
\hline
\end{tabular}


Table 3. Basic characteristics

\begin{tabular}{|c|c|c|c|c|c|c|c|c|c|c|c|}
\hline & & & & $\begin{array}{l}\text { daily (di- } \\
\text { vided } \\
\text { into } \\
2 \text { doses) } \\
\text {, after } 3 \\
\text { months } \\
\text { de- } \\
\text { crease to } \\
2.5 \text { to } 3 \text {. } \\
5 \mathrm{mg} / \mathrm{kg} / \\
\text { day }\end{array}$ & & & & & & & \\
\hline Levell & 1995 & $\begin{array}{l}\text { Systemic } \\
\text { ci- } \\
\text { closporin } \\
2.5 \mathrm{mg} / \\
\mathrm{kg}\end{array}$ & $\begin{array}{l}\text { Topical } \\
\text { dithra- } \\
\text { nol } 2 \% \\
\text { to } 8 \%+ \\
0 . \\
5 \% \text { sali- } \\
\text { cylic acid } \\
+ \text { UVB }\end{array}$ & $\begin{array}{l}\text { CsA: } 2 \\
\text { daily } \\
\text { doses. } \\
\text { Dith: } \\
\text { once } \\
\text { daily for } \\
15 \text { min- } \\
\text { utes pre- } \\
\text { ceded by } \\
\text { UVB }\end{array}$ & $\begin{array}{l}\text { Up to } 16 \\
\text { weeks (4 } \\
\text { months) } \\
\text { until } \\
\text { clear }\end{array}$ & $\begin{array}{l}\text { Up to } 8 \\
\text { months }\end{array}$ & 29 & No & 1 & 1 & A $2 / B$ \\
\hline Mahrle & 1995 & $\begin{array}{l}\text { Systemic } \\
\text { ci- } \\
\text { closporin } \\
2.5 \mathrm{mg} / \\
\mathrm{kg}\end{array}$ & $\begin{array}{l}\text { Etreti- } \\
\text { nate } 0.5 \\
\mathrm{mg} / \mathrm{kg}\end{array}$ & $\begin{array}{l}\text { Once } \\
\text { daily }\end{array}$ & $\begin{array}{l}22 \text { weeks } \\
(5, \quad 5 \\
\text { months) }\end{array}$ & 4 weeks & 137 & No & 1 & 1 & B \\
\hline
\end{tabular}

\section{Biological therapy}

\begin{tabular}{|c|c|c|c|c|c|c|c|c|c|c|c|}
\hline Igarashi & 2012 & $\begin{array}{l}\text { Ustek- } \\
\text { inumab } \\
45 \mathrm{mg} \text { or } \\
90 \mathrm{mg}\end{array}$ & Placebo & $\begin{array}{l}\text { Subcuta- } \\
\text { neous in- } \\
\text { jection } \\
\text { week } 0 \text {, } \\
4 \text {, every } \\
12 \text { weeks }\end{array}$ & 64 weeks & 8 weeks & 102 & No & 2 & 1 & A2 \\
\hline $\begin{array}{l}\text { Ka- } \\
\text { vanaugh }\end{array}$ & 2009 & $\begin{array}{l}\text { Goli- } \\
\text { mumab } \\
50 \mathrm{mg} \text { or } \\
100 \mathrm{mg}\end{array}$ & Placebo & $\begin{array}{l}\text { Subcuta- } \\
\text { neous in- } \\
\text { jection } \\
\text { every } 4 \\
\text { weeks }\end{array}$ & $\begin{array}{l}20 \text { weeks } \\
(5 \\
\text { months) }\end{array}$ & 4 weeks & 287 & No & 1,2 & 1 & B \\
\hline Rich & 2008 & $\begin{array}{l}\text { Inflix- } \\
\text { imab } 5 \\
\mathrm{mg} / \mathrm{kg}\end{array}$ & Placebo & $\begin{array}{l}\text { In- } \\
\text { fusion at } \\
\text { week } 0 \text {, } \\
2,6 \text { and } \\
\text { every }\end{array}$ & $\begin{array}{l}46 \text { weeks } \\
(11, \quad 5 \\
\text { months })\end{array}$ & 4 weeks & 305 & No & 2 & 1,3 & A2 \\
\hline
\end{tabular}


Table 3. Basic characteristics (Continued)

8 weeks

onward

\begin{tabular}{|c|c|c|c|c|c|c|c|c|c|c|c|}
\hline \multicolumn{12}{|c|}{ Radiotherapy } \\
\hline Kwang & 1995 & $\begin{array}{l}\text { Electron } \\
\text { beam } 0 . \\
75 \mathrm{~Gy}\end{array}$ & Placebo & $\begin{array}{l}0.75 \text { Gy } \\
\text { per week } \\
\text { (total } 6 \\
\text { Gy) }\end{array}$ & $\begin{array}{l}8 \\
\text { weeks (2 } \\
\text { months) }\end{array}$ & $\begin{array}{l}12 \\
\text { months }\end{array}$ & 12 & Yes & 1 & 1,3 & B \\
\hline $\begin{array}{l}\text { Linde- } \\
\text { lof }\end{array}$ & 1989 & $\begin{array}{l}\text { Grenz } \\
\text { rays } 5 \mathrm{~Gy}\end{array}$ & Placebo & $\begin{array}{l}5 \\
\text { Gy once } \\
\text { a week }\end{array}$ & $\begin{array}{l}10 \text { weeks } \\
(2, \quad 5 \\
\text { months })\end{array}$ & $\begin{array}{l}6 \\
\text { months }\end{array}$ & 24 & Yes & 1 & 1 & $\mathrm{~A} 2 / \mathrm{B}$ \\
\hline Yu & 1992 & $\begin{array}{l}\text { Super- } \\
\text { ficial ra- } \\
\text { diother- } \\
\text { apy } 450 \\
\text { cGy }\end{array}$ & $\begin{array}{l}\text { 'Sham } \\
\text { radio- } \\
\text { therapy' }\end{array}$ & $\begin{array}{l}\text { Fort- } \\
\text { nightly }\end{array}$ & $\begin{array}{l}14 \\
\text { days (1/2 } \\
\text { month) }\end{array}$ & 18 weeks & 10 & Yes & 1 & 1,3 & B \\
\hline
\end{tabular}

Primary outcomes

(a) Global improvement of nail psoriasis as rated by a clinician

(b) Improvement of nail psoriasis scores (NAS, NAPSI)

(c) Improvement of nail psoriasis in the participant's opinion

Secondary outcomes

(a) Adverse effects (and serious adverse effects, i.e. serious enough to require withdrawal of the treatment)

(b) Effects on quality of life

(c) Improvement in nail features, pain score, nail thickness, thickness of subungual hyperkeratosis, number of affected nails, and nail growth

Level of evidence

A2: Randomised controlled trial of good quality (adequate control group, good study design, size of the study, consistence)

B: Randomised clinical trial of low quality

Table 4. Finger nail severity and improvement

\begin{tabular}{|c|c|c|c|c|c|c|c|c|c|c|c|}
\hline & & \multicolumn{9}{|c|}{ Mean \% score improvement after treatment } & \multirow{3}{*}{$\begin{array}{l}\text { Time of } \\
\text { assess- } \\
\text { ment }\end{array}$} \\
\hline & & \multirow{2}{*}{$\begin{array}{l}\text { Baseline } \\
\text { score }\end{array}$} & \multicolumn{4}{|c|}{ Short-term treatment } & \multicolumn{4}{|c|}{ Medium-term treatment } & \\
\hline & & & \multicolumn{2}{|c|}{ Moderate } & \multicolumn{2}{|l|}{ Good } & \multicolumn{2}{|c|}{ Moderate } & \multicolumn{2}{|l|}{ Good } & \\
\hline Study & Year & & $\begin{array}{l}\text { Inter- } \\
\text { vention }\end{array}$ & $\begin{array}{l}\text { Com- } \\
\text { parison }\end{array}$ & $\begin{array}{l}\text { Inter- } \\
\text { vention }\end{array}$ & $\begin{array}{l}\text { Com- } \\
\text { parison }\end{array}$ & $\begin{array}{l}\text { Inter- } \\
\text { vention }\end{array}$ & $\begin{array}{l}\text { Com- } \\
\text { parison }\end{array}$ & $\begin{array}{l}\text { Inter- } \\
\text { vention }\end{array}$ & $\begin{array}{l}\text { Com- } \\
\text { parison }\end{array}$ & \\
\hline
\end{tabular}

Topical

therapy

Interventions for nail psoriasis (Review)

Copyright @ 2013 The Cochrane Collaboration. Published by John Wiley \& Sons, Ltd. 
Table 4. Finger nail severity and improvement (Continued)

\begin{tabular}{|c|c|c|c|c|c|c|c|c|c|c|}
\hline $\begin{array}{l}\text { Baran: } \\
\text { Topical } \\
\text { clobe- } \\
\text { tasol vs } \\
\text { placebo } \\
\text { lacquer }\end{array}$ & 1999 & No score & $\begin{array}{l}61.5(\mathrm{n}= \\
16)\end{array}$ & $\begin{array}{l}7.7(\mathrm{n}= \\
2)\end{array}$ & - & - & - & - & - & $\begin{array}{l}\text { Av- } \\
\text { erage } 2,5 \\
\text { months } \\
\text { (1.2 to } 6 . \\
6 \\
\text { months) }\end{array}$ \\
\hline $\begin{array}{l}\text { Baran: } \\
\text { Topical } \\
\text { clobe- } \\
\text { tasol vs } \\
\text { placebo } \\
\text { lacquer }\end{array}$ & $1999 a$ & No score & - & - & - & - & $\begin{array}{l}53.3(\mathrm{n}= \\
8)\end{array}$ & $\begin{array}{l}26.7(n= \\
4)\end{array}$ & - & $\begin{array}{l}\text { Average } \\
7 \\
\text { months } \\
\text { (5.1 to } 8 . \\
9 \\
\text { months) }\end{array}$ \\
\hline $\begin{array}{l}\text { Can- } \\
\text { navo: } \\
\text { Topical } \\
\text { ci- } \\
\text { closporin } \\
70 \% \text { in } \\
\text { maize } \\
\text { oil vs } \\
\text { maize } \\
\text { oil }\end{array}$ & 2003 & Both 8 & - & - & $\begin{array}{l}77.0(\mathrm{n}= \\
8)^{s b}\end{array}$ & $\begin{array}{l}12.0(\mathrm{n}= \\
8)^{n s b}\end{array}$ & - & - & - & 12 weeks \\
\hline $\begin{array}{l}\text { de Jong: } \\
\text { 5-fluo- } \\
\text { rouracil } \\
\text { in Be- } \\
\text { lanyx® } \\
\text { lotion } \\
\text { vs Be- } \\
\text { lanyx }{ }^{\circledR} \\
\text { lotion }\end{array}$ & 1999 & $\begin{array}{l}7.1 \text { vs } 7 . \\
1\end{array}$ & $\begin{array}{l}32.0(\mathrm{n}= \\
57)^{n s, s b}\end{array}$ & $\begin{array}{l}39.0(\mathrm{n}= \\
57)^{n s, s b}\end{array}$ & - & - & - & - & - & 12 weeks \\
\hline $\begin{array}{l}\text { Flori: } \\
\text { Hyaluron } \\
\text { acid + } \\
\text { chon- } \\
\text { droitin } \\
\text { sul- } \\
\text { phates } \\
\text { vs } \\
\text { placebo }\end{array}$ & 1994 & $\begin{array}{l}1.6 \text { vs } 1 \text {. } \\
6\end{array}$ & $\begin{array}{l}55.4(\mathrm{n}= \\
15)\end{array}$ & $\begin{array}{l}23.9(\mathrm{n}= \\
15)\end{array}$ & - & - & - & - & - & 90 days \\
\hline $\begin{array}{l}\text { Rigopou- } \\
\text { los: }\end{array}$ & 2007 & $\begin{array}{l}1.5 \text { vs } 1 \text {. } \\
4\end{array}$ & - & - & $\begin{array}{l}75.0(\mathrm{n}= \\
16)^{n s, s b}\end{array}$ & $\begin{array}{l}68.0(\mathrm{n}= \\
14)^{n s, s b}\end{array}$ & - & - & - & 12 weeks \\
\hline
\end{tabular}


Table 4. Finger nail severity and improvement (Continued)

\begin{tabular}{|c|c|c|c|c|c|c|c|c|c|}
\hline $\begin{array}{l}\text { Tazaroter } \\
\text { cream } \\
\text { vs clo- } \\
\text { betasol } \\
\text { propi- } \\
\text { onate }\end{array}$ & & & & & & & & & \\
\hline $\begin{array}{l}\text { Scher: } \\
\text { Tazaroten } \\
\text { gel vs } \\
\text { vehicle } \\
\text { gel }\end{array}$ & 2001 & No score & - & - & - & \multicolumn{3}{|c|}{$\begin{array}{l}\text { Not enough information of total improve- } \\
\text { ment for both groups }\end{array}$} & 24 weeks \\
\hline $\begin{array}{l}\text { Tosti: } \\
\text { Cal- } \\
\text { cipotriol } \\
\text { vs be- } \\
\text { tametha- } \\
\text { son } \\
\text { dipropi- } \\
\text { onate + } \\
\text { salicylic } \\
\text { acid }\end{array}$ & 1998 & Both 2.3 & $\begin{array}{l}26.5(\mathrm{n}= \\
13)^{n s}\end{array}$ & $\begin{array}{l}30.4(\mathrm{n}= \\
16)^{n s}\end{array}$ & & $\begin{array}{l}49.2(\mathrm{n}= \\
8)^{n s, s b}\end{array}$ & $\begin{array}{l}51.7(\mathrm{n}= \\
10)^{n s, s b}\end{array}$ & - & $\begin{array}{l}12 \text { and } \\
20 \text { weeks } \\
\text { (respon- } \\
\text { ders } \\
\text { at week } \\
12 \text { con- } \\
\text { tinued to } \\
\text { week 20) }\end{array}$ \\
\hline $\begin{array}{l}\text { Tzung: } \\
\text { Cal- } \\
\text { cipotriol } \\
\text { vs cal- } \\
\text { cipotriol } \\
+\quad \text { be- } \\
\text { tametha- } \\
\text { sone } \\
\text { dipropi- } \\
\text { onate }\end{array}$ & 2008 & No score & \multicolumn{3}{|c|}{ Both reduction in total score $(\mathrm{n}=32)^{n s, s b}$} & - & - & - & 12 weeks \\
\hline $\begin{array}{l}\text { Sys- } \\
\text { temic } \\
\text { therapy }\end{array}$ & & & & & & & & & \\
\hline $\begin{array}{l}\text { Gũ mũ } \\
\text { ș el: } \\
\text { Methotrey } \\
\text { ate vs ci- } \\
\text { closporin }\end{array}$ & 2011 & $\begin{array}{l}39.1 \text { vs } \\
42.1\end{array}$ & - & - & - & $\begin{array}{l}43.3(\mathrm{n}= \\
17) \\
n s+n s b\end{array}$ & $\begin{array}{l}37.2(\mathrm{n}= \\
17) \\
n s+n s b\end{array}$ & - & 24 weeks \\
\hline
\end{tabular}


Table 4. Finger nail severity and improvement (Continued)

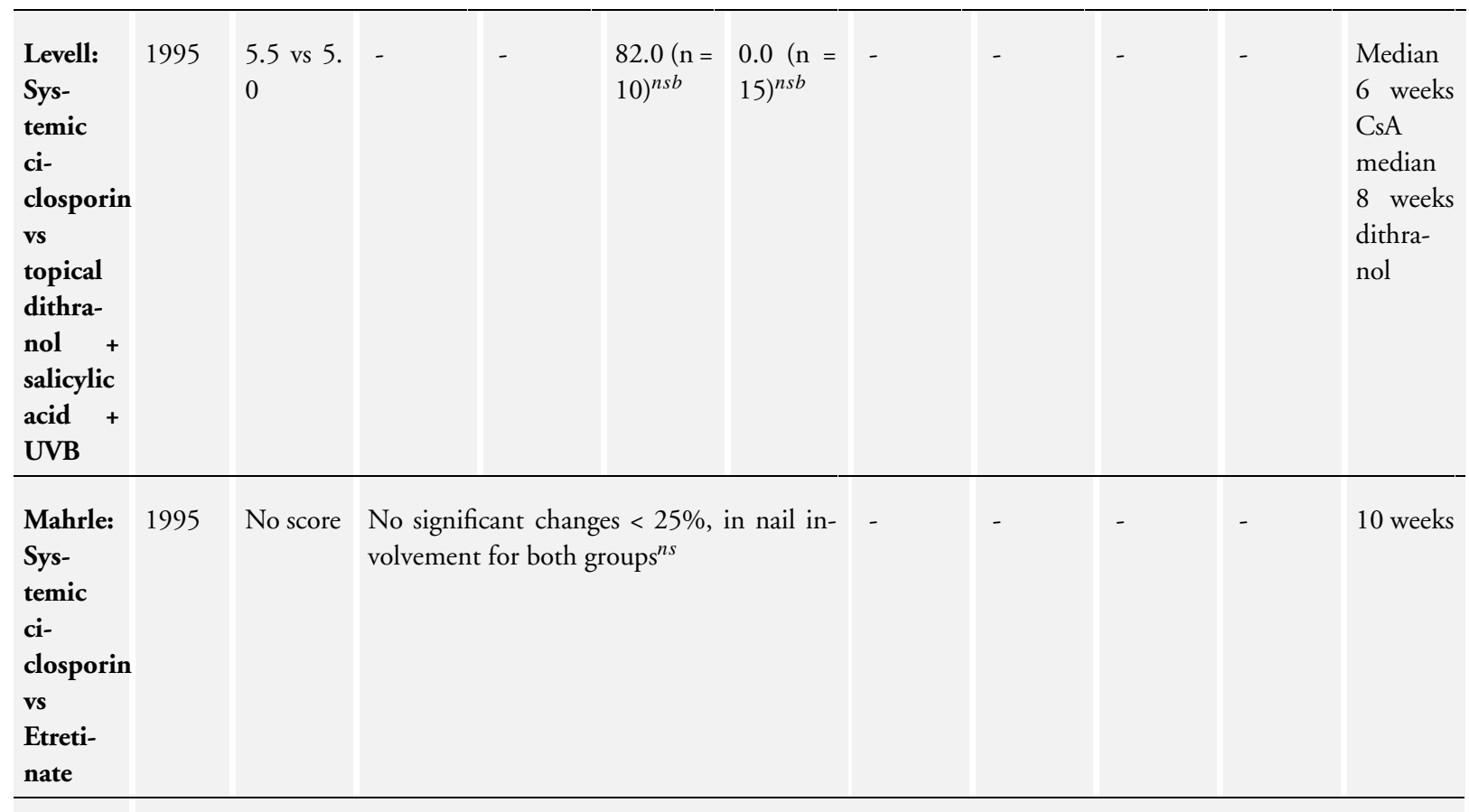

Biologi-

cal ther-

apy

\begin{tabular}{|c|c|c|c|c|c|c|c|c|c|c|c|}
\hline $\begin{array}{l}\text { Igarashi: } \\
\text { Ustek- } \\
\text { inumab } \\
45 \\
\text { mg vs } \\
\text { placebo }\end{array}$ & 2012 & $\begin{array}{l}3.7 \text { vs } 4 . \\
6\end{array}$ & \multicolumn{4}{|c|}{$\begin{array}{l}\text { No significant changes }<25 \% \text {, in nail in- } \\
\text { volvement for both groups }{ }^{n s}\end{array}$} & - & - & - & - & 12 weeks \\
\hline $\begin{array}{l}\text { Igarashi: } \\
\text { Ustek- } \\
\text { inumab } \\
90 \\
\text { mg vs } \\
\text { placebo }\end{array}$ & 2012 & $\begin{array}{l}4.1 \text { vs } 4 . \\
6\end{array}$ & \multicolumn{4}{|c|}{$\begin{array}{l}\text { No significant changes }<25 \% \text {, in nail in- } \\
\text { volvement for both groups }{ }^{n s}\end{array}$} & - & - & - & - & 12 weeks \\
\hline $\begin{array}{l}\text { Ka- } \\
\text { vanaugh: } \\
\text { Goli- } \\
\text { mumab } \\
50 \quad \text { mg } \\
\text { vs } \\
\text { placebo }\end{array}$ & 2009 & $\begin{array}{l}4.7 \text { vs } 4 . \\
4\end{array}$ & $\begin{aligned} & 25.0(\mathrm{n} \\
= & 95)^{s}\end{aligned}$ & $\begin{array}{l}0.0(\mathrm{n}= \\
83)\end{array}$ & - & - & $\begin{array}{l}33.0(\mathrm{n}= \\
95)^{s}\end{array}$ & $\begin{array}{l}0.0(\mathrm{n}= \\
83)\end{array}$ & - & - & $\begin{array}{l}14 \text { and } \\
24 \text { weeks }\end{array}$ \\
\hline
\end{tabular}

Copyright $\odot 2013$ The Cochrane Collaboration. Published by John Wiley \& Sons, Ltd. 
Table 4. Finger nail severity and improvement (Continued)

\begin{tabular}{|c|c|c|c|c|c|c|c|c|c|c|}
\hline $\begin{array}{l}\text { Ka- } \\
\text { vanaugh: } \\
\text { Goli- } \\
\text { mumab } \\
100 \mathrm{mg} \\
\text { vs } \\
\text { placebo }\end{array}$ & 2009 & $\begin{array}{l}4.6 \text { vs } 4 . \\
4\end{array}$ & $\begin{aligned} & 43.0(\mathrm{n} \\
= & 109)^{s}\end{aligned}$ & $\begin{array}{l}0.0(\mathrm{n}= \\
83)\end{array}$ & - & $\begin{array}{l}54.0(\mathrm{n}= \\
109)^{s}\end{array}$ & $\begin{array}{l}0.0 \\
83)\end{array}(\mathrm{n}=$ & - & - & $\begin{array}{l}14 \text { and } \\
24 \text { weeks }\end{array}$ \\
\hline $\begin{array}{l}\text { Rich: } \\
\text { Inflix- } \\
\text { imab vs } \\
\text { placebo }\end{array}$ & 2008 & $\begin{array}{l}4.6 \text { vs } 4 . \\
3\end{array}$ & $\begin{array}{l}26.8(\mathrm{n}= \\
240)^{s}\end{array}$ & $\begin{array}{l}-7.7(\mathrm{n}= \\
65)^{s}\end{array}$ & - & $57.2^{s}$ & $-4.1^{s}$ & - & - & $\begin{array}{l}10 \text { and } \\
24 \text { weeks }\end{array}$ \\
\hline $\begin{array}{l}\text { Radio- } \\
\text { therapy }\end{array}$ & & & & & & & & & & \\
\hline $\begin{array}{l}\text { Kwang: } \\
\text { Elec- } \\
\text { tron } \\
\text { beam vs } \\
\text { placebo }\end{array}$ & 1995 & No score & \multicolumn{3}{|c|}{$\begin{array}{l}\text { Statistical improvement at } 3 \text { months after } 8 \\
\text { weeks' therapy }{ }^{s+s b} \\
\text { No separate data between intervention and } \\
\text { comparison groups were given }\end{array}$} & - & - & - & - & 12 weeks \\
\hline $\begin{array}{l}\text { Linde- } \\
\text { lof: } \\
\text { Grenz } \\
\text { rays vs } \\
\text { placebo }\end{array}$ & 1989 & No score & \multicolumn{3}{|c|}{$\begin{array}{l}\text { Moderate therapeutic response } \\
\text { No separate data between intervention and } \\
\text { comparison groups were given }\end{array}$} & - & - & - & - & 10 weeks \\
\hline $\begin{array}{l}\text { Yu: } \\
\text { Super- } \\
\text { ficial ra- } \\
\text { diother- } \\
\text { apy vs } \\
\text { 'Sham } \\
\text { radio- } \\
\text { therapy' }\end{array}$ & 1992 & $\begin{array}{l}5.5 \text { vs } 5 . \\
4\end{array}$ & \multicolumn{3}{|c|}{$\begin{array}{l}<25 \%(20 \%)(\mathrm{no} / \text { worse) improvement for } \\
\text { both groups after } 2 \text { weeks' treatment }(\mathrm{n}=8) \\
s+s b, \text { measure point at week } 10\end{array}$} & - & - & - & - & 10 weeks \\
\hline
\end{tabular}

This table shows the mean \% score improvement of fingernail severity in time. Outcomes are divided into moderate and good improvement after short-term, medium-term, or both treatment, regardless of the outcome measure used and the number of nail features assessed. The baseline score therefore consists of different kind of scores, e.g. NAPSI, NAS, point scales. We didn't show improvement less than $25 \%$ (no/worse group) for a better overview of relevant data. Also, the follow up is not reported in this figure. Responses of more than $50 \%$ after short-term treatment and of more than $25 \%$ after medium-term treatment are shown in graphs in Figure 4.

If possible, the data of significance compared to the other treatment was shown. If this was not reported in the studies, the significance compared to baseline was shown.

s: significant between the two treatment groups; ns: not significant between the two treatment groups; sb: significant to baseline; nsb: not significant to baseline.

Definitions:

Interventions for nail psoriasis (Review)

Copyright @ 2013 The Cochrane Collaboration. Published by John Wiley \& Sons, Ltd. 
No/worse improvement $=$ no improvement, worse, very severe, severe, no change $;<25 \%$ improvement of the NAPSI (we have omitted this group)

Moderate improvement $=$ moderate, mild-moderate, medium, moderately; $25 \%$ to $75 \%$ improvement of the NAPSI

Good improvement $=$ mild, slightly, marked, almost complete recovery, no lesion, absent, cured, normal, clearance; $75 \%$ to $100 \%$ improvement of the NAPSI

Table 5. '\% participants with adverse effects'

\begin{tabular}{|c|c|c|c|}
\hline & $\begin{array}{l}\text { Intervention and control } \\
\text { group }\end{array}$ & Adverse effects & $\begin{array}{l}\% \text { participants (numbers/to- } \\
\text { tal) }\end{array}$ \\
\hline \multirow[t]{8}{*}{$\begin{array}{l}\text { Topical therapy } \\
\text { I: Weighted average } 10.7 \% * \\
\text { C: Weighted average } 2.9 \% *\end{array}$} & $\begin{array}{l}\text { I: Clobetasol (Baran 1999; } \\
\text { Baran 1999a) } \\
\text { C: Placebo lacquer }\end{array}$ & Not assessed & - \\
\hline & $\begin{array}{l}\text { I: Topical ciclosporin (Cannavo } \\
\text { 2003) } \\
\text { C: Maisoil }\end{array}$ & $\begin{array}{l}\text { I: No adverse events were found } \\
\text { C: No adverse events were } \\
\text { found }\end{array}$ & $\begin{array}{l}\text { I: } 0.0 \%(0 / 8) \\
\text { C: } 0.0 \%(0 / 8)\end{array}$ \\
\hline & $\begin{array}{l}\text { I: 5-Fluorouracil (de Jong } \\
\text { 1999) } \\
\text { C: Belanyx® lotion }\end{array}$ & $\begin{array}{l}\text { I: Pain, swelling, discoloura- } \\
\text { tions, inflammation, onycholy- } \\
\text { sis, perforation } \\
\text { C: No adverse events were } \\
\text { found }\end{array}$ & $\begin{array}{l}\text { I: } 10.5 \%(6 / 57) \\
\text { C: } 0.0 \%(0 / 57)\end{array}$ \\
\hline & $\begin{array}{l}\text { I: Hyaluronic acid and chon- } \\
\text { droitin sulphates (Flori 1994) } \\
\text { C: Placebo }\end{array}$ & $\begin{array}{l}\text { I: No adverse events were found } \\
\text { C: No adverse events were } \\
\text { found }\end{array}$ & $\begin{array}{l}\text { I: } 0.0 \%(0 / 15) \\
\text { C: } 0.0 \%(0 / 15)\end{array}$ \\
\hline & $\begin{array}{l}\text { I: Tazarotene } 0.1 \% \text { cream ( } \\
\text { Rigopoulos 2007) } \\
\text { C: Clobetasol propionate } 0 . \\
05 \% \text { (Rigopoulos 2007) }\end{array}$ & $\begin{array}{l}\text { I: Desquamation, erythema, ir- } \\
\text { ritation } \\
\text { C: Burning on the nail fold skin }\end{array}$ & $\begin{array}{l}\text { I: } 18.8 \%(3 / 16) \\
\text { C: } 7.1 \%(1 / 14)\end{array}$ \\
\hline & $\begin{array}{l}\text { I: Tazarotene } 0.1 \% \text { gel (Scher } \\
2001 \text { ) } \\
\text { C: Vehicle gel }\end{array}$ & $\begin{array}{l}\text { I: Peeling, irritation, parony- } \\
\text { chia, and erythema of the prox- } \\
\text { imal nail fold } \\
\text { C: No adverse events were } \\
\text { found }\end{array}$ & $\begin{array}{l}\text { I: } 23.8 \%(5 / 21) \\
\text { C: } 0.0 \%(0 / 10)\end{array}$ \\
\hline & $\begin{array}{l}\text { I: Calcipotriol (Tzung 2008) } \\
\text { C: Calcipotriol + betametha- } \\
\text { sone dipropionate (Tzung } \\
2008 \text { ) }\end{array}$ & $\begin{array}{l}\text { I: No adverse events were found } \\
\text { C: No adverse events were } \\
\text { found }\end{array}$ & $\begin{array}{l}\text { I: } 0.0 \%(0 / 17) \\
\text { C: } 0.0 \%(0 / 15)\end{array}$ \\
\hline & $\begin{array}{l}\text { I: Calcipotriol (Tosti 1998) } \\
\text { C: Betamethasone + salicylic } \\
\text { acid (Tosti 1998) }\end{array}$ & $\begin{array}{l}\text { I: Erythema, irritation, burn- } \\
\text { ing, urticaria } \\
\text { C: Erythema }\end{array}$ & $\begin{array}{l}\text { I: } 12.0 \%(3 / 25) \\
\text { C: } 14.3 \%(3 / 21)\end{array}$ \\
\hline
\end{tabular}


Table 5. '\% participants with adverse effects' (Continued)

\begin{tabular}{|c|c|c|c|}
\hline \multirow[t]{6}{*}{$\begin{array}{l}\text { Systemic therapy } \\
\text { I: Weighted average } \\
\text { (excl Levell 1995) 69.8\%* } \\
\text { C: Weighted average } \\
\text { (excl Levell 1995) 60.3\%* }\end{array}$} & $\begin{array}{l}\text { I: Methotrexate } 15 \mathrm{mg} / \text { week ( } \\
\text { Gü mü ș el 2011) } \\
\text { C: Ciclosporin } 5 \mathrm{mg} / \mathrm{kg} \quad( \\
\text { Gü mú ș el 2011) }\end{array}$ & $\begin{array}{l}\text { I: Nausea, telogen effluvium. } \\
\text { One had an elevation of liver } \\
\text { transaminase and therefore dis- } \\
\text { continuation of treatment } \\
\text { C: Hypercholesterolaemia, hir- } \\
\text { sutism, menstrual abnormali- } \\
\text { ties, mild pain on the distal part } \\
\text { of nail. Two had an elevation of } \\
\text { creatinine and lipids and there- } \\
\text { fore discontinuation of treat- } \\
\text { ment }\end{array}$ & $\begin{array}{l}\text { I: } 22.2 \%(4 / 18) \\
\text { C: } 26.3 \%(5 / 19)\end{array}$ \\
\hline & $\begin{array}{l}\text { I: Ustekinumab } 45 \text { or } 90 \mathrm{mg} \text { ( } \\
\text { Igarashi 2012) } \\
\text { C: Placebo }\end{array}$ & $\begin{array}{l}\text { I: Such as: nasopharyngitis, in- } \\
\text { creased triglycerides, increased } \\
\text { creatine phosphokinase, sea- } \\
\text { sonal allergy, infections } \\
\text { C: Exacerbation of skin psoria- } \\
\text { sis, infections }\end{array}$ & $\begin{array}{l}\text { I: } 97.4 \% \text { not specific for nail } \\
\text { psoriasis }(150 / 154) \\
\text { C: } 65.6 \% \text { not specific for nail } \\
\text { psoriasis }(21 / 32)\end{array}$ \\
\hline & $\begin{array}{l}\text { I: Golimumab } 50 \text { and } 100 \mathrm{mg} \\
\text { (Kavanaugh 2009) } \\
\text { C: Placebo }\end{array}$ & $\begin{array}{l}\text { I: Mostly infections: upper res- } \\
\text { piratory tract infections, na- } \\
\text { sopharyngitis } \\
\text { C: Mostly upper respiratory } \\
\text { tract infections, headache, and } \\
\text { serious adverse events (not spec- } \\
\text { ified) }\end{array}$ & $\begin{array}{l}\text { I: } 65 \% \text { not specific for nail pso- } \\
\text { riasis }(222 / 343) \\
\text { C: } 59 \% \text { not specific for nail pso- } \\
\text { riasis }(67 / 113)\end{array}$ \\
\hline & $\begin{array}{l}\text { I: Ciclosporin (Levell } 1995) \\
\text { C: Topical dithranol 2\% to } 8 \% \\
+0.5 \% \text { salicylic acid + UVB }\end{array}$ & $\begin{array}{l}\text { I: Minimal toxicity } \\
\text { C: Burning }\end{array}$ & $\begin{array}{l}\text { I: Some participants, not spe- } \\
\text { cific for nail psoriasis } \\
\text { C: Some participants, not spe- } \\
\text { cific for nail psoriasis }\end{array}$ \\
\hline & $\begin{array}{l}\text { I: Ciclosporin (Mahrle 1995) } \\
\text { C: Etretinate }\end{array}$ & $\begin{array}{l}\text { I: Mostly gastrointestinal, skin } \\
\text { and mucous membrane symp- } \\
\text { toms, nervous system and psy- } \\
\text { chiatric disorders, general ad- } \\
\text { verse reactions } \\
\text { C: Mostly skin and mucous } \\
\text { membrane symptoms, and gen- } \\
\text { eral adverse reactions }\end{array}$ & $\begin{array}{l}\text { I: } 32.1 \% \text {, not specific for nail } \\
\text { psoriasis }(45 / 140) \\
\text { C: } 57.1 \% \text {, not specific for nail } \\
\text { psoriasis }(40 / 70)\end{array}$ \\
\hline & $\begin{array}{l}\text { I: Infliximab (Rich 2008) } \\
\text { C: Placebo }\end{array}$ & $\begin{array}{l}\text { I: Infections, headache, in- } \\
\text { creased hepatic enzymes, fa- } \\
\text { tigue } \\
\text { C: Infections, headache, psori- } \\
\text { asis, pharyngitis }\end{array}$ & $\begin{array}{l}\text { I: } 82.0 \% \text {, not specific for nail } \\
\text { psoriasis }(244 / 298) \\
\text { C: } 71 \% \text {, not specific for nail } \\
\text { psoriasis }(54 / 76)\end{array}$ \\
\hline
\end{tabular}


Table 5. '\% participants with adverse effects' (Continued)

\section{Radiotherapy}

I: Weighted average $40.5 \% *$

C: Weighted average $0.0 \% *$

\author{
I: Electron beam (Kwang 1995) I: Temporary brownish-black I: $100.0 \%(12 / 12)$ \\ C: Placebo \\ discolourations \\ C: $0.0 \%(0 / 12)$ \\ C: No adverse events were \\ found
}
I: Grenz rays (Lindelof 1989)
C: Placebo
I: Slight pigmentation of the
nail fold
I: $22.7 \%(5 / 22)$
C: No adverse events were
found

I: Superficial radiotherapy (Yu I: No adverse events were found I: $0.0 \%(0 / 8)$
1992)
C: 'Sham radiotherapy'
C: No adverse events were C: $0.0 \%(0 / 8)$
found

*: These are the weighted average of participants with adverse effects with this type of intervention group. The control group consists of a placebo or active comparison.

$\mathrm{I}=$ intervention

$\mathrm{C}=$ control

The analysis corresponding to these data are shown in Analysis 4.1.

Table 6. Mean improvement of nail features $\geq 50 \%$

\begin{tabular}{|c|c|c|c|c|c|c|c|c|c|c|}
\hline Study & $\begin{array}{l}\text { Interven- } \\
\text { tion } \\
\text { and con- } \\
\text { trol group }\end{array}$ & $\begin{array}{l}\text { Features } \\
\text { not speci- } \\
\text { fied }\end{array}$ & Pitting & $\begin{array}{l}\text { Leukony- } \\
\text { chia }\end{array}$ & $\begin{array}{l}\text { Red spots } \\
\text { lunula }\end{array}$ & $\begin{array}{l}\text { Crum- } \\
\text { bling }\end{array}$ & $\begin{array}{l}\text { Onychol- } \\
\text { ysis }\end{array}$ & $\begin{array}{l}\text { Splin- } \\
\text { ter haem- } \\
\text { orrhages }\end{array}$ & $\begin{array}{l}\text { Oil } \\
\text { drop dis- } \\
\text { coloura- } \\
\text { tions }\end{array}$ & $\begin{array}{l}\text { Subun- } \\
\text { gual hy- } \\
\text { perker- } \\
\text { atosis }\end{array}$ \\
\hline \multicolumn{11}{|c|}{ Short-term treatment } \\
\hline Cannavo & $\begin{array}{l}\text { I: Topical } \\
\text { ci- } \\
\text { closporin } \\
70 \% \text { in } \\
\text { maize oil } \\
\text { (median) } \\
\text { C: } \\
\text { Maisoil }\end{array}$ & - & $\begin{array}{l}100 \%{ }^{n s b} \\
\text { no data }\end{array}$ & - & - & $\begin{array}{l}100 \% s b \\
\text { no data }\end{array}$ & $\begin{array}{l}100 \% \text { sb } \\
\text { no data }\end{array}$ & - & $\begin{array}{l}75 \%{ }^{n s b} \\
\text { no data }\end{array}$ & $\begin{array}{l}83 \%^{s b} \\
\text { no data }\end{array}$ \\
\hline De Jong & $\begin{array}{l}\text { I: } \\
1 \% \text { 5-flu- } \\
\text { orouracil } \\
\text { in Be- } \\
\text { lanyx® } \\
\text { lotion } \\
\text { C: Be- } \\
\text { lanyx® } \\
\text { lotion }\end{array}$ & - & - & - & - & - & - & - & $\begin{array}{l}63 \%{ }^{n s, s b} \\
57 \%{ }^{n s, s b}\end{array}$ & - \\
\hline
\end{tabular}


Table 6. Mean improvement of nail features $\geq 50 \% \quad$ (Continued)

\begin{tabular}{|c|c|c|c|c|c|c|c|c|c|c|}
\hline Igarashi & $\begin{array}{l}\text { I: Ustek- } \\
\text { inumab } \\
45 \text { or } 90 \\
\mathrm{mg} \\
\mathrm{C} \text { : } \\
\text { Placebo }\end{array}$ & $\begin{array}{l}\# \\
\#\end{array}$ & - & - & - & - & - & - & - & - \\
\hline Kwang & $\begin{array}{l}\text { I: } \\
\text { Electron } \\
\text { beam } 0 . \\
75 \mathrm{~Gy} \\
\text { C: } \\
\text { Placebo }\end{array}$ & - & - & - & - & - & - & - & - & $\begin{array}{l}X \\
X\end{array}$ \\
\hline Levell & $\begin{array}{l}\text { I: Sys- } \\
\text { temic ci- } \\
\text { closporin } \\
2.5 \quad \mathrm{mg} / \\
\mathrm{kg} \\
\mathrm{C}: \text { Topi- } \\
\text { cal } \\
\text { dithra- } \\
\text { nol } 2 \% \text { to } \\
8 \%+0 . \\
5 \% \text { sali- } \\
\text { cylic acid } \\
+ \text { UVB }\end{array}$ & $\begin{array}{l}\# \\
\#\end{array}$ & - & - & - & - & - & - & - & - \\
\hline Lindelof & $\begin{array}{l}\text { I: Grenz } \\
\text { rays } 5 \mathrm{~Gy} \\
\text { C: } \\
\text { Placebo }\end{array}$ & $\begin{array}{l}\# \\
\#\end{array}$ & - & - & - & - & - & - & - & - \\
\hline Mahrle & $\begin{array}{l}\text { I: Sys- } \\
\text { temic ci- } \\
\text { closporin } \\
2.5 \quad \mathrm{mg} / \\
\mathrm{kg} \\
\mathrm{C} \text { : Etreti- } \\
\text { nate }\end{array}$ & $\begin{array}{l}\# \\
\#\end{array}$ & - & - & - & - & - & - & - & - \\
\hline $\begin{array}{l}\text { Rigopou- } \\
\text { los }\end{array}$ & $\begin{array}{l}\text { I: } \\
\text { Tazarotene } \\
0.1 \% \\
\text { cream } \\
\text { C: Clobe- } \\
\text { tasol pro- } \\
\text { pionate } 0 . \\
05 \%\end{array}$ & - & $\begin{array}{l}75 \%{ }^{n s, s b} \\
67 \% \%^{n s, s b}\end{array}$ & - & - & - & $\begin{array}{l}58 \%{ }^{n s, s b} \\
57 \%^{n s, s b}\end{array}$ & - & $\begin{array}{l}85 \%^{n s, s b} \\
82 \%^{n s, s b}\end{array}$ & $\begin{array}{l}80 \%{ }^{n s, s b} \\
66 \% \%^{n s, s b}\end{array}$ \\
\hline
\end{tabular}


Table 6. Mean improvement of nail features $\geq \mathbf{5 0} \% \quad$ (Continued)

\begin{tabular}{|c|c|c|c|c|c|c|c|c|c|c|}
\hline Tosti & $\begin{array}{l}\text { I: Cal- } \\
\text { cipotriol } \\
\text { C: Be- } \\
\text { tametha- } \\
\text { son } \\
\text { dipropi- } \\
\text { onate } 64 \\
\text { mg/g } \\
+ \text { salicylic } \\
\text { acid } 0.03 \\
\text { g/g }\end{array}$ & - & - & - & - & - & - & - & - & $\begin{array}{l}<50 \%{ }^{n s *} \\
<50 \%^{n s *}\end{array}$ \\
\hline Tzung & $\begin{array}{l}\text { I: Cal- } \\
\text { cipotriol } \\
0.005 \% \\
\text { C: Cal- } \\
\text { cipotriol } \\
0.005 \%+ \\
\text { be- } \\
\text { tametha- } \\
\text { sone } \\
\text { dipro- } \\
\text { pionate } 0 . \\
05 \%\end{array}$ & - & - & - & - & - & - & - & $\begin{array}{l}\mathrm{X}^{s} \\
\mathrm{X}^{s}\end{array}$ & - \\
\hline $\mathrm{Yu}$ & $\begin{array}{l}\text { I: Superfi- } \\
\text { cial radio- } \\
\text { therapy } \\
450 \mathrm{cGy} \\
\text { C: 'Sham } \\
\text { radio- } \\
\text { therapy' }\end{array}$ & $\begin{array}{l}\# \\
\#\end{array}$ & - & - & - & - & - & - & - & - \\
\hline
\end{tabular}

Medium and long-term treatment

\begin{tabular}{|c|c|c|c|c|c|c|c|c|c|c|}
\hline $\begin{array}{l}\text { Baran } \\
1999\end{array}$ & $\begin{array}{l}\text { I: Topical } \\
8 \% \\
\text { clobetasol } \\
\text { C: } \\
\text { Placebo } \\
\text { lacquer }\end{array}$ & - & - & - & - & - & $\begin{array}{l}\mathrm{X} \\
\text { no data }\end{array}$ & - & - & - \\
\hline $\begin{array}{l}\text { Baran } \\
1999 a\end{array}$ & $\begin{array}{l}\text { I: Topical } \\
8 \% \\
\text { clobetasol } \\
\text { C: } \\
\text { Placebo } \\
\text { lacquer }\end{array}$ & - & - & - & - & - & $\begin{array}{l}\mathrm{X} \\
\text { no data }\end{array}$ & - & - & - \\
\hline
\end{tabular}


Table 6. Mean improvement of nail features $\geq \mathbf{5 0 \%} \quad$ (Continued)

\begin{tabular}{|c|c|c|c|c|c|c|c|c|c|c|}
\hline Flori & $\begin{array}{l}\text { I: } \\
\text { Hyaluronic } \\
\text { acid + } \\
\text { chon- } \\
\text { droitin } \\
\text { sulphates } \\
\text { C: } \\
\text { Placebo }\end{array}$ & - & - & - & - & - & $\begin{array}{l}68.8 \% \\
s, s b \\
<\quad 50 \% \\
s b * *\end{array}$ & - & - & $\begin{array}{l}70 \%{ }^{s, s b} \\
<\quad 50 \% \\
s b * *\end{array}$ \\
\hline $\begin{array}{l}\text { Gü mü } \\
\text { ș el }\end{array}$ & $\begin{array}{l}\text { I: } \\
\text { Methotrex- } \\
\text { ate } 15 \mathrm{mg} \\
\mathrm{C}: \quad \mathrm{Ci}- \\
\text { closporin } \\
5 \mathrm{mg} / \mathrm{kg}\end{array}$ & $\begin{array}{l}\text { \# } \\
\#\end{array}$ & - & - & - & - & - & - & - & - \\
\hline Igarashi & $\begin{array}{l}\text { I: Ustek- } \\
\text { inumab } \\
45 \text { or } 90 \\
\text { mg } \\
\text { C: } \\
\text { Placebo }\end{array}$ & $\begin{array}{l}\# \\
\#\end{array}$ & - & - & - & - & - & - & - & - \\
\hline $\begin{array}{l}\text { Ka- } \\
\text { vanaugh }\end{array}$ & $\begin{array}{l}\text { I: Goli- } \\
\text { mumab } \\
50 \text { or } 100 \\
\text { mg } \\
\text { C: } \\
\text { Placebo }\end{array}$ & $\begin{array}{l}\# \\
\#\end{array}$ & - & - & - & - & - & - & - & - \\
\hline $\begin{array}{l}\text { Rich } \\
* * *(\% \text { partici }\end{array}$ & $\begin{array}{l}\text { I: In- } \\
\text { fliximab } 5 \\
\mathrm{mg} / \mathrm{kg} \\
\mathrm{C}: \\
\text { Placebo/ } \\
\text { inflix- } \\
\text { imab }\end{array}$ & - & $\begin{array}{l}56 \% \%^{s} \\
68 \% \%^{s}\end{array}$ & $\begin{array}{l}82 \%^{s} \\
82 \%^{s}\end{array}$ & $\begin{array}{l}96 \%^{s} \\
100 \%^{s}\end{array}$ & $\begin{array}{l}67 \%^{s} \\
76 \% s\end{array}$ & $\begin{array}{l}73 \% \%^{s} \\
78 \%{ }^{s}\end{array}$ & $\begin{array}{l}88 \%{ }^{s} \\
90 \%{ }^{s}\end{array}$ & $\begin{array}{l}81 \%^{s} \\
86 \%^{s}\end{array}$ & $\begin{array}{l}79 \%^{s} \\
84 \%^{s}\end{array}$ \\
\hline Scher & $\begin{array}{l}\text { I: } \\
\text { Tazarotene } \\
\text { gel } 0.1 \% \\
\text { C: Vehi- } \\
\text { cle gel }\end{array}$ & - & $\begin{array}{l}X^{s} \\
\text { no data }\end{array}$ & - & - & - & $\begin{array}{l}\mathrm{X}^{s} \\
\text { no data }\end{array}$ & - & - & - \\
\hline
\end{tabular}

This table contains the eight nail features used in the NAPSI score. The percentages are score improvements compared to baseline at the end of treatment duration. Comparison between studies is difficult, because not all studies assessed all eight features of the NAPSI. It is unclear if this is an improvement of more or less than $50 \%$.

$\mathrm{I}=$ intervention

$\mathrm{C}=$ control

$\mathrm{S}=$ significant between the two treatment groups

Interventions for nail psoriasis (Review)

Copyright @ 2013 The Cochrane Collaboration. Published by John Wiley \& Sons, Ltd. 
ns = not significant between the two treatment groups

$\mathrm{sb}=$ significant to baseline

$\mathrm{nsb}=$ not significant to baseline

$\#$ = nail feature was not specified in the trial

$\mathrm{X}=$ most improved nail feature in this study, but unknown percentage

*: After 3 months, there was a response of $26.5 \%^{n s}$ in the calcipotriol group vs $30.4 \%{ }^{n s}$ in the betamethasone group.

**: After 90 days, there was a response of $35.5 \%^{s b}$ for onycholysis and $23.8 \%{ }^{s b}$ for hyperkeratosis.

*** Rich reported percentage of participants with complete clearance at week 50, not a percentage of score improvement. We have no data about the improvement of the remaining percentage of participants.

Table 7. Most common nail psoriasis features

\begin{tabular}{ll}
\hline Nail matrix & Nail bed \\
\hline $\begin{array}{l}\text { Pitting } \\
\text { (Small depressions in surface of the nail plate) }\end{array}$ & $\begin{array}{l}\text { Subungual hyperkeratosis } \\
\text { (Thickening of the nail bed) }\end{array}$ \\
\hline $\begin{array}{l}\text { Leukonychia } \\
\text { (White areas in the nail plate) }\end{array}$ & $\begin{array}{l}\text { Onycholysis } \\
\text { (Separation of the nail plate from the underlying nail bed) }\end{array}$ \\
\hline $\begin{array}{l}\text { Red spots in the lunula } \\
\text { (White half-moon area of the nail) }\end{array}$ & $\begin{array}{l}\text { Splinter haemorrhages } \\
\text { (Thin longitudinal dark brown streaks under the nail plate) }\end{array}$ \\
\hline $\begin{array}{l}\text { Nail plate crumbling } \\
\text { (White depressed (rough) areas of the nail plate) }\end{array}$ & $\begin{array}{l}\text { Oildrop or salmon patch } \\
\text { (Red-brown discolourations under the nail plate) }\end{array}$ \\
\hline
\end{tabular}

\title{
A P P E N I C E S
}

\section{Appendix I. CENTRAL (Cochrane Library) search strategy}

\author{
\#1 (psoriasis) \\ \#2 MeSH descriptor Psoriasis explode all trees \\ \#3 (\#1 OR \#2) \\ $\# 4$ (nail $^{*}$ ) or $\left(\right.$ toenail $\left.{ }^{*}\right)$ or (fingernail ${ }^{*}$ ) or (thumbnail ${ }^{*}$ ) \\ \#5 MeSH descriptor Nail Diseases explode all trees \\ \#6 MeSH descriptor Nails explode all trees \\ \#7 (ungual or ungueal or unguium ) or (onycholysis) or (paronychia) or (subungual hyperkeratosis) \\ \#8 MeSH descriptor Paronychia explode all trees \\ $\# 9$ (pitting) or (punctate) or (onych* or anonych* or leukonych* or paronych* or pachyonychia) \\ \#10 (\#4 OR \#5 OR \#6 OR \#7 OR \#8 OR \#9) \\ \#11 (\#3 AND \#10)
}

Interventions for nail psoriasis (Review) 


\section{Appendix 2. MEDLINE (OVID) search strategy}

1. randomized controlled trial.pt.

2. controlled clinical trial.pt.

3. randomized.ab.

4. placebo.ab.

5. clinical trials as topic.sh.

6. randomly.ab.

7. trial.ti.

8.1 or 2 or 3 or 4 or 5 or 6 or 7

9. (animals not (humans and animals)).sh.

10. 8 not 9

11. psoriasis.mp. or exp Psoriasis/

12. psoria\$.mp.

13. 11 or 12

14. nail\$.mp. or exp Nails/

15. (toenail\$ or fingernail $\$$ or thumbnail\$).tw.

16. onycholysis.mp.

17. (ungual or ungueal or unguium).mp.

18. paronychia.mp. or exp Paronychia/

19. subungual hyperkeratosis.mp.

20. (pitting or punctate).mp.

21. leukonychia.mp.

22. onych\$.mp.

23. (onych\$ or anonych\$ or leukonych\$ or paronych\$ or pachyonychia).tw.

24. 21 or 17 or 20 or 15 or 14 or 22 or 18 or 23 or 16 or 19

25. 24 and 13 and 10

\section{Appendix 3. EMBASE (OVID) search strategy}

1. random $\$ . m p$.

2. factorial\$.mp.

3. (crossover $\$$ or cross-over $\$$ ).mp.

4. placebo\$.mp. or PLACEBO/

5. (doubl\$ adj blind\$).mp.

6. (singl\$ adj blind\$).mp.

7. (assign\$ or allocat\$).mp.

8. volunteer\$.mp. or VOLUNTEER/

9. Crossover Procedure/

10. Double Blind Procedure/

11. Randomized Controlled Trial/

12. Single Blind Procedure/

13. 1 or 2 or 3 or 4 or 5 or 6 or 7 or 8 or 9 or 10 or 11 or 12

14. psoriasis.mp. or exp Psoriasis/

15. psoria\$.mp. ]

16. 14 or 15

17. nail\$.mp. or exp Nails/

18. (toenail\$ or fingernail\$ or thumbnail\$).tw.

19. onycholysis.mp.

20. (ungual or ungueal or unguium).mp.

21. paronychia.mp. or exp Paronychia/

22. subungual hyperkeratosis.mp.

23. (pitting or punctate).mp.

Interventions for nail psoriasis (Review)

Copyright $\odot 2013$ The Cochrane Collaboration. Published by John Wiley \& Sons, Ltd. 
24. leukonychia.mp.

25. onych\$.mp.

26. (onych\$ or anonych\$ or leukonych\$ or paronych\$ or pachyonychia).tw.

27.25 or 21 or 26 or 17 or 20 or 22 or 18 or 24 or 19 or 23

28. 27 and 16 and 13

\section{Appendix 4. LILACS search strategy}

((Pt RANDOMIZED CONTROLLED TRIAL OR Pt CONTROLLED CLINICAL TRIAL OR Mh RANDOMIZED CONTROLLED TRIALS OR Mh RANDOM ALLOCATION OR Mh DOUBLE-BLIND METHOD OR Mh SINGLE-BLIND METHOD OR Pt MULTICENTER STUDY) OR ((tw ensaio or tw ensayo or tw trial) and (tw azar or tw acaso or tw placebo or tw control\$ or tw aleat\$ or tw random\$ or (tw duplo and tw cego) or (tw doble and tw ciego) or (tw double and tw blind)) and tw clinic\$)) AND NOT ((CT ANIMALS OR MH ANIMALS OR CT RABBITS OR CT MICE OR MH RATS OR MH PRIMATES OR MH DOGS OR MH RABBITS OR MH SWINE) AND NOT (CT HUMAN AND CT ANIMALS)) [Palavras] and psoriasis or psoria $\$$ [Palavras]

\section{CONTRIBUTIONSOFAUTHORS}

Link with editorial base and co-ordinate contributions from co-authors (PS)

Draft protocol (MV and PS)

Design of search strategies (PS, MV, and AV)

Identify relevant titles and abstracts from searches (AV, NB, and MV)

Obtain copies of trials (AV and NB)

Selection of trials (AV, NB, and MV)

Extract data from trials (AV and NB)

Enter data into RevMan (AV and NB)

Carry out analysis (AV, NB, LH, and PS)

Interpret data (AV, NB, PS, LH, ML, and MP)

Draft final review (AV, NB, PS, LH, ML, and MP)

Update review (AV and PS)

\section{DECLARATIONSOF INTEREST}

Mark Lebwohl has been an advisor for Abbott; Amgen; Anacor Pharmaceuticals, Inc; BioLineRX Ltd; Celgene Corporation; DermiPsor Ltd; Eli Lilly \& Co., Galderma; GlaxoSmithKline-Stiefel; Janssen Biotech Inc.; LEO Pharmaceuticals; Maruho Co., Ltd; Novartis; Pfizer; Ranbaxy; and Valeant. Mark Lebwohl has received honoraria from each of these companies, except DermiPsor Ltd. He was an Investigator and received grants for his employer from Amgen, Celgene Corporation, Janssen Biotech Inc., LEO Pharmaceuticals, and Ranbaxy. He was an Investigator for Eli Lilly \& Co..

Anna-Christa de Vries, Nathalie Bogaards, Lotty Hooft, Marieke Velema, and Marcel Pasch had no conflicts of interest.

Phyllis Spuls has been an invited speaker for an organisation like the European Academy of Dermatology and Venereology (EADV) Preceptorship meeting that was sponsored by Abbott and Wyeth-Pfizer. The department in which Phyllis Spuls is Principal Investigator received an unrestricted research grant in 2010 from Schering-Plough for research. Furthermore, the department in which Phyllis Spuls is Principal Investigator performs studies together with many pharmaceutical industries, such as Janssen, Centocor, Schering-Plough, Pfizer, Amgen, Celgene Corporation, and Abbott.

Interventions for nail psoriasis (Review)

Copyright (๑) 2013 The Cochrane Collaboration. Published by John Wiley \& Sons, Ltd. 
She received payment for joining the executive board for the EPIDEPSO study in 2012, the PPI steering committee in 2010 and 2011 , and the EDF guideline committee, as well as fees for consulting from LEO Pharmaceuticals in 2011. She has also been involved in the design and conduct of the PIECE study, which is an investigator-initiated RCT of infliximab versus etanercept that was independent of industry and government support. Data are to be analysed in December 2012 and January 2013 (including nail psoriasis data).

\section{SOURCES OF SUPPORT}

\section{Internal sources}

- Department of Dermatology of the University of Amsterdam-Academic Medical Center, Netherlands.

- Dutch Cochrane Centre, Amsterdam, Netherlands.

- Mount Sinai School of Medicine, New York, USA.

\section{External sources}

- No sources of support supplied

\section{DIFFERENCES BETWEEN PROTOCOLANDREVIEW}

In the Background section, we changed our goal. Instead of creating a 'guideline' based on the best available evidence, we decided to review the available evidence, possibly for others to compile guidelines.

In the Methods section, we changed the primary outcome 'Improvement of nail psoriasis in the clinician's opinion' to 'Global improvement of nail psoriasis as rated by a clinician' to make it more readable.

Because of insufficient data and the lack of information required to implement the Methods, we changed the methods of the review. In our protocol, we had stated our intention to perform a meta-analysis and pool the data. However, we could not fulfil these intentions because of too much clinical and methodological heterogeneity between the studies. We decided to report the data as qualitative descriptions, presented in three intervention groups (topical, systemic, and radiotherapy), in accordance with the primary and secondary outcomes of this review, instead of classification by outcome, as we believe that this is more useful in clinical practice. We presented a table per treatment with the extracted data of fingernail severity and improvements reported in the studies (Table 4).

In the Types of outcome measures section, to conclude something about the efficacy of the treatment of these heterogeneous trials, we decided to dichotomise the participants with less, equal, or more than $50 \%$ improvement, regardless of which score measurement was used. Therefore, we proportionally converted the scores to percentage improvement.

We added the following assessments to the Risk of bias in included studies section: selective reporting (reporting bias) and other bias.

In the Measures of treatment effect section, we revised the protocol text where we planned to express the results as risk ratio (RR) and 95\% confidence intervals (CI) for dichotomous outcomes and standardised mean differences (MD) and 95\% CI for continuous outcomes. It was impossible to extract or calculate all relevant data, like the $95 \%$ CI or standard deviation (SD). The diversity of study outcome and design made it impossible to do so.

In the Unit of analysis issues section, we made major changes to make it more readable. We adjusted the protocol text to a more appropriate one according to the extracted low quality data. Unfortunately, it was not possible to perform meta-analysis. No data of any proposed analysis was given in the original studies. Therefore, we only focused on the 'internally controlled studies', 'cross-over trials', and 'repeated measurements'. The rest of the protocol text was omitted.

In the Data synthesis section, we decided to dichotomise the variables for a better overview if meta-analysis was not possible. Therefore, we collected and analysed, where possible, the available data reporting participants with at least $50 \%$ nail score improvement and the 'mean nail score improvement' per intervention after short- and medium-term treatment duration. We analysed participants with adverse effects for any treatment. 


\section{INDEX TERMS}

\section{Medical Subject Headings (MeSH)}

Antibodies, Monoclonal [therapeutic use]; Cyclosporine [therapeutic use]; Dermatologic Agents [*therapeutic use]; Methotrexate [therapeutic use]; Nail Diseases [*drug therapy; ${ }^{*}$ radiotherapy]; Psoriasis [*drug therapy; ${ }^{*}$ radiotherapy]; Quality of Life; Randomized Controlled Trials as Topic

\section{MeSH check words}

Humans 